OPEN ACCESS

Edited by:

Monica Fernandez-Aparicio, Institut National De La Recherche

Agronomique (INRA), France

Reviewed by:

Hong An

University of Missouri, United States

Xingyong Yang,

Chongqing Normal University, China

Gary Peng,

Agriculture and Agri-Food Canada,

Canada

Bruce D. Gossen,

Agriculture and Agri-Food Canada,

Canada

*Correspondence:

Jacqueline Batley

jacqueline.batley@uwa.edu.au

Specialty section:

This article was submitted to

Plant Breeding

a section of the journal

Frontiers in Plant Science

Received: 18 May 2017

Accepted: 02 October 2017

Published: 06 November 2017

Citation:

Neik TX, Barbetti MJ and Batley J (2017) Current Status and Challenges

in Identifying Disease Resistance

Genes in Brassica napus.

Front. Plant Sci. 8:1788.

doi: $10.3389 /$ fpls.2017.01788

\section{Current Status and Challenges in Identifying Disease Resistance Genes in Brassica napus}

\author{
Ting Xiang Neik ${ }^{1}$, Martin J. Barbetti ${ }^{2}$ and Jacqueline Batley ${ }^{1 *}$ \\ ${ }^{1}$ School of Biological Sciences, University of Western Australia, Perth, WA, Australia, ${ }^{2}$ School of Agriculture and Environment
} and Institute of Agriculture, University of Western Australia, Perth, WA, Australia

Brassica napus is an economically important crop across different continents including temperate and subtropical regions in Europe, Canada, South Asia, China and Australia. Its widespread cultivation also brings setbacks as it plays host to fungal, oomycete and chytrid pathogens that can lead to serious yield loss. For sustainable crop production, identification of resistance $(R)$ genes in $B$. napus has become of critical importance. In this review, we discuss four key pathogens affecting Brassica crops: Clubroot (Plasmodiophora brassicae), Blackleg (Leptosphaeria maculans and L. biglobosa), Sclerotinia Stem Rot (Sclerotinia sclerotiorum), and Downy Mildew (Hyaloperonospora parasitica). We first review current studies covering prevalence of these pathogens on Brassica crops and highlight the $R$ genes and QTL that have been identified from Brassica species against these pathogens. Insights into the relationships between the pathogen and its Brassica host, the unique host resistance mechanisms and how these affect resistance outcomes is also presented. We discuss challenges in identification and deployment of $R$ genes in $B$. napus in relation to highly specific genetic interactions between host subpopulations and pathogen pathotypes and emphasize the need for common or shared techniques and research materials or tighter collaboration between researchers to reconcile the inconsistencies in the research outcomes. Using current genomics tools, we provide examples of how characterization and cloning of $R$ genes in $B$. napus can be carried out more effectively. Lastly, we put forward strategies to breed resistant cultivars through introgressions supported by genomic approaches and suggest prospects that can be implemented in the future for a better, pathogen-resistant B. napus.

Keywords: Brassica napus, $R$ gene, genomics, host-pathogen interaction, qualitative resistance, pathotype

\section{INTRODUCTION}

Brassica napus is cultivated worldwide for its edible oil (B. napus var. oleifera or napus; oilseed rape), as a vegetable for human consumption (B. napus var. pabularia; Siberian or rape kale) or animal fodder (B. napus var. napobrassica; rutabagas, swedes). Its economic importance across some of the major production countries/regions is highlighted in Table 1.

With intensified B. napus cultivation in many countries, to meet the demands for oil and vegetable production, the incidence and severity of disease caused by various pathogens has also increased (Sanogo et al., 2015; Van de Wouw et al., 2016a). The major diseases and 
TABLE 1 | Economic importance of B. napus.

\begin{tabular}{|c|c|c|c|c|}
\hline Year & Country/Region & $\begin{array}{l}\text { Economic value ( } \$ \mathrm{~m} \text { or } \$ \mathrm{~b} \mathrm{pa}) \text { and/or area } \\
\text { of cultivation/production ( } \mathrm{kha} \text { ) }\end{array}$ & $\begin{array}{l}\text { Harvested production } \\
\qquad(1,000 \text { tons })\end{array}$ & References \\
\hline 2014-2016 & Australia & $\mathrm{A} \cup \$ 1.7 \mathrm{~b} / 2,160 \mathrm{kha}$ & 3,435 & $\begin{array}{l}\text { Australian Bureau of Statistics, 2016; Australian } \\
\text { Oilseeds Federation, } 2016\end{array}$ \\
\hline 2017 & Canada & $\$ 15.4$ b (between years 2007-2010)/9,059 kha & 2,100 & Rempel et al., 2014; Statistics Canada, 2017 \\
\hline 2016 & France & $€ 1,935 \mathrm{~m} / 2,234 \mathrm{kha}$ & 6,200 & Eurostat, 2016 \\
\hline 2014 & China (rapeseed) & US\$3.6 billion*/7,534 kha & 14,931 & National Bureau of Statistics of China, 2015 \\
\hline
\end{tabular}

${ }^{\star}$ Economic benefits of importing Canadian canola.

key pathogens that cause serious damage on B. napus worldwide include the chytrid Clubroot pathogen (Plasmodiophora brassicae); fungal pathogens such as Sclerotinia Stem Rot (Sclerotinia sclerotiorum), Blackleg (Leptosphaeria maculans, L. biglobosa), White Rust (Albugo candida), Light Leaf Spot (Pyrenopeziza brassicae), Alternaria Blight (Alternaria brassicae, A. brassicicola, other Alternaria spp.) and White Leaf Spot (Pseudocercosporella capsellae); the oomycete Downy Mildew pathogen (Hyaloperonospora parasitica), and the bacterial Blackrot pathogen (Pseudomonas syringae).

Fungicidal or cultural control measures offer inconsistent and expensive disease management options, especially for low input and low return cropping systems. Effective host resistance is the most cost-effective and reliable means of disease control and resistance(s) have been identified for all major diseases; including race/pathotype-dependent and -independent resistances. Many of these pathogens do not restrict themselves to B. napus but infect, to varying degrees, different Brassica crop species (Ren et al., 2016). As such, the great genetic diversity within and between the different Brassica crop species and other nonBrassica species within the Brassicaceae provides a rich resource for resistance $(R)$ genes against the different major pathogens.

$B$. napus (AACC, $n=19$ ) is an amphidiploid, formed by interspecific hybridization of the two diploid species B. rapa (AA, $n=10)$ and $B$. oleracea (CC, $n=9)$. During this hybridization, several rearrangement events occurred that resulted in extensive reordering among the diverged genomes (Truco et al., 1996). This is supported by the recently published genome sequences of B. rapa (Wang et al., 2011; Cai C. et al., 2017), B. napus (Chalhoub et al., 2014), B. oleracea (Parkin et al., 2014; Liu S. et al., 2014), $B$. juncea and B. nigra (Yang et al., 2016) and the pan-genome of B. oleracea (Golicz et al., 2016). The A and C genomes in B. napus are highly homologous, due to their common ancestry (Liu S. et al., 2014). Evidence of the A and C genomes sharing high genome similarity is also provided from common ancestral blocks between B. rapa and B. oleracea (Parkin et al., 2005, 2014; Schranz et al., 2006).

Plants recognize pathogens either through the pathogen's pathogen-associated molecular patterns (PAMPs) with the plant's pattern recognition receptors (PRRs) or the pathogen's virulence molecules, termed effectors, interacting with the plant $R$ genes (Jones and Dangl, 2006). Although different definitions of $R$ genes have been put forward (Kushalappa et al., 2016), we associate $R$ genes with the conventionally described version that is a single/major gene that results in qualitative resistance and is highly specific (Chisholm et al., 2006; Bent and Mackey, 2007). In contrast, quantitative resistance involves more than one gene, which often lie within a major QTL region that displays large phenotypic variance (Remington and Purugganan, 2003). The specificity between the host $R$ gene and the pathogen effector happens only for pathogens that have adapted to the plant. This plant immunity is termed effector-triggered immunity (ETI), signified by localized cell death that constitutes a hypersensitive response (HR) - an "all-or-none" effect, which is often the exception rather than the rule (Dodds and Rathjen, 2010). Mostly, plants respond to pathogens by mounting resistance called PAMP-triggered immunity (PTI), which is a non-host resistance. Plants also defend themselves by triggering defense related hormone signaling pathways such as jasmonates (JA), salicylates (SA), ethylene (ET), abscisic acid (ABA), and brassinosteroids (BR) (Kazan and Lyons, 2014). This type of resistance is called systemic acquired resistance (SAR) and often incurs broad-spectrum and long lasting immunity (Durrant and Dong, 2004; Netea et al., 2011). Evidence shows that $R$ gene mediated plant immunity and SAR involving defense response hormone signaling are tightly regulated (Larkan et al., 2013; Ma and Borhan, 2015) revealing the complexity of the plant immunity (Thomma et al., 2011; Stotz et al., 2014). In Brassica species, both major $R$ genes and quantitative QTL have been identified for all key host pathogens. However, the number of these genes that have been characterized and cloned is very limited. This causes challenges for breeding for resistance and an increased reliance on chemical control. Current advances in genomics in $B$. napus have provided us with a good platform to search for candidate $R$ genes using advanced molecular tools (Edwards et al., 2013; Zhang Y.-M. et al., 2016; Bayer et al., 2017).

Here, we review past and current studies on identification of $R$ genes across a wide range of Brassica species, focusing on four major fungal pathogens and the diseases they cause, viz. Clubroot (Plasmodiophora brassicae), Blackleg (L. maculans and L. biglobosa), Sclerotinia Stem Rot (Sclerotinia sclerotiorum), and Downy Mildew (Hyaloperonospora parasitica). We ascertain sources of $R$ genes based on genes mapped in Brassica hosts for each of these pathogens and discuss possibilities of these $R$ genes for breeding resistant $B$. napus using genomics tools. We highlight challenges in identification and deployment of $R$ genes, and discuss options and strategies for the most effective utilization of $R$ genes to improve resistance to major fungal, oomycete or chytrid pathogens of B. napus. 


\section{SOURCES OF $\boldsymbol{R}$ GENES FOR KEY PATHOGENS}

\section{Clubroot}

Plasmodiophora brassicae, causal agent for Clubroot, has a wide host range including non-cruciferous plants (Ren et al., 2016). Clubroot has caused severe cruciferous crop yield loss of up to $50 \%$ in Canada (Strelkov and Tewari, 2005) and $20-30 \%$ in China (Chai et al., 2014). The pathogen physiology, progress in efforts to combat this disease, and an update on its epidemiology in Canada, Europe and China, have recently been the subject of various reviews (Chai et al., 2014; Diederichsen et al., 2014; Dixon, 2014; Strelkov and Hwang, 2014; Ríčarová et al., 2016). Furthermore, sources of $P$. brassicae $R$ genes and genetic mapping studies have been reviewed by Piao et al. (2004); Rahman et al. (2014). To date, at least $19 R$ genes/QTL have been mapped for Clubroot resistance in B. napus, mostly from the study by Werner et al. (2007). However, only two Clubroot resistance genes have been cloned, Crrla and $C R a$, both in B. rapa (Table 2 and Figure 1).

Sources of $P$. brassicae $R$ genes in $B$. rapa have been particularly promising as there are many race-specific, single, dominant $R$ genes present, as compared with $B$. oleracea which has a more continuous resistance profile involving various combinations of both major and minor genes (Diederichsen et al., 2009; Rahman et al., 2011). Due to the different physiological resistance mechanisms toward $P$. brassicae in $B$. rapa and B. oleracea, complete resistance is often reported in the former but not in the latter (Tanaka et al., 2006; Donald et al., 2008; Hwang et al., 2012). Recent screening efforts in China have identified B. rapa to have good resistance against Canadian pathotype 3 (Zhang et al., 2015). Hence, it is not uncommon that breeding efforts make use of $B$. rapa, in particular using the European fodder turnip as the recurrent parent, to introduce resistance into B. rapa, B. napus, and B. oleracea (Diederichsen et al., 2009). The introgressed regions can be characterized using SNP genotyping and next generation sequencing in order to identify and characterize these resistance genes and determine if they are the same gene or distinct. They could then be deployed in a more targeted manner.

In Canada, most oilseed B. napus shows little, or at best only moderate, resistance to Williams pathotypes 3 and 5 , while $B$. napus rutabaga lines have better resistance (Jakir Hasan et al., 2012). However, in Australia, the majority of B. napus was found to be resistant (Donald et al., 2006), reflecting the influence of the local abiotic environments on the pathogenicity of the fungus, or the origin of host and/or pathogen influencing the resistance outcome (Donald et al., 2006; Donald and Porter, 2014). Further QTL or Genome-Wide Association Study (GWAS) studies should be performed in B. napus in order to identify these resistance genes.

Traditionally, the $\mathrm{AB}$ genome amphidiploid $B$. juncea does not show high resistance. It often shows low, moderate (Peng et al., 2014) or intermediate (Sharma et al., 2012) resistance. However, more recently, one accession of $B$. juncea was found to be highly resistant to the local pathotype 4 under field conditions in China (Ren et al., 2016). Another good source of resistance from the B genome is diploid B. nigra, which has been reported to display high resistance against all local pathotypes in Canada (Jakir Hasan et al., 2012; Chu et al., 2013; Peng et al., 2014). There is therefore the potential for all A, B and C genomes of the Brassica species to harbor $R$ genes against $P$. brassicae.

\section{Sclerotinia Stem Rot}

Similar to the Clubroot pathogen, the Sclerotinia Stem Rot pathogen Sclerotinia sclerotiorum also has a wide host range, including members outside the crucifer family (Zhao et al., 2004). In the Brassica species, this pathogen can cause up to $80 \%$ yield losses in China (Mei et al., 2011) and has previously been reported to cause a loss of AU\$23 million to the canola industry in Western Australia (Dafwa, 2015). The resistance studies on Sclerotinia Stem Rot have mainly focused on the inheritance type at different developmental stages; namely seedling leaf and adult stem stages of the host plant. Thus far, no $R$ genes have been cloned for this pathogen (Wu et al., 2016b). However, candidate $R$ genes against $S$. sclerotiorum have been identified and physically mapped on the B. napus genome (Li et al., 2015). These are NBSLRR genes with gene copies found on chromosomes A6 and C7 (Li et al., 2015). Candidate $R$ genes against S. sclerotiorum, belonging to the CC-NBS-LRR class, were also identified on chromosome A9 in B. napus (Mei et al., 2013). Yet, the majority of the QTL for S. sclerotiorum have been identified in the $\mathrm{C}$ genome (C9 and C6) (Li et al., 2015), indicating that B. oleracea is a good source of $R$ genes for $S$. sclerotiorum. This was recently confirmed for many B. oleracea var. capitata genotypes from China (You et al., 2016).

There can be strong correlation between leaf and stem resistance across some specific Brassica genotypes (Mei et al., 2011; Wu et al., 2013). For example, a few Chinese B. oleracea var. capitata genotypes were found to express extremely high level stem and leaf resistances (You et al., 2016). However, when diverse sets of Brassica genotypes from different parts of the world were evaluated, for most genotypes there was generally no correlation between leaf and stem resistances (Uloth et al., 2013; You et al., 2016). Where there is a strong correlation, such cases share common genes (Li et al., 2015). This contrasting finding could reflect that high resistance against Sclerotinia Stem Rot in both stem and leaf is highly specific at the subpopulation level of the host species. The QTL region for stem resistance on chromosome $\mathrm{C} 2$ in B. napus was found to be homoeologous with that on chromosome A2, and falls within the syntenic region of their respective progenitor genomes (Wei et al., 2014), suggesting that the $R$ genes could be inherited from a common ancestral chromosome, that is largely conserved.

Although, monogenic control of single dominant genes against $S$. sclerotiorum has been found outside the Brassica genus, for example in common bean (Phaseolus vulgaris; Schwartz et al., 2006), it is highly likely that monogenic control is present in Brassicas where only a HR and/or lesions $\leq 2 \mathrm{~mm}$ diameter have been observed on stems (Uloth et al., 2013, 2015a; You et al., 2016) or cotyledons (Garg et al., 2008, 2010b; Uloth et al., 2014; Ge et al., 2015). The genetic control of resistance genes is further complicated by the influence of inoculation methods (Zhao et al., 2004; Yin et al., 2010) and physiological traits, such 


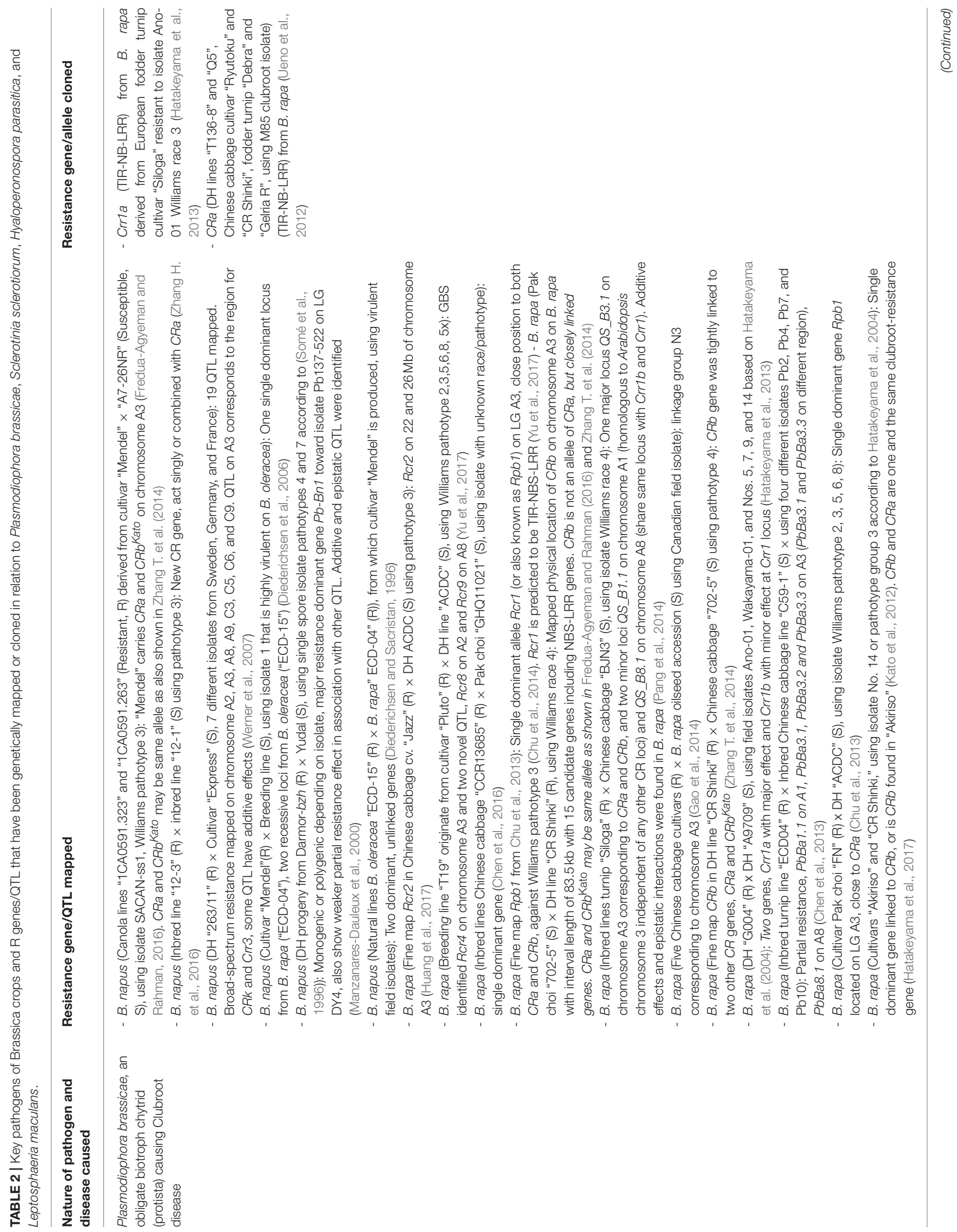



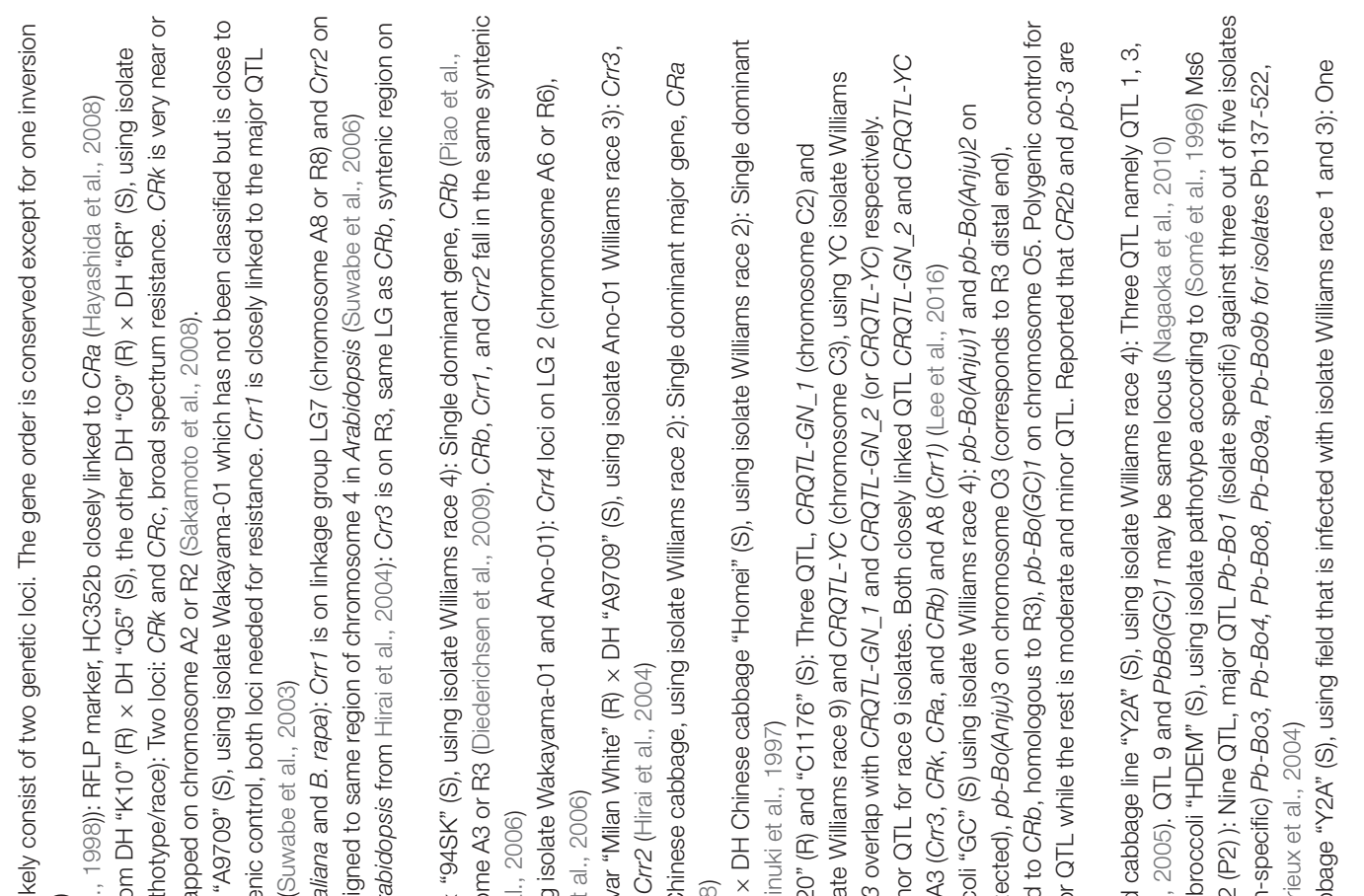

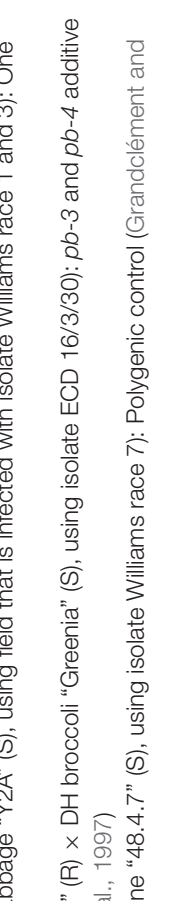

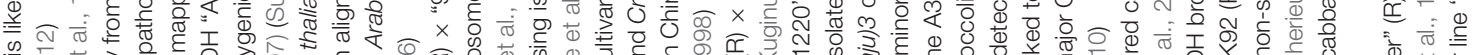

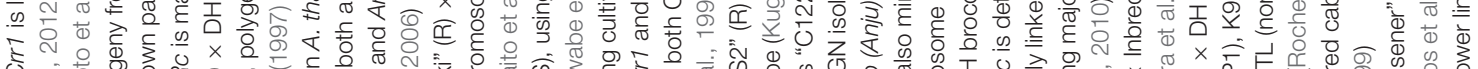

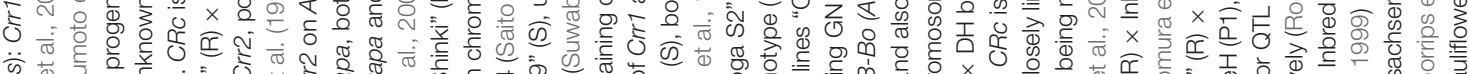

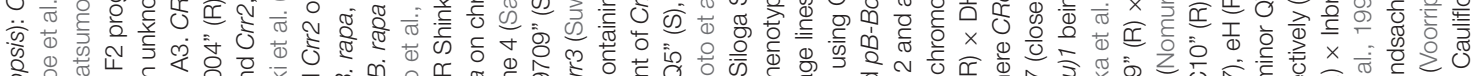

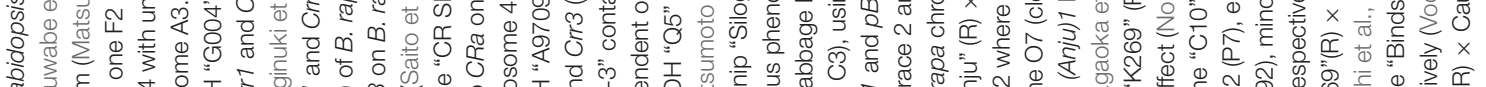

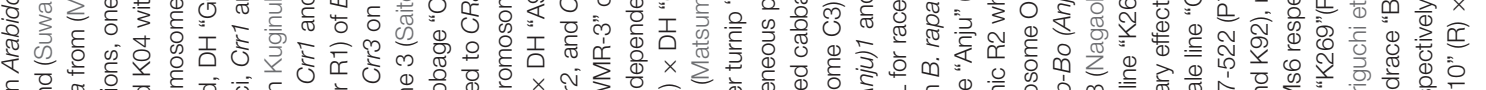

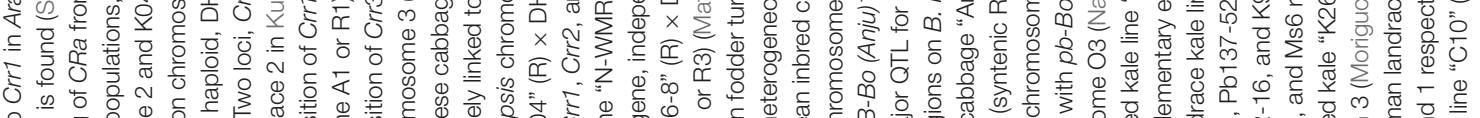

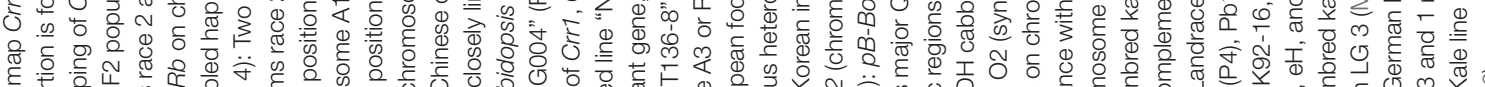

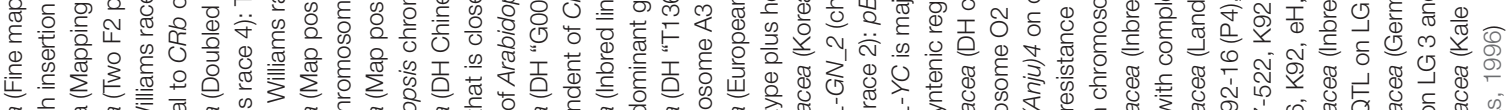

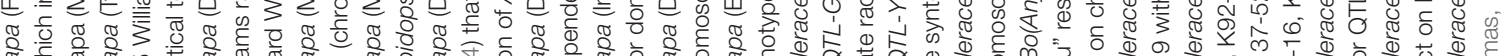

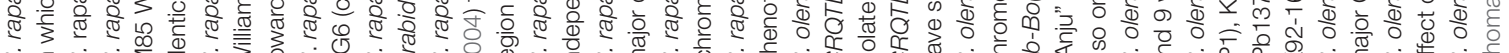
め. 


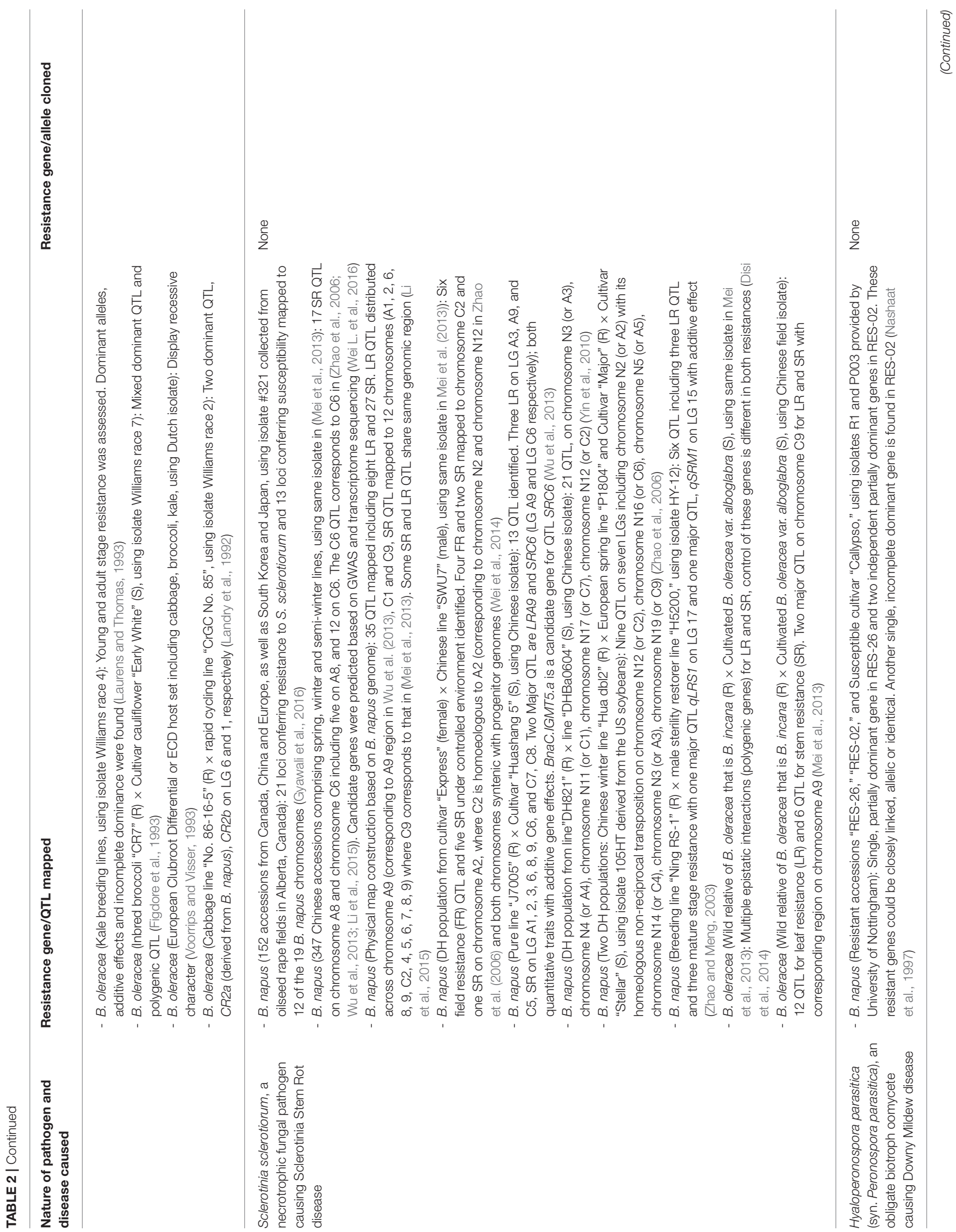




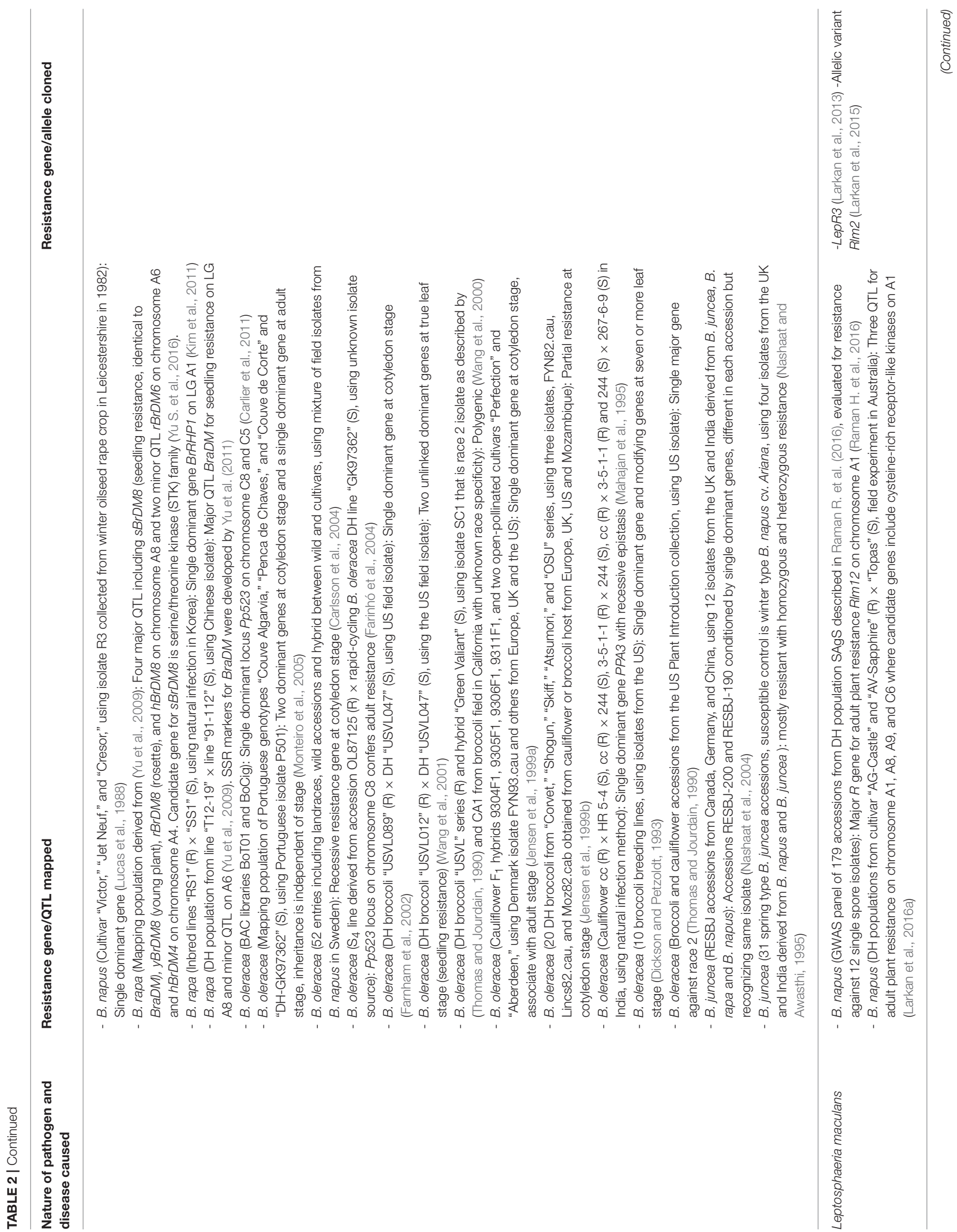




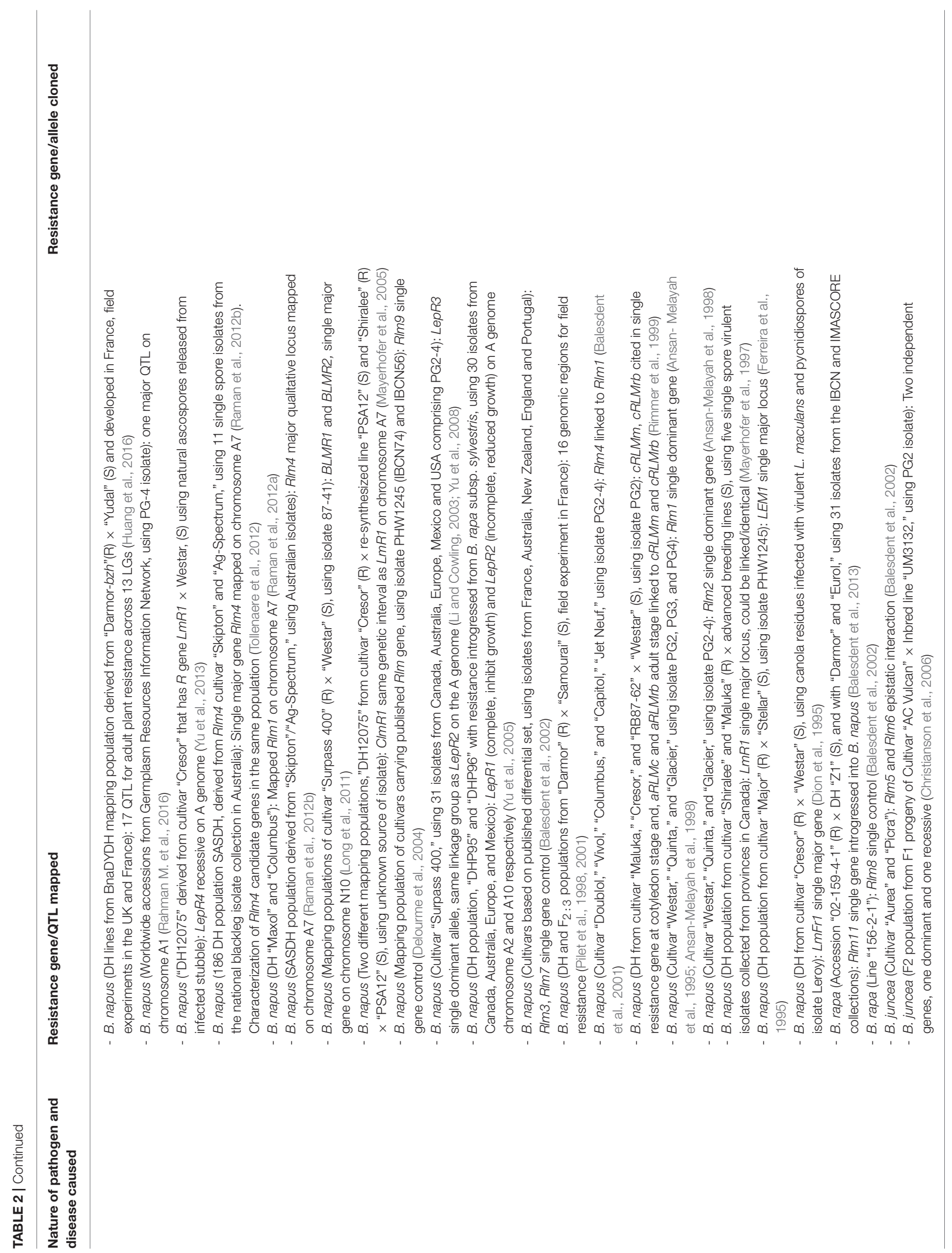




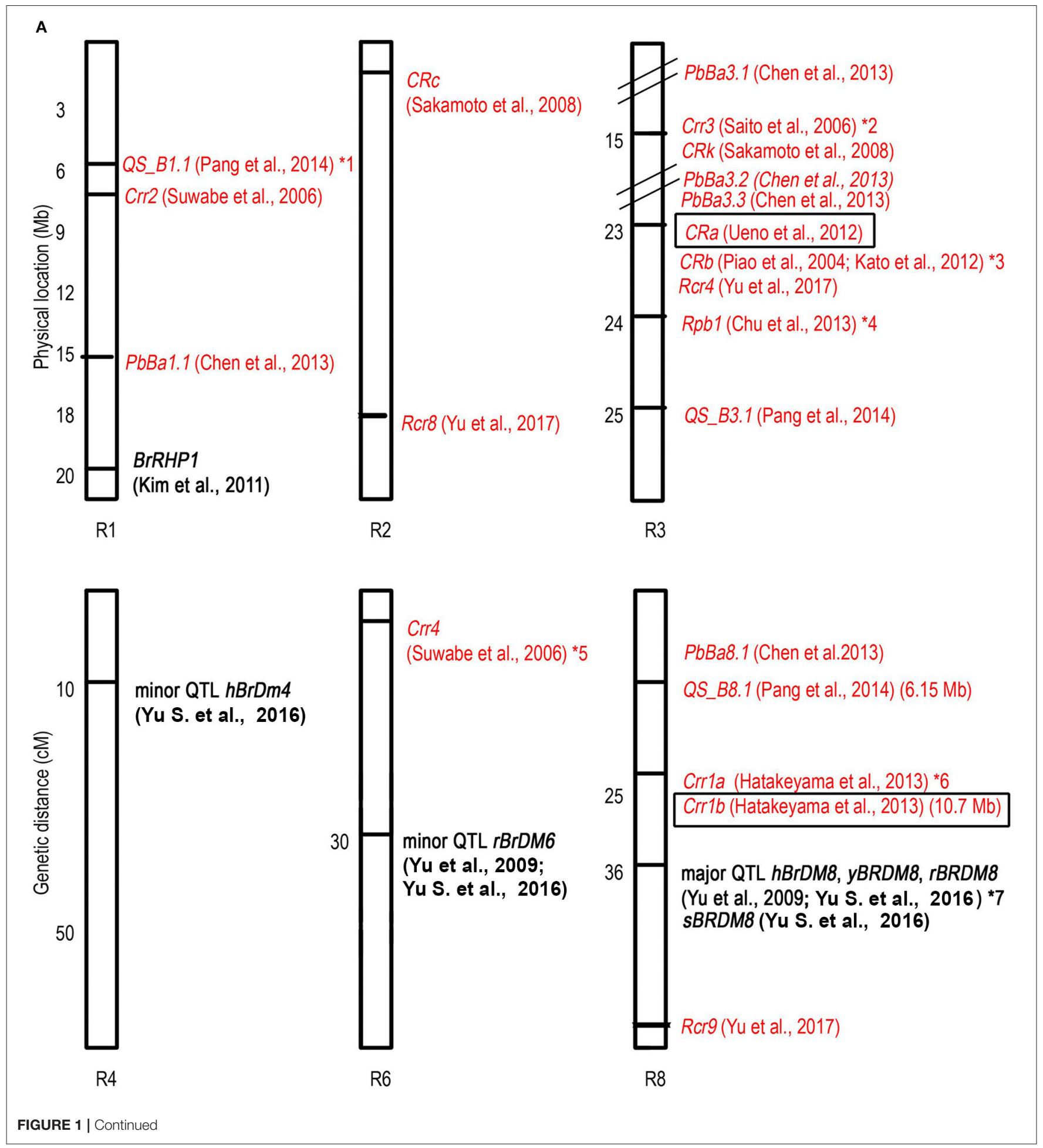

as flowering time, as their QTL were found to be in the same genomic regions (Zhao et al., 2006; Mei et al., 2013; Wei et al., 2014). Despite this, Li et al. (2007) both defined the importance of the type and time of inoculation and how expression of field stem resistance becomes independent of flowering time provided assessment is delayed until 3 weeks after inoculation.
Identification of resistance genes against S. sclerotiorum has been hampered by inconsistencies in time and type of inoculation. Lines that have been shown to be highly resistant in one study can be susceptible in a different study. The use of common isolates and techniques will assist in moving this research forward. 


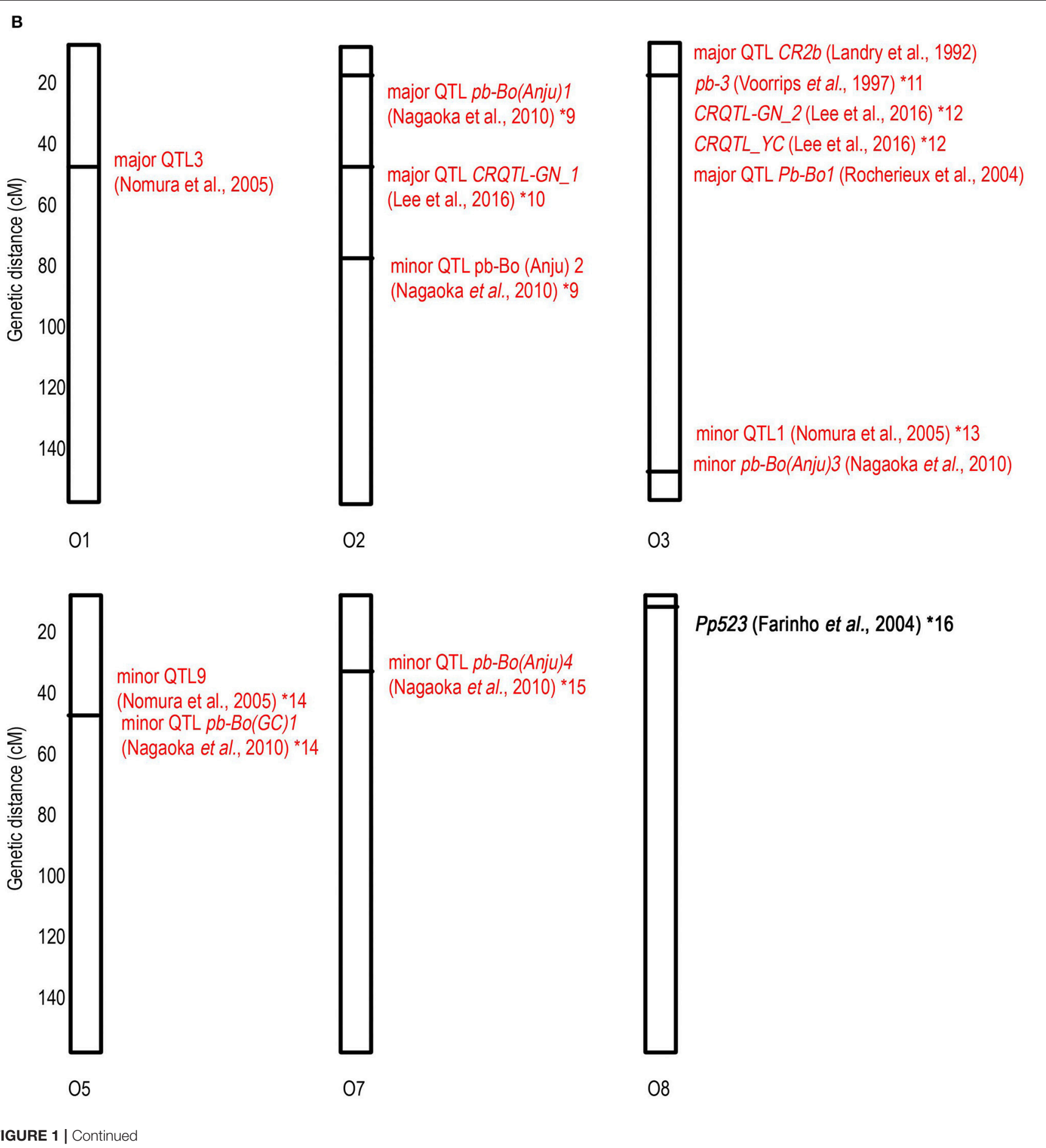

B genome Brassicas are commonly reported to have high levels of Sclerotinia Stem Rot resistance (Navabi et al., 2010). There is a range in resistance across the Australian B. napus rapeseed varieties carrying one or more $B$. carinata introgressions (Uloth et al., 2013). The Australian B. juncea varieties were shown to be generally more susceptible overall to Sclerotinia Stem Rot (Uloth et al., 2015a), but the Indian (Barbetti et al., 2015) and
Chinese (Li et al., 2006a, 2009) B. juncea varieties displayed high levels of host resistance. Wild weedy Brassicaceae species have shown particular promise for high level resistance to Sclerotinia Stem Rot (Garg et al., 2010a; You et al., 2016), including genera such as Raphanus (Uloth et al., 2013). In particular, $B$. napus and B. juncea with introgression(s) from wild crucifers, including Erucastrum cardaminoides, Diplotaxis tenuisiliqua, and 

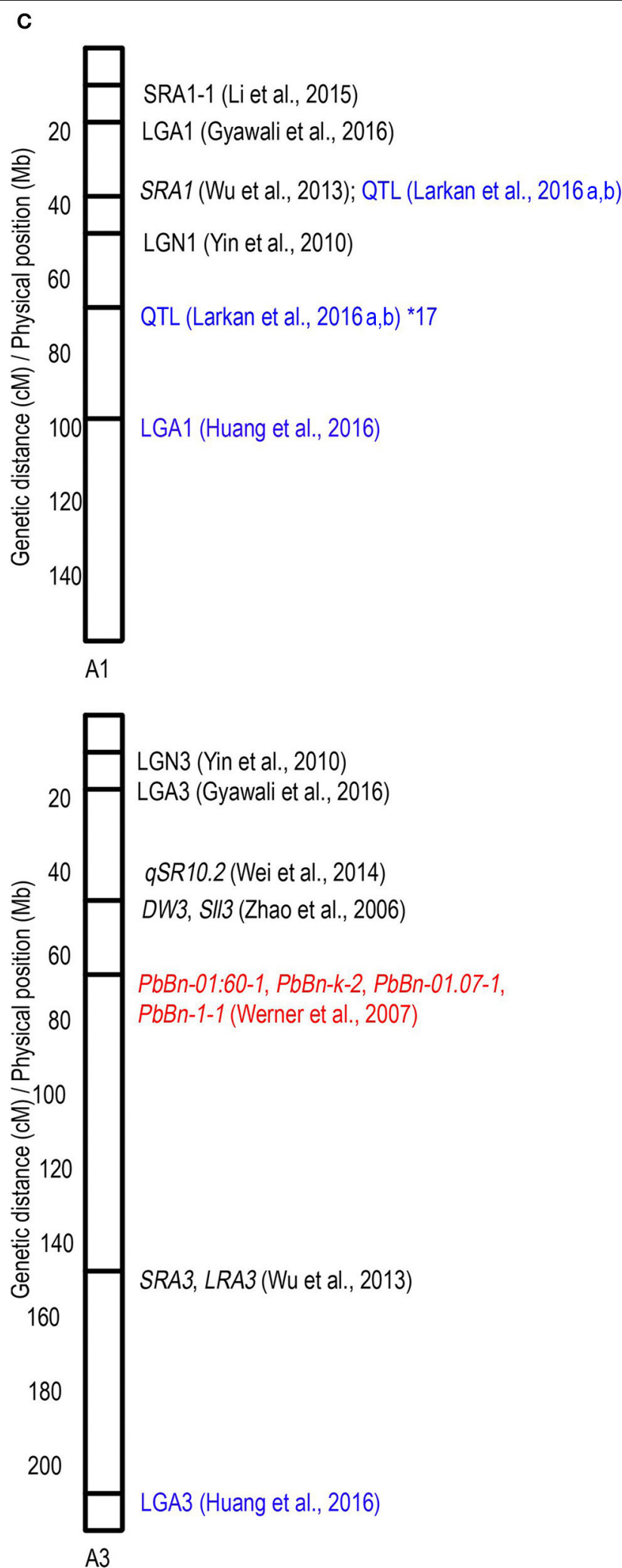

SIl2 (Zhao et al., 2006); LGA2 (Gyawali et al., 2016)

LGA2 (Huang et al., 2016)

qSR10-1 (Wei et al., 2014)

SRA2-1 (Li et al., 2015)

SRA2 (Wu et al., 2013); PbBn-k-1 (Werner et al., 2007)

LepR1 (Yu et al., 2005)

LGA2 (Huang et al., 2016)

LGA2 (Huang et al., 2016)

A2
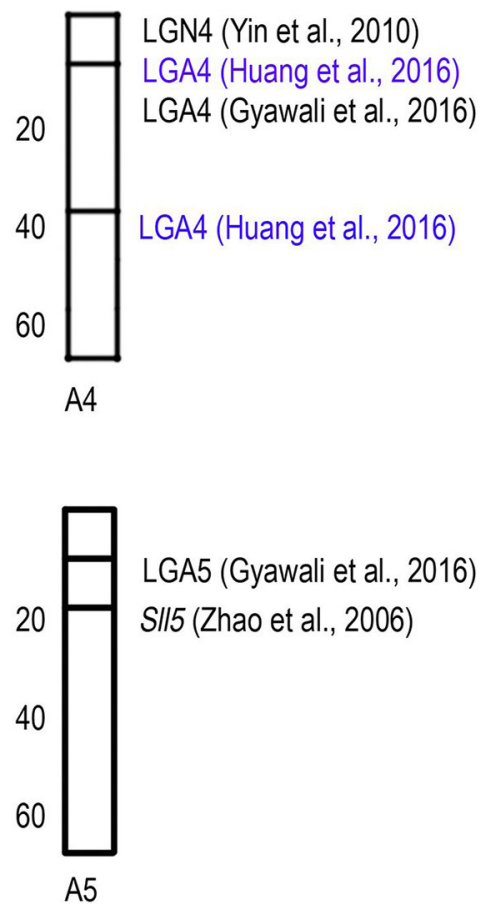

FIGURE 1 | Continued 


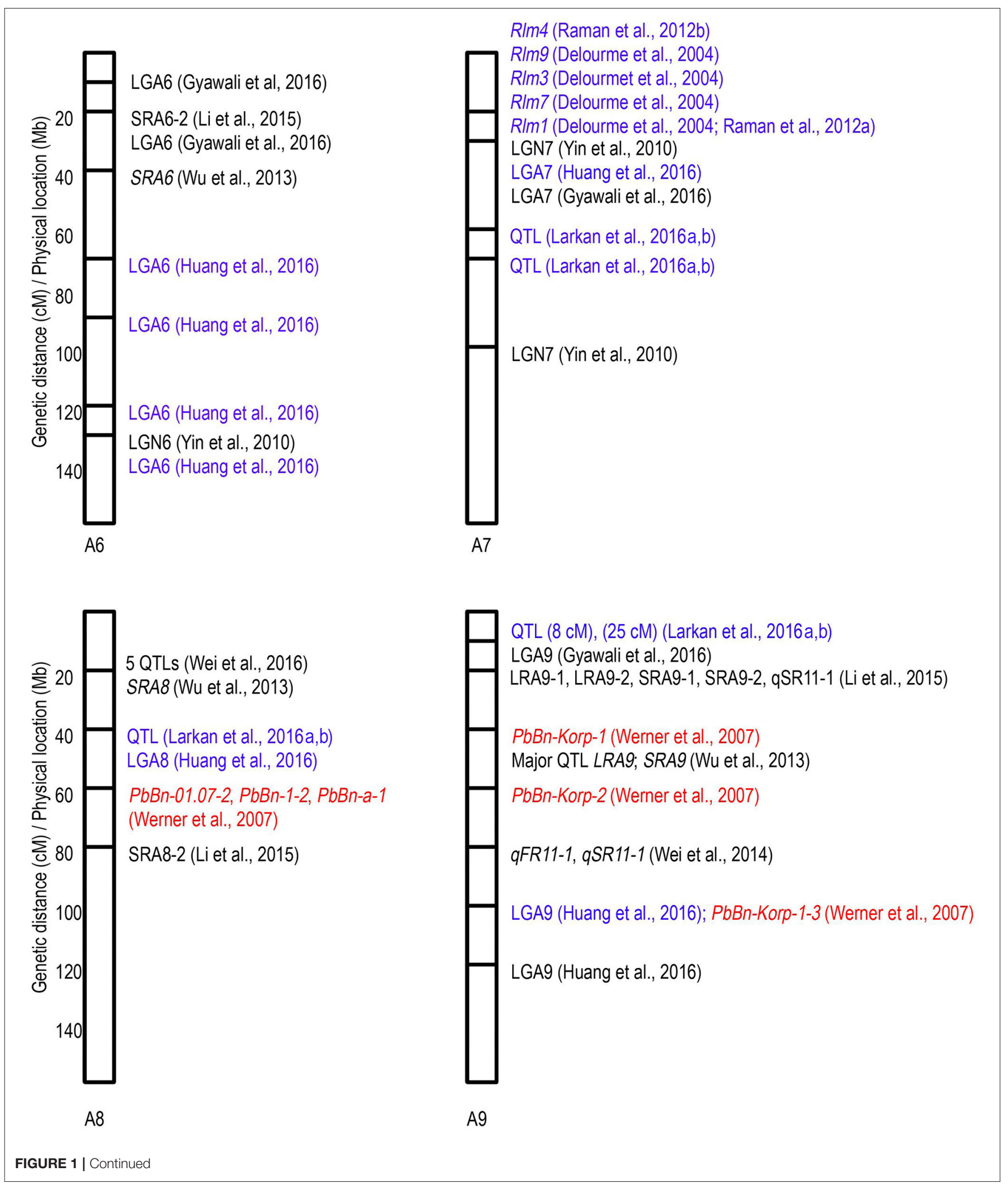

E. abyssinicum showed high levels of stem resistance (Garg et al., 2010a). In addition, resistance sources from the wild $B$. incana and B. insularis have been identified (Mei et al., 2011, 2013).
Characterisation of these introgression regions using genomic technologies, and identification of candidate Sclerotinia $R$ genes, through sequencing the introgression regions, will be the first 

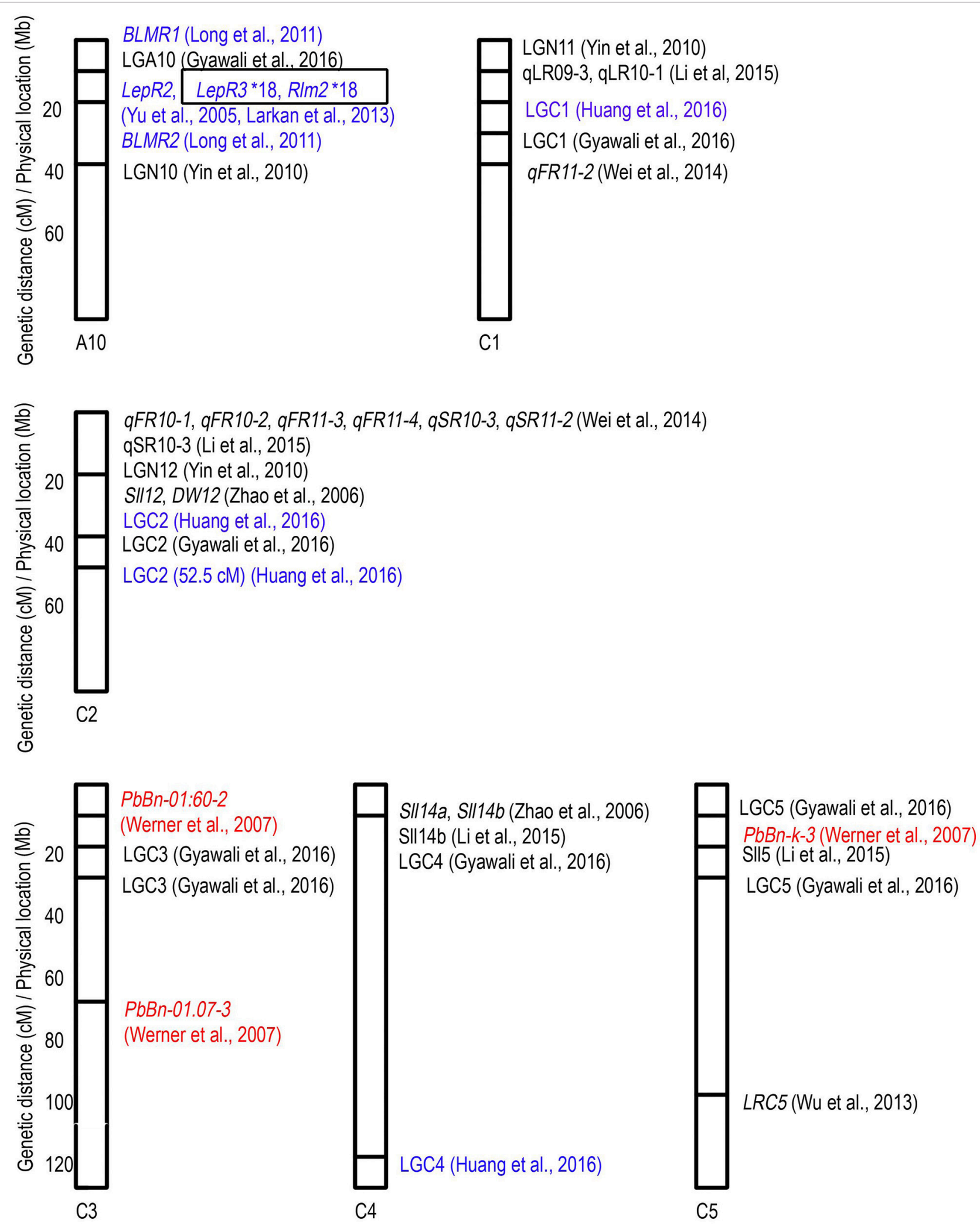

FIGURE 1 | Continued 

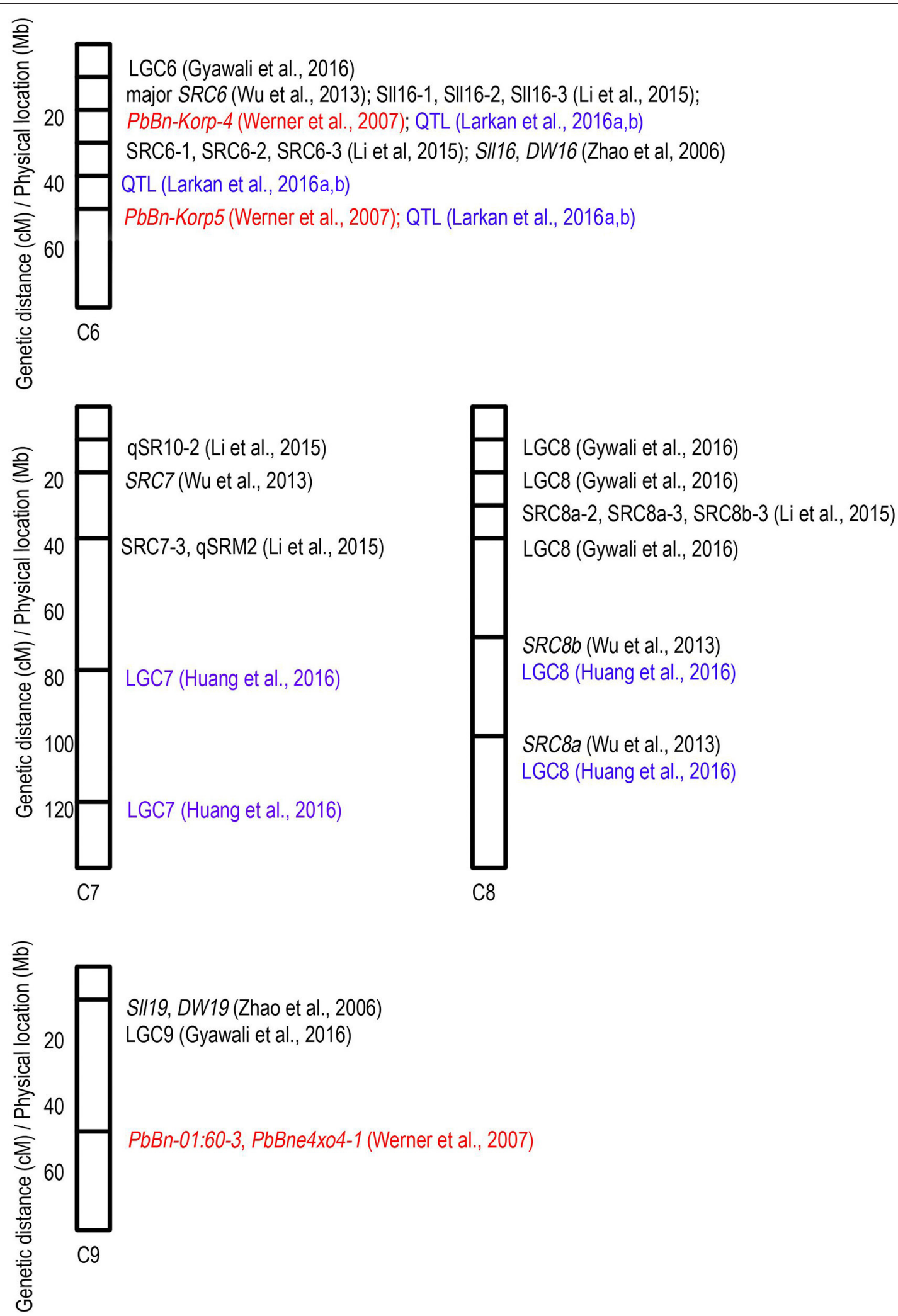

FIGURE 1 | Continued 
FIGURE 1 | Continued

$R$ genes/QTL mapped on B. rapa (A), B. oleracea (B), and B. napus (C). Each vertical rectangular is a chromosome, with the chromosome name followed by chromosome number at the bottom. Black font denotes $R$ genes/QTL mapped for $S$. sclerotiorum, blue font $L$. maculans, red font $P$. brassicae and bold black font $H$. parasitica. Boxed $R$ gene is cloned. Where genetic distance applies, the chromosome position is stated in parentheses at the end of the locus. ${ }^{*}$, Independent minor loci, homologous to $A$. thaliana chromosome 3; ${ }^{2}$, Crr3 is independent of Crr1 and Crr2; ${ }^{*}$ 3, Syntenic with A. thaliana chromosome 4. Crr1 and Crr2 also share the same syntenic region; *4, Close to CRa and CRb, also known as RCr1 (Chu et al., 2014), predicted as TIR-NBS-LRR (Yu F. et al., 2016); *5, Independent of Crr1, Crr2, and Crr3; *6, Two genes, Crr1a and Crr1b were identified at originally single Crr1 locus; ${ }^{*} 7$, All at the same locus and are identical to major QTL BraDM (Yu et al., 2009); *8, Candidate gene, Bra016457, is serine/threonine (S/T) kinase. The major QTL in *7 and *8 lie between 17.6 and $17.8 \mathrm{Mb}$ on chromosome R8; ${ }^{*}$, Syntenic with CRc on chromosome R2; ${ }^{*} 10$, Strong collinearity with chromosome A2 in B. rapa where CRc gene is located. Also overlap with $p b-B o(A n j u) 1$; ${ }^{*} 11$, Identified by Voorrips et al. (1997) but mapped on chromosome O3 by Nagaoka et al. (2010); *12, CRQTL-GN_2 (15.5-24.3 cM) and CRQTL_YC (8.5-38.1 cM) have similar location. Syntenic regions for these two QTL are on chromosome R3 (Crr3, CRk, CRa, and CRb), R8 (Crr1); ${ }^{*} 13$, Same linkage group with QTL-LG1 (Moriguchi et al., 1999); ${ }^{*} 14$, May be the same locus; ${ }^{*} 15$, Closely linked to $C R b$, homologous to chromosome R3; ${ }^{*} 16$, Adult resistance; ${ }^{*} 17$, Field resistance for $L$. maculans. Candidate gene is cysteine rich RLK; ${ }^{*} 18, L e p R 3$ and RIm2 are allelic variants.

step toward understanding the interaction between the host and pathogen.

The characterization of $R$ genes for resistance against S. sclerotiorum in B. napus is particularly challenging. The interaction in this pathosystem is more complex than previously thought (Amselem et al., 2011). Host resistance studies in B. napus and other Brassicaceae genotypes have also demonstrated that not only did S. sclerotiorum cause pathotypespecific HR in B. napus cotyledons (Garg et al., 2008, 2010c; Barbetti et al., 2014), it also caused non-pathotype-specific resistance response in some genotypes of $B$. napus, Raphanus sativus, $B$. juncea, and $B$. nigra, where the host was resistant against different pathotypes tested (Barbetti et al., 2014; Ge et al., 2015). These two resistance outcomes against S. sclerotiorum rely on the specific combination between host genotype-pathogen isolate. The question is how do we distinguish these two resistances using molecular tools so that we can exploit the $R$ genes? An enabler in the search for effective high level resistance to Sclerotinia Stem Rot has been the ability to define the sub-specific variation of S. sclerotiorum and to characterize pathotypes of this pathogen (Ge et al., 2012). This has not only provided explanation for many conflicting findings in search for effective new resistances but, more importantly, allowed identification of the first Brassica resistances to Sclerotinia Stem Rot that are truly pathotype-independent (Barbetti et al., 2014). Utilisation of this information and careful selection of pathotypes, inoculation methods and use of introgression lines, combined with technologies such as gene expression profiling and genome sequencing will be the first step to identification of resistance genes.

\section{Downy Mildew}

The pathogen Hyaloperonospora parasitica is responsible for up to $90 \%$ yield loss of Chinese cabbage (B. rapa) in China (Yu et al., 2009). Although, five $R$ genes from Arabidopsis that encode both TIR- and CC-NBS-LRR have been cloned for resistance to $H$. parasitica; namely RPP2 (Sinapidou et al., 2004) and RPP5 (Parker et al., 1997) on chromosome 4, RPP8 (McDowell et al., 1998), RPP1 (Botella et al., 1998) and RPP13 (BittnerEddy et al., 2000) on chromosome 3 (Botella et al., 1998), no $R$ gene has been cloned from Brassica species. However, Ppa3, a single dominant $R$ gene against this pathogen was mapped in B. oleracea using molecular markers (Singh et al., 2012). The major locus Pp523 on chromosome C8 has also been identified to confer resistance at the adult stage in $B$. oleracea (Farinhó et al., 2004; Carlier et al., 2012), with a syntenic locus on chromosome 1 in A. thaliana (Farinhó et al., 2007). Another major gene $R P P 31$ for adult resistance against Downy Mildew was genetically mapped on chromosome 5 in A. thaliana (McDowell et al., 2005). Since many more $R$ genes have been cloned or mapped in Arabidopsis, the orthologous genes in Brassica can be investigated through genomics approaches, for example comparative analysis of genomes (Yu et al., 2014) and pan-genome analysis (Golicz et al., 2016).

Genetic inheritance of specific resistance to $H$. parasitica has been reported in B. oleracea (Natti et al., 1967), B. napus (Lucas et al., 1988; Nashaat et al., 1997), and B. juncea (Nashaat and Awasthi, 1995; Nashaat et al., 2004; Chattopadhyay and SéguinSwartz, 2005). Among these reports, Natti et al. (1967) was the only one that reported the existence of separate races (1 and 2) in broccoli (B. oleracea var. italica). Sherriff and Lucas (1990) used 33 isolates, collected from four different Brassica species (B. napus, B. juncea, B. oleracea, and B. campestris) and geographic locations to infect a set of Brassica accessions (including B. napus, B. juncea, B. oleracea, B. carinata, B. nigra, B. campestris and Raphanobrassica). However, the study failed to delineate pathotypes of $H$. parasitica, which might explain variability in the resistance outcome. More recently, Mohammed et al. (2017) tested 131 Brassicaceae lines which highlighted excellent resistance to Downy Mildew, and was the first study to demonstrate the existence of very high levels of pathotypeindependent resistance in Australian B. napus rapeseed varieties. However, no molecular analysis of these lines has been performed in order to identify resistance genes.

The resistance loci expressed in the cotyledon does not necessarily translate to adult plant resistance in $B$. oleracea against $H$. parasitica, as the resistance outcome can be different between the growth stages (Dickson and Petzoldt, 1993; Coelho et al., 1998). However, in some instances, there was association of resistance at cotyledon stage with that expressed at the adult stage (Jensen et al., 1999a; Wang et al., 2000). Similarly, screening tests on seedling cotyledons across B. napus cultivars were claimed to provide an accurate estimation of expression of field susceptibilities/resistance on seedling and more mature leaves for Downy Mildew (Ge et al., 2008). These contrasting findings indicate that the resistance outcome in the host against 
Downy Mildew is likely to be QTL-specific where the QTL is associated with developmental stages of the plant. Identification of such QTL should be particularly useful for breeding purposes, especially where both seedling and adult plant resistances together are required.

The genetic mechanism of resistance in the Brassica- $H$. parasitica pathosystem needs further clarification, as a HR has been observed in both host and non-host species ( $\mathrm{Li}$ et al., 2011). Further, there is no evidence of clear-cut differences between Brassica host species which displayed a hypersensitive, partially resistant or susceptible reaction, compared with nonhost species, during the early stages of infection, at spore germination and host penetration (Li et al., 2011). This may simply mean that the expression of the important components of host resistance in Brassicas relates to resistance mechanisms occurring during later stages of infection. Besides, $H$. parasitica infects a wide host range including Sinapis and Raphanus species and even species outside of the Brassicaceae, with these latter hosts mostly resistant to $H$. parasitica (Dickinson and Greenhalgh, 1977). Another intriguing aspect of the host resistance against $H$. parasitica is that the genetic control can be recessively inherited (Carlsson et al., 2004). Controlled infection studies using the wider host range, combined with molecular analysis such as gene expression and GWAS studies could be utilized as a first step toward understanding of the genetic mechanisms of resistance.

The sources of isolate, either geographic location from which the isolate was sourced or the host from which the isolate was found, influence the phenotypic outcome. Isolates sourced from different locations within the U.S.A. produced consistent disease scores within a test host genotype (Dickson and Petzoldt, 1993). By contrast, in Australia, significant sub-specific variation occurs and this needs to be considered in host-pathogen studies on resistance. Similarly, resistance was isolate specific whereby an English isolate was more virulent than a Danish isolate on B. oleracea cultivars (Jensen et al., 1999a). Unfortunately, none of these studies allows comparison of $H$. parasitica pathotype structure over time, or across different crops, different countries or continents. To date, it has not been possible to universally characterize $H$. parasitica pathotypes due to unavailability of host differentials used. Hence, there is clearly a need to develop and deploy a group of universal host differentials such that pathotypes of $H$. parasitica can be delineated, otherwise progress toward developing new varieties with resistance to the existing H. parasitica populations will be curtailed.

\section{Blackleg}

The potential for L. maculans to cause severe damage was highlighted by the widespread total collapse of susceptible oilseed rape varieties in Western Australia in the early 1970s (Sivasithamparam et al., 2005) and subsequently in the early 2000s with the collapse of single dominant gene-based resistance from B. rapa ssp. sylvestris in various regions of Australia. L. maculans also causes severe damage to oilseed rape in the UK (Barnes et al., 2010), Canada and mainland Europe (Hwang et al., 2016). The less aggressive blackleg pathogen, L. biglobosa, is more prevalent in China (Liu Z. et al., 2014) and was recently reported to be present in New Zealand (Lob et al., 2013). Although no severe B. napus yield loss has been reported from L. biglobosa, researchers have taken precautions to prevent the spread of L. maculans into China (Zhang X. et al., 2014; Cai X. et al., 2017).

We focus on the host resistance against L. maculans in this review. Published work on sources of Blackleg resistance genes in Brassica species have been increasing over the years, with the focus more recently toward quantitative resistance (Jestin et al., 2011; Huang et al., 2016; Larkan et al., 2016a), and the need to bridge this historical knowledge gap has been highlighted (Delourme et al., 2006, 2012; Rimmer, 2006). Although 12 Blackleg qualitative race specific $R$ genes have been genetically mapped and more have been recognized (Table 2), it remains uncertain if some of these genes are actually the same gene with different nomenclature or allelic variants of the same gene. This uncertainty arises from researchers using different crosses, different isolates and different marker systems. For example the genes $L m R 1, c R L M m, R l m 4, c R L M r b$, and LEM1 were all mapped on chromosome A7 in B. napus using Australian cultivars Shiralee, Maluka, Skipton and the French cultivar Major, respectively (Ferreira et al., 1995; Mayerhofer et al., 1997; Rimmer et al., 1999; Balesdent et al., 2001; Rimmer, 2006), with different molecular markers and therefore, until one is cloned, it is unknown if they are the same gene. This uncertainty has implications in breeding as breeders do not know whether they are using the same or different sources of resistance. Furthermore, it is recommended in Australia to rotate the source of resistance gene grown annually so the pathogen population cannot build up to cause severe yield loss (Van De Wouw et al., 2016b). The lack of knowledge of the number of resistance genes makes this more difficult to achieve and often means a pool of fewer resistance genes is used.

Another example relates to the LepR3 gene in B. napus which has been shown to interact with AvrLm1 (Larkan et al., 2013), however phenotypic studies suggest that AvrLm1 may also be recognized by $R \operatorname{lm} 1$, thus raising the question of the relationship between these two $R$ genes (Rouxel and Balesdent, 2013). The relationship between $R \operatorname{lm} 4$ (Raman et al., 2012b) and $R \operatorname{lm} 7$ (Balesdent et al., 2002), implicated to be responsible for the HR outcome on B. napus during attack by $L$. maculans carrying the allele AvrLm4 or AvrLm7 respectively, is also unknown. Cloning studies on these effectors revealed that AvrLm4 and AvrLm7 are two distinct alleles of the same gene, termed AvrLm4-7, and can induce resistance in $B$. napus that harbors either $R \operatorname{lm} 4$ or $R \operatorname{lm} 7$. However, the relationship between the two $R$ genes, is yet to be determined (Parlange et al., 2009). It is also possible that $R \operatorname{lm} 3, R \operatorname{lm} 4$ and $R \operatorname{lm} 7$ may all be allelic variations of the same gene, based on evidence showing the location of these genes on a clustered region on chromosome A7 in B. napus and not being found together in the same B. napus pure lines, with a recent study showing an unusual interplay between AvrLm47 and AvrLm3 (Delourme et al., 2004; Larkan et al., 2016b; Plissonneau et al., 2017a). Clearly there is a need to reconcile different nomenclatures for these genes and the relationship between them. Toward this, a roundtable discussion amongst experts in the field was conducted during the Brassica2016 conference and a consensus reached to join research efforts to 
bridge this gap (Plissonneau et al., 2017b). The success story of clarifying AvrLmJ1 and AvrLm5 are indeed the same Avr gene (Plissonneau et al., 2017a), is an example that should be followed by Brassica and blackleg researchers to clarify nomenclature for other genes.

Compared with other Brassica pathogens, the molecular characterization of avirulence genes in L. maculans is more widely studied (Table 3). We have now been able to study how the pathogen adapts to its new host via strict interaction at the molecular level. For example, the interaction between Rlm3 and AvrLm3 is suppressed by AvrLm4-7 when attacked by the L. maculans isolate that carries this allele (Plissonneau et al., 2016), although this isolate can be uncommon in the Canadian rapeseed fields (Kutcher et al., 2010; Zhang H. et al., 2016). There is positive influence of the frequency of the virulent allele avrLm1 on avrLm6 due to genetic linkage between the two alleles in the pathogen genome (Van De Wouw et al., 2010). This observation is important when decision making is required for which variety to rotate in the field. For example, selecting a variety with $R \operatorname{lm} 1$ directly after growing a variety containing $R \operatorname{lm} 6$ would not be advised as there would be higher infection due to the presence of avrLm1.

The sources of Blackleg $R$ genes were more frequently found and more diversified in the winter type B. napus compared to the spring-type cultivars (Rouxel et al., 2003b), where Rlm4 is the most common $R$ gene in the latter (Rouxel et al., 2003b; Marcroft et al., 2012a). Both B. rapa and B. napus have proven to be good sources of Blackleg resistance genes on the A genome. Some genes from $B$. rapa have been introgressed into B. napus, such as the LepR-series of $R$ genes from $B$. rapa ssp. sylvestris (Yu et al., 2005, 2008, 2013). Researchers have also attempted to exploit the B genome for resistance, and $R$ genes/QTL that are highly resistant to $L$. maculans have been introgressed from the B genome (Rimmer and van den Berg, 1992; Plieske et al., 1998), particularly into B. napus (Sacristan and Gerdemann, 1986; Chevre et al., 1996; Fredua-Agyeman et al., 2014). The resistance level in the introgressed $B$. napus was the same as that in the donor $B$ genome source, although expression of phenotype was shown to be influenced by temperature (Plieske et al., 1998). These novel sources of $R$ genes introgressed into $B$. napus will enable continued resistance against the pathogen, through expanding the number of resistance alleles available for breeding, particularly in times of climatic uncertainty.

Both LepR1 and LepR2 are involved in cotyledon resistance and are also associated with resistance at the adult stage in B. napus (Yu et al., 2005). However, the mechanism of resistance at both stages is different because Yu et al. (2005) showed that presence of LepR1 provided complete resistance, while LepR2 only offered partial resistance at the cotyledon stage, yet both genes ensured complete resistance at the adult stage. A very different pattern of resistance exists for the Chinese B. napus lines derived from winter type and spring type parents, where $R$ gene mediated resistance in these lines conferred by both $R \operatorname{lm} 3$ and $R \operatorname{lm} 4$ was effective at both seedling and adult plant stages against L. maculans (Zhang et al., 2016b). Similarly, the Australian winter B. napus lines harboring either $R \operatorname{lm} 1, R \operatorname{lm} 3$ or a combination of both display stable resistance against $L$. maculans where resistance is effective at both seedling and adult plant stages (Light et al., 2011). Such examples, taken together, imply that while $R$ genes can be effective at both cotyledon and adult stages, they can also act interdependently or dependently at different plant developmental stages, and are likely affected by the genotype of host and pathogen, as well as by environmental conditions. The $R$ gene effective at seedling stage can also lie in the same QTL region as that of adult plant resistance (Raman et al., 2012b). Whether this adult plant resistance is mediated by the same $R$ gene or by quantitative non-specific resistance genes is yet to be confirmed. An increased understanding of this molecular basis for resistance, for example through further genome sequencing and gene cloning, will enable the genes to be deployed more effectively. Further, expression of $R$ gene mediated resistance can also be expressed differently across other host plant components; for example, $R \operatorname{lm} 1$ and $R \operatorname{lm} 4$ exhibit major gene resistance on $B$. napus pods, not only on cotyledons (Elliott et al., 2016).

Besides qualitative resistance, quantitative resistance has also been assessed and reported in B. napus against L. maculans (Huang et al., 2009). Methods to determine quantitative resistance more efficiently such as inoculation at different parts of the leaves under controlled conditions have been evaluated (Huang et al., 2014). Several QTL responsible for quantitative resistance against $L$. maculans have been identified in French, European and Australian B. napus cultivars (Jestin et al., 2011; Raman et al., 2012b; Huang et al., 2016; Larkan et al., 2016a). However, the genetic control of quantitative resistance against Blackleg is poorly understood as it is very difficult to compare QTL, even with the same molecular markers and lines being utilized, due to environmental differences and a lack of knowledge of the pathogen presence in the field.

\section{GENETICS}

\section{$R$ Genes/QTL Mapped}

The genetic inheritance of pathogen resistance, based either on a gene-for-gene interaction where the $R$ gene is either a single dominant gene (complete resistance) or involves multiple genes (partial resistance) has been established for the four key pathogens of this review (Table 2). The $R$ genes/QTL mapped for the key pathogens are illustrated in Figure $\mathbf{1}$.

Whilst numerous QTL and $R$ genes have been genetically mapped (Table 2), to date, only four resistance genes have been cloned, for Clubroot and Blackleg resistance. Two Blackleg resistance genes have been cloned; LepR3 was cloned from B. napus cv. Surpass 400 (hybridization between B. rapa ssp. sylvestris and B. oleracea ssp. alboglabra) (Larkan et al., 2013) and $R \operatorname{lm} 2$, an allelic variant of LepR3, from Glacier DH24287 (Larkan et al., 2015). LepR3 is characterized to have a similar function to the $C f-9$ gene from tomato that confers resistance toward the biotrophic ascomycete fungus Cladosporium fulvum (Jones et al., 1994), which shares the same mode of attack as L. maculans (Stotz et al., 2014). LepR3/Rlm2 are receptorlike proteins (RLP) that interact specifically with the effectors AvrLm1 and AvrLm2, respectively, at the plant cell surface. This class of disease resistance protein is not the same as the 


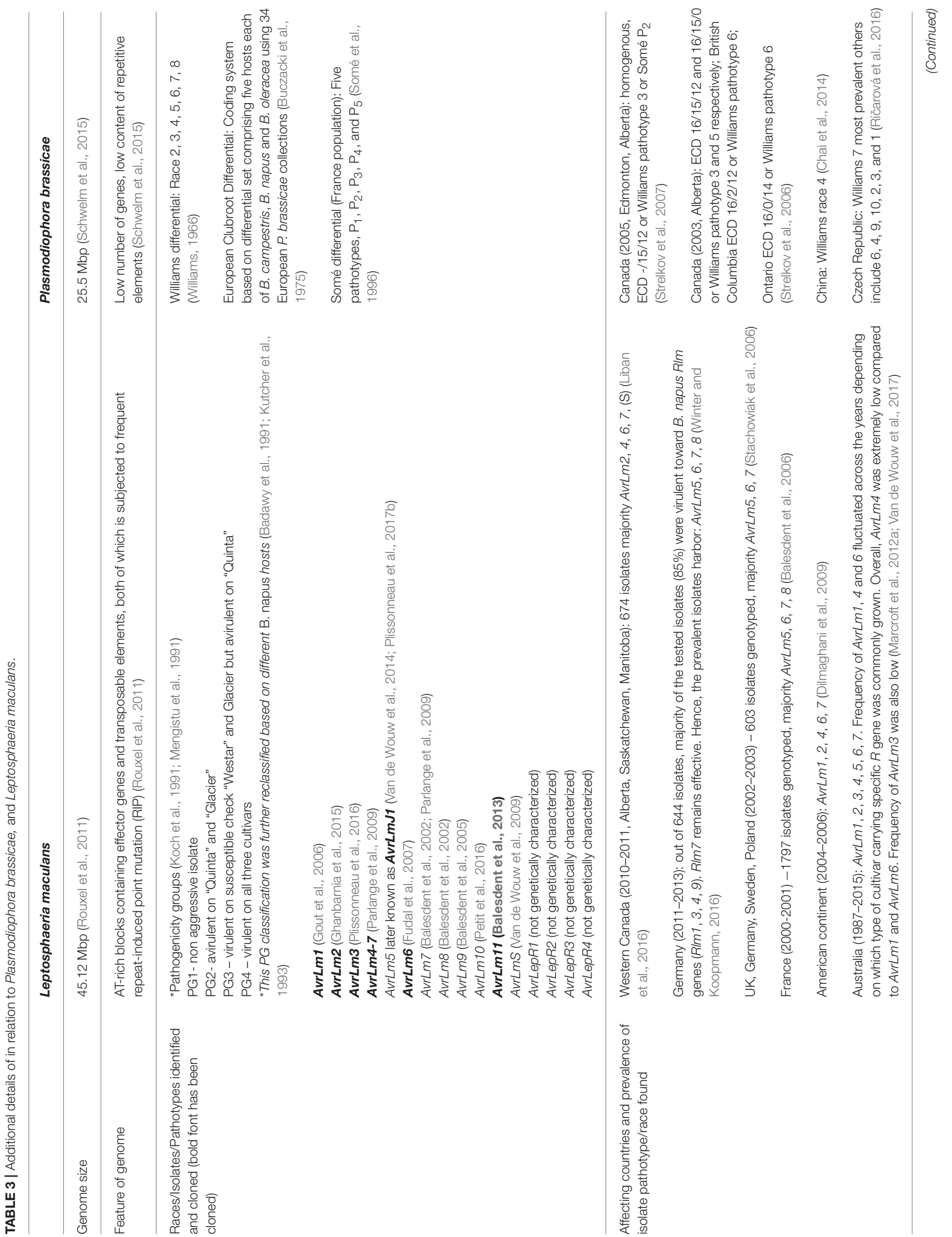


cloned $R$ genes for $P$. brassicae in B. rapa which are NBSLRRs, thus raising the question, is RLP considered part of effector triggered immunity (ETI)? In recognizing this "gray area," a review by Stotz et al. (2014) tried to re-classify plant immunity for apoplastic fungal pathogens such as L. maculans and Cladosporium fulvum, for which the defense mechanism seemed to deviate from the classical NBS-LRR recognition in the host cell cytoplasm where effectors are being secreted. Stotz et al. (2014) proposed the new resistance defense triggered by apoplastic fungal pathogens as "effector-triggered defense" (ETD) that involves RLPs recognizing effectors outside host cell cytoplasm. In Brassica species genome wide $R$ gene identification studies have focused only on NBS-LRR genes, future studies should include RLPs and RLKs in the analysis, as this may pave the way for cloning of further $R$ genes in Brassica species (Rameneni et al., 2015; Sekhwal et al., 2015; Li P. et al., 2016).

Recent advances in genome sequencing and assembly have allowed us to tap into the rich genetic resources from different crop species and their wild relatives (Bevan et al., 2017). A reference genome is useful to align and compare all the different QTL mapping experiments. By having a reference genome, the physical location of the markers in QTL maps that are linked with candidate genes can be determined (Zhang Y.-M. et al., 2016). Currently, the genome sequence of the Brassica diploids, B. rapa (Wang et al., 2011; Cai C. et al., 2017), B. oleracea (Parkin et al., 2014; Liu S. et al., 2014), and B. nigra (Yang et al., 2016) and the amphidiploids B. napus (Chalhoub et al., 2014; Bayer et al., 2017), B. juncea (Yang et al., 2016) have been published. This along with the advanced genotyping tools such as the $60 \mathrm{~K}$ Brassica Infinium SNP array (Clarke et al., 2016) and Genotyping by Sequencing (GBS) (Bus et al., 2012; Bayer et al., 2015; Cheng et al., 2016; Scheben et al., 2017a), have allowed rapid identification of genome-wide QTL and GWAS regions for $R$ genes for Clubroot (Lee et al., 2016; Li L. et al., 2016), Sclerotinia Stem Rot (Wei L. et al., 2016; Wu et al., 2016a) and Blackleg (Raman H. et al., 2016).

Genome sequencing in Brassicas has now been expanded to include the $B$. oleracea pan-genome where genomes of nine lines were assembled and compared for structural variation (Golicz et al., 2016). Pan-genome sequencing is an important advance, as the diversity of a species is not represented by a single cultivar, and in B. oleracea only $81 \%$ genes were present in all lines. Of the $19 \%$ variable genes, those associated with disease resistance were found to be among the most prevalent. Therefore, in identification of resistance genes we should look at the variable genes, not only those in the reference genome sequence. Genome resequencing (Cheng et al., 2016) and pangenomics (Golicz et al., 2016) approaches are promising tools to make identification, characterization and cloning of candidate $R$ genes more achievable and reliable (Figure 2). The pan-genome approach to study structural variation of the genes in Brassica genomes, with whole-genome gene expression and methylation studies has already proved very useful toward uncovering the structure, function and evolutionary origin of $R$ genes (Parkin et al., 2014; Golicz et al., 2016). Copy number variation (CNV) has already been studied for the AP2/ERF superfamily involved in plant stress tolerance in B. napus, CNV of $R$ genes in Brassica is only now being investigated (Batley et al., 2016) and has been 
Whole genome sequencing (Tollenaere et al., 2012)

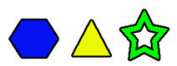

RLP? RLK? NBS-LRR?

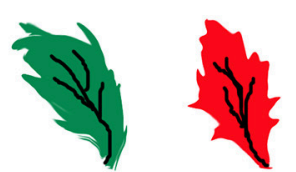

Resistant Susceptible

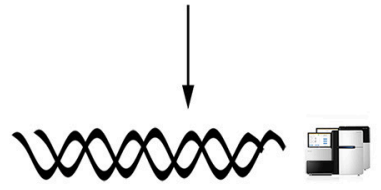

Genotype by sequencing

(Lee et al., 2016)

Bulked segregant RNA sequencing

(Yu et al., 2016)

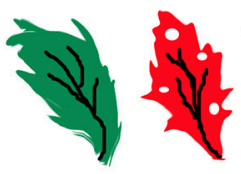

Phenotyping

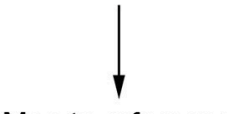

Map to reference
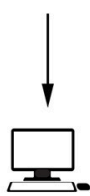

Genome-wide association analysis

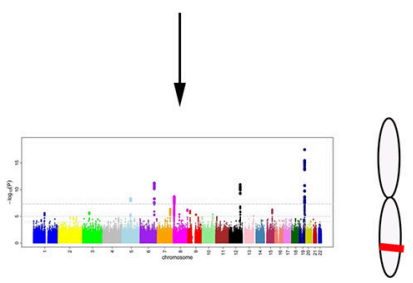

Identify marker locus significantly associated with $Q T L$ region or $R$ gene

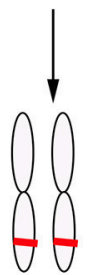

Homoeologous gene? Duplicated gene?

(Fomeju et al., 2015)

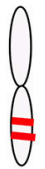

Structural variaion? Copy number variation? (Golicz et al., 2016) 
implicated in important crops such as cereals (maize and rice), Solanaceae and soybean (Springer et al., 2009; McHale et al., 2012; Xu et al., 2012; Saxena et al., 2014; Wei C. et al., 2016). This gene expansion through structural variation allows the plant to adapt to rapid changes in the environment (Cheung et al., 2009).

\section{CHALLENGES}

\section{Genome Complexity}

Brassica napus is a relatively young crop in evolutionary history that results from an accumulated series of polyploidisation events (Mason and Snowdon, 2016). Prior to hybridization, the whole genome triplication in the diploids (B. rapa and B. oleracea) was preceded by three events of whole genome duplication in the ancestor genome that have further contributed to complicated gene rearrangement, duplication and loss (Town et al., 2006; Chen, 2007). Despite the genome complexity, Brassica species have become models to study evolutionary events and how rich genetic resources can be exploited from the plant (Pires and Gaeta, 2011; Liu S. et al., 2014).

Domesticated B. napus has a lower genetic diversity compared to its diploid progenitors $B$. rapa and B. oleracea, evidenced by similar gene order and content between the three species due to strong genetic bottlenecks during cultivation (Cheung et al., 2009; Mason and Snowdon, 2016). By contrast, homoeologous rearrangements/recombination occurs more frequently in resynthesized $B$. napus, thereby contributing greatly toward genetic diversity, which provides a good source of $R$ genes for breeding resistant B. napus cultivars (Gaeta and Pires, 2010). Recently, efforts were made to produce introgressed $B$. napus in a novel way, from B. juncea (A genome source) and B. carinata (C genome source) (Chatterjee et al., 2016) (rather than from B. oleracea and B. rapa) from where more sources of $R$ genes can then be utilized and identified. While in B. napus, the homoeologous genes are often co-expressed (Chen, 2007), there could also be bias in homoeolog expression, as found in B. juncea (Yang et al., 2016) and B. rapa (Cheng et al., 2012). How the different levels of gene expression affect the stability of $R$ genes remains to be determined. The fate of homoeologous genes, whether they are silenced, expressed, or both copies diverge where the gene function may or may not change (sub- and neo-functionalization) is a result of the genetic and epigenetic interactions between redundant genes (Comai, 2005), biased gene expression (Yang et al., 2016), gene fractionation (Subramaniam et al., 2013) or accelerated amino acid sequence evolution and positive selection (Liu and Adams, 2010). These polyploidy events could potentially result in a selective advantage, for example higher seed yield in B. napus (Osborn et al., 2003).

Although race-specific $R$ genes are easier to manipulate for breeding resistant crops compared to polygenic resistance, which involves many genes and the effect of environmental factors, the identification of $R$ genes in B. napus still remains a challenge due to the complexity of its genome. For example, a major QTL for resistance to S. sclerotiorum was duplicated through homoeologous non-reciprocal transposition (HNRT) in B. napus (Zhao et al., 2006). The quantitative resistance genes against
L. maculans are affected by gene duplication in homoeologous regions in B. napus (Fomeju et al., 2014, 2015). L. maculans $R$ genes, $\operatorname{Lmr} 1$ and $C \operatorname{lm} R 1$ from cultivars Shiralee and Cresor respectively, were mapped on regions that are highly duplicated within and between genomes in B. napus, and originated from the common ancestor before divergence of B. oleracea and B. rapa (Mayerhofer et al., 2005). Evolutionary information regarding resistance genes such as these is useful for breeding purposes, as it highlights specific genera/species likely to be most useful in developing new cultivars with highly effective and durable disease resistances. For $H$. parasitica, the single dominant gene $P p 523$ was mapped onto two regions on chromosome $\mathrm{C} 8$ and another on $\mathrm{C}$, reflecting triplicated regions in B. oleracea (Carlier et al., 2011).

The success stories of cloning Crr1a and CRa (Clubroot $R$ genes encoding TIR-NB-LRR) from B. rapa (Hatakeyama et al., 2013) and LepR3/Rlm2 (Larkan et al., 2013) in B. napus, revealed that the $R$ genes are organized as members of allelic variants or tandem repeats. The clustering effect of the $R$ genes for these two pathogens provides further evidence of complexity of the genome organization. Clustering of $R$ genes is also prevalent in association with Clubroot, Blackleg, and Sclerotinia Stem Rot resistance on both B. rapa (Kato et al., 2013) and B. napus (Delourme et al., 2004; Kato et al., 2013; Li et al., 2015). Such gene clustering effects are common in plant genomes for quick adaptive response to pathogens via recombination events (Hulbert et al., 2001; Meyers et al., 2003). Clustering of $R$ genes may potentially enable recognition of different pathogen races carrying different avirulence genes, such as in Clubroot $R$ genes on chromosome A8 (Pang et al., 2014). Epistatic interaction was also observed for Clubroot in B. napus (Manzanares-Dauleux et al., 2000), where a single dominant resistance gene does not explain the resistance outcome in its entirety. It was also reported that the same genomic region in B. napus can act as both QTL and/or major gene based on different pathotypes of Clubroot (ManzanaresDauleux et al., 2000; Rocherieux et al., 2004). The clustering and duplication of $R$ genes can also cause problems in $R$ gene identification as these genes tend to collapse in genome sequence assemblies. Reliance on the single reference genome sequence can therefore hamper efforts and future work should incorporate novel technologies such as isolated chromosome sequencing or targeted amplification of genomic regions of interest.

\section{Genetic Variation}

Further to the complexity of $R$ genes, resistance levels vary with different host species within B. napus for the key pathogens discussed in this review. Often, intermediate/heterogeneous phenotypes were obtained when using the pathogen isolates either derived from differential sets or from host cultivars. This could be due to genetic variation within the host cultivars and/or even within the pathogen.

\section{Host}

Brassica napus has a low genetic diversity due to the recent evolutionary history (Snowdon et al., 2007; Prakash et al., 2011). Although B. napus has a comparatively lower level of genetic variation (Wu et al., 2014), breeding programs have 
made extensive use of interspecific hybridization within the Brassicaceae family, including with Sinapis arvensis, to broaden the genetic diversity for Blackleg resistance (Winter et al., 2003; Snowdon et al., 2007). Depending on the genetic background of the $B$. napus host, for example winter, spring type cultivars or resynthesized lines, the $R$ gene diversity can be high or low (Rouxel et al., 2003b). This can affect the assessment of disease on the plant where a wide range of scores is obtained (Larkan et al., 2016b).

Genetic mapping studies on the key pathogenic resistances showed that breeding materials or cultivars were mostly used to generate mapping populations (Table 1; Diers and Osborn, 1994; Plieske and Struss, 2001). However, other genetic sources should be tapped into to increase the genetic pool for breeding resistant $B$. napus. For example, resynthesized lines can provide a good source of genetic diversity compared to cultivars (Becker et al., 1995). This is evidenced by the successful introgression of the resistance gene LepR3 from B. rapa into B. napus (Larkan et al., 2013). Fodder and vegetable rape genetic material can also contribute significant amount of $R$ genes, because of high genetic variation in these species (Hasan et al., 2006). Genomewide SNPs have been studied in natural accessions and synthetic B. napus, inferring sequence polymorphism in genes linked to agronomically important traits such as seed quality (Huang et al., 2013; Qian et al., 2014; Schmutzer et al., 2015) and this could be expanded to disease resistance studies.

\section{Pathogen}

A high level of genetic variation in S. sclerotiorum populations was found in B. napus fields in Australia (Sexton et al., 2006) and Canada (Kohn et al., 1991). In particular, the Australian S. sclerotiorum, with different isolates/pathotypes, caused variable resistance outcomes ranging from intermediate resistance to a HR to complete resistance in different host B. napus genotypes (Garg et al., 2010b; Ge et al., 2015). This poses important questions regarding this pathosystem: Does this host resistance come from specificity of the host species genotype, from the pathogen genotype or from a combination of both? Is there a role for non-host resistance to adapted pathogens? Could there be specificity of the host cultivar? Can host specificity and non-host specificity be displayed in different genotypes of the same host? Until the genetic basis for the various resistance levels in this pathosystem is unveiled, we will not know if the B. napus genotypes are going through a process of losing or acquiring host status (marginal host), or are intermediate between host and nonhost status, much like the barley resistance to rust where the host-pathogen interaction is indeed very specialized (Niks and Marcel, 2009).

For L. maculans, high genetic diversity has been found within populations. In France, evidence for this was found through an isolation by distance (IBD) study where there was high gene flow and high dispersal rates of spores among populations across large geographical distances (Travadon et al., 2011). These characteristics offer the pathogen a survival advantage to cope with the host resistance in the field, highlighting the role of coevolutionary dynamics between pathogen and host in conferring resistance. Similarly, in Australia, L. maculans also displayed high genetic variation between geographic locations such that the isolates from Western Australia were shown to be genotypically different from those collected from the eastern states. Studies using SNPs (Zander et al., 2013; Patel et al., 2015), microsatellite and minisatellite markers (Hayden et al., 2007) indicated that some populations are panmictic. Gene loss in L. maculans has contributed to genetic variation between isolates (Golicz et al., 2015). The source of genetic diversity for L. maculans could also depend on the specific host morphotype from which the pathogen is adapted to. For instance L. maculans "brassicae" from cultivated Brassica and L. maculans "lepidii" from Lepidium sp. were identified in the International Blackleg of Crucifers Network (IBCN) collection as one of the seven subgroups of the species complex based on ITS-RFLPs (Mendes-Pereira et al., 2003). This species complex, differing in specificity and pathogenicity on $B$. napus, potentially complicates the cloning of $R$ genes in $B$. napus (Voigt et al., 2005).

High genetic diversity was reported for $P$. brassicae. For example, in Japan where the pathogen showed different pathogenicity levels on the cruciferous crops and cruciferous weeds (Jones et al., 1982; Tanaka and Ito, 2013). However, pure pathotype/genotype isolates of $P$. brassicae can still be obtained from single root hairs, which minimizes the variability of pathogenicity, thus a more reliable interpretation of the hostpathogen relationship can be established (Diederichsen et al., 2016). For $H$. parasitica, a molecular study also revealed high genetic diversity within the species, probably due to the broad host range of this pathogen where it can infect, for example, various Brassica and Raphanus species (Choi et al., 2003).

\section{Pathotype Classification}

With the exception of the recent development of host differentials to delineate pathotypes of Sclerotinia Stem Rot (Ge et al., 2012), host differential sets to delineate pathotypes/races of the other pathogens have generally been established for some time (as early as the 1960s). Examples include Clubroot (Williams, 1966; Buczacki et al., 1975; Somé et al., 1996), Blackleg (Mengistu et al., 1991; Purwantara et al., 2000; Balesdent et al., 2002, 2005; Van de Wouw et al., 2009) and Downy Mildew differentials (Natti, 1958). The usefulness of pathotype classification became obscured when research groups used unknown, different and/or universally unobtainable sources of host differentials that prevented application of a universal and consistent set of host differentials. The "loss" of the Downy Mildew differentials used by Natti (1958) well illustrates these challenges. Application of different host genotype differentials not commonly available across different locations and/or countries has meant findings in terms of definition of pathogen races/pathotypes is, at best, of limited use and then only to that particular locality. Use of pathogen isolates without appropriate pathotype/race classification, can easily lead to misleading $R$ gene identification when it comes to qualitative or quantitative resistance classifications. To overcome this, an additional differential host differential set was established for Clubroot in Japan using local Chinese cabbage cultivars and local field isolates (Kuginuki et al., 1999; Hatakayema et al., 2006) and similarly for Downy Mildew using European isolates 
from B. oleracea (Coelho et al., 2012). Furthermore, as new pathogen isolates carrying new avirulence genes emerge as a normal consequence of pathogen evolutionary dynamics, host differential sets need to be updated and standardized to enable them to effectively delineate future new pathotypes/races.

Application of different scoring systems could also lead to complications in the identification of $R$ genes. For example, in Downy Mildew, at least three scoring systems have been applied (Dickson and Petzoldt, 1993; Wang et al., 2000). It is also imperative that a robust race/pathotype differentiation system be utilized to separate different and group similar races/pathotypes. While for $L$. maculans and $P$. brassicae established race differentiation systems are robust, for $H$. parasitica and some other pathogens this is not the case. A little utilized but extremely robust system was developed and utilized for the barley scald fungus, Rhynchosporium secalis by Goodwin et al. (1990). The Goodwin et al. (1990) pathogen isolate differentiation system utilizes an octal nomenclature classification that codes pathogen isolates according to their pathogenicity (expressed as disease severity) on the host differentials, mathematically confirming appropriateness of differential host and then grouping these genotypes into sets according to their genetic inheritance. This allows continuity with any previous studies that have different nomenclatures. Its suitability is illustrated by its recent successful application to define the first pathotypes within S. sclerotiorum populations on B. napus within Western Australia (Ge et al., 2012). Despite these differentials being made available worldwide, upon request, there has been little uptake outside of Australia, India and Eastern Europe to date. The Goodwin et al. (1990) pathogen isolate differentiation system applied to $H$. parasitica isolates would also be highly beneficial for the same reasons.

\section{Rapid Evolution of Virulent Pathotypes and Host-Pathogen Interaction}

In B. napus, resistance toward race-specific pathogens such as L. maculans and P. brassicae has been overcome. New virulent pathotypes of $P$. brassicae that have the potential to cause resistance breakdown in B. napus have been identified (Strelkov et al., 2016; see Table 3). Mass cultivation of cultivars containing particular $R$ genes favors selection of pathogen strains that are better adapted or have greater virulence due to strong selection pressures exerted on the pathogen. Care should be taken that introgressed lines with single dominant gene resistance are not widely grown homogeneously in commercial fields year after year (Marcroft et al., 2012b). Whilst they may be effective in the short term (one to two seasons), they will likely lose their efficacy over a period of time, as occurred in as little as 3-4 years for $L$. maculans (Li et al., 2003). In France, complete deletion of the Blackleg avirulence gene AvrLm4-7 was found (Daverdin et al., 2012).

The genetic mechanism of resistance in Brassica is different for each pathosystem. For the B. napus-L. maculans and $-P$. brassicae pathosystems, it is generally straightforward because distinct major gene resistances and respective cotyledon and root phenotypes have been well established using the Blackleg differential and Williams (1966) systems, making host single dominant $R$ gene effects relatively easy to study. In contrast, in the B. napus-S. sclerotiorum pathosystem, although a hypersensitive reaction was found for S. sclerotiorum on cotyledons (Garg et al., 2008; Ge et al., 2015) and stems (Garg et al., 2010a), it occurred in relation with specific host genotype-S. sclerotiorum isolate or pathotype combinations. In other words, the resistance outcome is pathotype-dependent and genotype expression of resistance is tied to the selected isolate or pathotype (Barbetti et al., 2014). Further, any QTL or gene expression results are tied to these particular host genotype-S. sclerotiorum isolate or pathotype combinations. The fact that seedling vs. adult and leaf vs. stem resistances are generally independently expressed (Uloth et al., 2013, 2014), has inhibited advancement of our understanding at a molecular level in comparison with that for L. maculans. Initially, for S. sclerotiorum, until there is wider utilization of the differentials developed to distinguish distinct pathotypes of $S$. sclerotiorum, as developed by $\mathrm{Ge}$ et al. (2012), it may be productive for molecular studies to focus more on using pathotype-independent resistances (i.e., genotypes showing resistance to all pathotypes) as recently highlighted by Barbetti et al. (2014). Failure to define subspecific variation in $S$. sclerotiorum remains an impediment to rapid progress in our understanding at a molecular level with the host genotype-S. sclerotiorum pathosystem. Further, it is evident that gene expression within the pathosystem involving S. sclerotiorum can be differentially expressed across different host genotypes depending upon their sensitivity toward environmental effects, for example small changes in temperature (Uloth et al., 2015b). Such variation further challenges outcomes for molecular studies into resistance against this pathogen, particularly with variations in expression of resistance across different temperatures, especially when temperature-phenotypes occur (Uloth et al., 2015b). Similar challenges occur in relation to the host genotype- $H$. parasitica pathosystem and likely occur wherever sub-specific pathogen variation occurs but has not been definitively characterized. In addition, comparisons made with known S. sclerotiorum pathotype delineations across approximately 60 Western Australian isolates showed that there was no relationship between pathotype with microsatellite or with IGS haplotype (Clarkson et al., 2017). Clearly there is a need for further molecular work, for instance metabolomics and proteomics, in addition to genomics, in conjunction with appropriate phenotyping across a range of environmental conditions to further investigate and understand these challenges both now and for the future.

\section{Abiotic Conditions}

Climatic conditions can influence the interaction between plants and pathogens and the pathogen distribution, contributing directly to the disease outcome on the host (Barbetti et al., 2012). Abiotic conditions including temperature and soil nutrient content could influence the resistance spectrum on the host A. thaliana against powdery mildew pathogens (Jorgensen, 2012). In the L. maculans-B. napus pathosystem, temperature effect influences the phenotypic outcome at different plant growth stages. For example, in general, during infection at 
nearly all growth stages from cotyledon to pod at higher temperature regimes (e.g., $18 / 24^{\circ} \mathrm{C}$ ), resistance expressed at the seedling stage was positively correlated with the adult stage, as compared to lower temperature regimes (e.g., $11 / 18^{\circ} \mathrm{C}$ ) ( $\mathrm{Li}$ et al., 2006b). Warmer temperature and high humidity levels favored L. maculans colonization of the host during a Rlm6-mediated resistance study on B. napus (Huang et al., 2006), confirming a related study on $R \operatorname{lm} 1$-mediated resistance by Badawy et al. (1992). Cold temperature and low soil acidity slow down or inhibit $P$. brassicae infection on $B$. napus, while the influence from soil micronutrient stops at high inoculum concentration (Gossen et al., 2014).

\section{STRATEGIES}

\section{Novel Sources of $R$ Genes and Transfer of $\boldsymbol{R}$ Genes}

Novel sources of $R$ genes for Blackleg can be sourced from other A- and C-genome Brassica species (Chen et al., 2010) or from the B genomes in B. nigra (Chevre et al., 1996), B. juncea (Christianson et al., 2006), and B. carinata (Plieske et al., 1998). Wild Brassicaceae species, such as Sinapis arvensis, also serve as a good source of $R$ genes for Blackleg (Snowdon et al., 2000). However $R$ genes from other wild species remain to be tapped. Besides identifying candidate $R$ genes through comparative genomic analysis, more screening work on wild and land races, including species from the Brassicaceae family, should be performed against the main pathogens to identify resistant plants. This would broaden the gene pool for introgression of novel $R$ genes or alleles into Brassica cultivars. Combining this information with genome sequencing will enable characterization of these novel resistance genes.

Although effector genes are usually unique and do not often share structural similarity but encode very diverse proteins, it is still possible to identify an $R$ gene that could recognize common or near identical effector gene(s) in different pathogen pathotypes/races/isolates, which already exists naturally in some plants/crops (Dangl et al., 1992). This type of $R$ gene is useful and can be transferred between hosts that are closely related or within the same genus or family. Some $R$ genes can also be transferred from host to non-host using GM technologies, providing broadspectrum immunity against one or more pathogens. One such successful example is the pepper Bs2 gene against bacterial spot disease transferred from its host pepper into non-host tomato (both members of Solanaceae family; Tai et al., 1999). The $B s 2$ gene encodes the $R$ gene NBS-LRR class (Tai et al., 1999) while the gene avrBs2 in Xanthomonas campestris pathovar vesicatoria, causal pathogen of bacterial spot disease, is essential for virulence activity and is highly conserved between and within the pathovars of X. campestris (Kearney and Staskawicz, 1990). This has opened up new possibilities to protect economically valuable crops, that lack $R$ gene resources, from disastrous pathogens.

\section{Breeding Resistant Cultivars}

Continuous efforts are on-going to breed resistant $B$. napus cultivars through introgression. B. rapa remains a good source of race specific $R$ genes that often result in high resistance against Clubroot (Strelkov et al., 2006) and Blackleg (Yu et al., 2008). For Clubroot, a single dominant gene from resistant $B$. rapa turnip morphotypes was successfully introduced into Chinese cabbage (Yoshikawa, 1980). Transfer of a Clubroot resistance gene was also performed from $B$. napus into $B$. oleracea, with the resistance gene believed to also be carried in the A genome of B. rapa (Chiang et al., 1980). In Canada, efforts to transfer a Clubroot resistance gene from the B. napus hybrid "Mendel" into a local susceptible spring $B$. napus cultivar was promising (Rahman et al., 2011). Transfer of a Clubroot $R$ gene was also made from B. rapa Chinese cabbage "Qulihuang" into B. napus “Topas” using marker-assisted selection (Hirani et al., 2016). For L. maculans, $R$ genes have been genetically mapped and identified in the A genome of B. napus (Alamery et al., in press). For S. sclerotiorum, introgression lines of $B$. juncea carrying genomic segments from the wild Brassicaceae $B$. fruticulosa demonstrated marker trait association for Sclerotinia Stem Rot resistance (Rana et al., 2017). Within breeding programs, it is important to make informed decisions about the source of novel $R$ genes and which parental genomes to cross, because the $R$ gene from the parents may be masked in the progenies of the resynthesized genomes due to one or more epistatic interactions, such as was found for a Clubroot $R$ gene (Werner et al., 2007). These challenges can be overcome by the latest genome editing techniques, such as CRISPR-Cas9 (Scheben et al., 2017b), as was recently reported in maize with precise mutation on the targeted allele (Svitashev et al., 2016; Liang et al., 2017).

The B genome offers good sources of resistance against two other pathogens besides $P$. brassicae and S. sclerotiorum; White Rust and White Leaf Spot (A. candida and P. capsellae, respectively). For White Rust, potential sources of resistance genes come from B. nigra and B. juncea (Westman et al., 1999), while resistance against White Leaf Spot potentially comes from B. carinata (Gunasinghe et al., 2016). For White Leaf Spot, in contrast with Clubroot and Blackleg, $B$. rapa is more susceptible than B. napus (Gunasinghe et al., 2014), but as with Downy Mildew, there is good resistance to White Leaf Spot in B. oleracea. In fact, complete resistance was recorded in $B$. oleracea var. capitata (Gunasinghe et al., 2016). However, B. juncea originating in India or Australia is highly susceptible to White Leaf Spot (Gunasinghe et al., 2014).

To breed resistant cultivars, it is important to consider the fitness cost to pathogen isolates when they do overcome host resistances. We can study the pathogen avirulence/virulence genes in the field that are adapted to the host cultivar and determine the genetic changes in the pathotype that cause heavy fitness consequences (Vera Cruz et al., 2000; Delmas et al., 2016). It is also important to consider the host $R$ gene as selection pressure on the pathogen can affect the stability of the $R$ gene. In terms of the linked genes in L. maculans, AvrLm1, and AvrLm6, high selection pressure on one Avr gene can cause a change in allele frequency of the other (Brun et al., 2010; Van De Wouw et al., 2010). Understanding the evolutionary potential between the pathogen and the host is essential in developing a durable resistant Brassica crop (McDonald and Linde, 2002). 


\section{Co-infection of $\boldsymbol{R}$ Genes to Immunise Brassica Crops}

In the L. maculans-B. napus cultivar "Surpass 400 " pathosystem, mixed inoculation of isolates (avirulent and virulent) with contrasting phenotypic effect (resistant vs. susceptible), can render $B$. napus resistant, even with only a small volume of avirulent isolate in the mixture of the two isolates ( $\mathrm{Li}$ et al., 2006a). Such "protection" effects are also observed in the field in Australia and have also been observed in the Phytophthora megasperma f.sp. glycinea-soybean pathosystem where a mixed isolate inoculation controlled the lesion spread (lower rate of spread; Ward, 1983). While the mechanism of improved resistance involving mixed isolate inoculations remains unknown, this approach does offer potential for possible "immunization" of host plant and further investigations into such are warranted. However, it should also be noted that the reverse can happen where co-infection results in increased disease susceptibility of the host. For example, co-infection of different pathogens such as A. candida (causal agent for White Rust) and $H$. parasitica (Downy Mildew) where the two pathogens can grow together within leaf and/or stem tissues of the same host plants (Cooper et al., 2008). Cooper et al. (2008) also showed that pre-infection of virulent $A$. candida can influence an otherwise avirulence outcome for $H$. parasitica such that it became virulent in $B$. juncea, as was also shown by Singh et al. (2002). However, pre-inoculation of the virulent $H$. parasitica on White Rust-susceptible $B$. juncea host promotes better resistance to White Rust disease (Singh et al., 2002), suggesting that type of isolate, infection sequence and pathogenicity of the isolate could determine the resistance outcome in the host (Kaur et al., 2011). The molecular basis of these co-infections across multiple pathogens remains unknown.

\section{Defense-Related Genes Other than $\boldsymbol{R}$ Genes}

In addition to the up-regulation of HR-related genes characterized by signaling hormones (Chu et al., 2014; Nováková et al., 2016b; Uloth et al., 2016), regulatory genes such as the transcription factors WRKY (Zhou et al., 1997) and calmodulinbinding transcription activator (CAMTA) (Rahman $\mathrm{H}$. et al., 2016) have also been implicated to regulate the disease response in Brassica pathosystems (Zhou et al., 1997). The WRKY gene was studied in B. napus-S. sclerotiorum and-Alternaria brassicae pathosystems, where gene expression was increased upon pathogen infection alongside defense-related hormones (Yang et al., 2009; Zhao et al., 2009). This gene was shown to enhance resistance against Downy Mildew in the Chinese broccoli B. oleracea var. italica (Jiang et al., 2016). Besides the WRKY gene, for the same host species, a pathogenicity-related defensin gene, which encodes defense-related cysteine-rich protein has also been shown to improve resistance against Downy Mildew (Jiang et al., 2012) and S. sclerotiorum (Zarinpanjeh et al., 2016). Identification of candidate genes for Clubroot resistance revealed Rho proteins may be involved (Kato et al., 2013). In Head Smut in maize, $Z m W A K$ was successfully identified as a regulator gene with quantitative effects on host resistance expression
(Balint-Kurti and Holland, 2015; Zuo et al., 2015). Further characterization of these genes should be performed in Brassica species, through genome wide identification and gene expression studies to determine their role in disease resistance.

\section{Molecular Identification of Pathotype and Pathogen Elicitors/Effectors}

To control disease outbreaks in crops, it is imperative that pathogen population variability in the field can be quickly identified. This can be achieved by having a full set of genetic markers for different pathogen pathotypes, not only contained within the local fields but universally. For example, initiatives for $P$. brassicae showed that $\mathrm{Cr} 811$ was a good candidate gene to differentiate pathotype 5 from the rest of the pathotypes (Feng et al., 2016).

Molecular characterization of pathogen effectors is gaining momentum. With better genome assemblies and higher gene prediction accuracies, we will soon have better insights into the structures and functions of effector proteins, which allows more efficient screening and identification of $R$ genes (Gibriel et al., 2016). Elicitor candidates for L. maculans (Wilson and Howlett, 2005; Nováková et al., 2016a), and effector candidates for S. sclerotiorum (Guyon et al., 2014), are both responsible for inducing HR. RNAi studies established that the transcription factor LmStuA in L. maculans regulates expression of effector genes (Soyer et al., 2015). Genomic studies researching L. maculans effectors AvrLmJ1 (Van de Wouw et al., 2014), AvrLm1 (Gout et al., 2006), AvrLm2 (Ghanbarnia et al., 2015), AvrLm3 (Plissonneau et al., 2016), AvrLm4-7 (Parlange et al., 2009), AvrLm1-2-6 (Fudal et al., 2007), and AvrLm11 (Balesdent et al., 2013) have provided new understandings on how they are strategically located within regions that are rich in transposable elements, such that they can be lost or inactivated rapidly during sexual reproduction (Rouxel et al., 2011; Howlett et al., 2015). This fungal genomic structure is unique to L. maculans and often the effectors display little or no sequence similarity to each other (Van De Wouw et al., 2010; Rouxel et al., 2011). Specific recognition between AvrLm4-7 and Rlm4 and Rlm7 genes and how the $\mathrm{R}$ and Avr effector proteins interact structurally has been examined using crystallography (Blondeau et al., 2015). There should be a focus on studies that provide additional molecular details at the gene level which would further our understanding of the factors leading to virulence and susceptibility associated with $R$-gene mediated resistance.

\section{FUTURE WORK}

Identifying $R$ genes in $B$. napus against the major pathogens discussed here can be a formidable task, for example seeing the difference in physiological host resistance response between Brassica hosts in P. brassicae, strong genetic linkage between resistance and other agronomic traits in $S$. sclerotiorum, the recessive nature of $R$ genes in $H$. parasitica, and nomenclature issue of $R$ genes in L. maculans.

Efforts to identify $R$ genes have been assisted by the development and application of differential host-pathogen 
pathotype/race/isolate combinations. Further improvements can be made by establishing freely-available universal host differential sets for each pathogen; differential sets that encompass the host resistances and pathogen sub-specific variation worldwide. One of the approaches that could be taken is an international collaborative network creating a world database for each pathogen. An example of this is the initiative established at the Brassica 2016 conference to resolve the Blackleg nomenclature issue (Plissonneau et al., 2017b). Since dynamic changes can happen with both host cultivars and pathogens in terms of cultivar resistance breakdowns and/or pathogens losing/gaining in terms of their pathogenicity/virulence over time, it is imperative that any universal database set up be regularly updated and kept current. For example, the international DivSeek, database, for phenotyptic data that can be linked with genotypic data (for seeds that are stored in seed bank), that was launched recently (Editorial, 2015) could be utilized as a model to set up the data bases needed.

Except for the four $R$ genes that have been cloned, the QTL for the major diseases in Brassica have been identified but the causal genes remain unknown. Cloning of $R$ genes has historically been undertaken using traditional methods, such as map-based cloning (Hatakeyama et al., 2013; Larkan et al., 2013). However, the recent genomics revolution has provided significant insights into the presence and absence of expressed genes in the Brassica $\mathrm{A}$ and $\mathrm{C}$ genomes using a pan-transcriptome approach (He et al., 2015). This, along with the recent pan-genome research (Golicz et al., 2016) readily allows cloning of $R$ genes in crops such as Brassica that have complex genomes. The success story of the cloned $R$ genes related to Clubroot and Blackleg tells us that the $R$ genes in the Brassica host plant acting against different major pathogen can belong to different classes, not necessarily the common NBS-LRR class. More $R$ gene cloning work in Brassica will help us better understand how the plant defends itself against these pathogens and we can use this knowledge to exploit novel $R$ genes in a quicker and more effective manner for breeding purposes.

The impact of climate change on crop diseases has been increasingly addressed over recent decades (Fizgerald, 2016), making the characterization of new $R$ genes more crucial than ever. MutRenSeq technology has been used to clone bread wheat stem rust resistance genes Sr22 and Sr45 (Steuernagel et al., 2016) and the potato late blight resistance gene, Rpi (Witek et al., 2016). This technique allows more rapid and precise cloning (Bent, 2016). For example, sequence-specific nucleases technology to target specific genes such as MILDEW-RESISTANCE LOCUS (MLO) in efforts to increase wheat (polyploid) resistance to Powdery Mildew have been undertaken (Gil-Humanes and Voytas, 2014; Wang et al., 2014). Such methodologies can now be similarly applied for precise alteration of disease resistance genes in Brassica.

Effective deployment of $R$ genes in breeding $B$. napus resistant crops for enduring sustainability demands detailed knowledge about the ecology and life history of both host and pathogen and how their interactions may shape their evolution over time (Burdon and Thrall, 2009; Burdon et al., 2014). Such knowledge could for example, allow prediction of the host resistance at different stages of the infection processes for the pathogen, potentially allowing identification and targeting of the resistance gene(s) effective at the earliest infection stage in order to maximize impedance and/or even prevent the establishment of the pathogen and also curtail subsequent pathogen inoculum production and consequent secondary spread of the disease. While this approach could be particularly applicable for a disease such as Clubroot, there are still challenges as it is not yet possible to identify the co-relationship between root hair infection (primary) and root cortex infection (secondary) (Voorrips, 1995). On the other hand, knowledge about controlling pathogen infection at different developmental stages of the host (e.g., seedling vs. adult) or even in different plant organs (e.g., cotyledons, leaves, stems, pods, and root) where the pathogen infection and colonization has the greatest adverse impact on the productivity of the plant (e.g., plant stems for $L$. maculans and $S$. sclerotiorum) have become more forthcoming for the major pathosystems in B. napus. Clearly, improving our understanding of the mechanism(s) at both life-stages of the pathogen infection and colonization processes, the development stages of the host, and the hostpathogen interactions should open up new opportunities to better understand and exploit approaches that maximize control of pathogen infection and spread to minimize consequent yield losses.

Sequencing of Brassica genomes will allow new discoveries and understandings regarding the genetic relationships of different $R$ genes, within and between members of the Brassicaceae. Although hybridization between divergent groups in the Brassicaceae, which contains rich resources of $R$ genes, is already possible, particularly in India, this is an area of great future potential that is likely to lead to identification of many new $R$ genes as these methodologies become more widely adopted and as rates of success with wide-hybridization events improve. While scientists are able to make informed decisions about utilizing race-specific and/or nonrace-specific resistance genes, further understanding of the benefits of different patterns of deployment for each type individually or rotation of both types, will identify better approaches toward maximizing the durability and effectiveness of both types of resistances, particularly $R$ genes. Further, field deployment of race-specific and/or non-race-specific resistance genes will have a large impact on the dynamics within pathogen populations. Combining race-specific and race nonspecific genes together in the one cultivar will also potentially increase durability of $R$ genes deployed within Brassica species, and has already been demonstrated for $R$ genes against $L$. maculans (Brun et al., 2000, 2010; Delourme et al., 2014). Improved resistance from gene pyramiding through marker-assisted selection was reported for the $P$. brassicae- $B$. rapa ssp. pekinensis pathosystem (Matsumoto et al., 2012). However, this remains a controversial approach with some suggesting that such an approach could lead to an undesired outcome of breakdown of the multiple $R$ genes pyramided (Essenberg et al., 2014). As we gain more knowledge about the molecular mechanisms of the plant immunity signaling pathway and the role of $R$ genes, this will 
open up more effective and durable strategies to overcome pathogen attack (Swiderski and Innes, 2001; Cheng et al., 2015).

Although next-generation sequencing for pathogen effectors is progressing rapidly, and with large amounts of new knowledge becoming available for use from both host and pathogen viewpoints, the challenge now is to transfer this new knowledge from the laboratory into the field in order to enable better disease management. In this review, we have highlighted the challenges in identification and deployment of $R$ genes, and evaluated options for the most effective utilization of $R$ genes to improve resistance to the major fungal, oomycete or chytrid pathogens of $B$. napus with the support of genomic advances. These insights will help bring us closer toward breeding B. napus with improved

\section{REFERENCES}

Alamery, S., Tirnaz, S., Bayer, P., Tollenaere, R., Chaloub, B., Edwards, D., et al. (in press). Genome-wide identification and comparative analysis of NBS-LRR resistance genes in Brassica napus. Crop Pasture Sci. doi: 10.1071/CP17214

Amselem, J., Cuomo, C. A., Van Kan, J. A., Viaud, M., Benito, E. P., et al. (2011). Genomic analysis of the necrotrophic fungal pathogens Sclerotinia sclerotiorum and Botrytis cinerea. PLoS Genet. 7:e1002230. doi: 10.1371/journal.pgen.1002230

Ansan- Melayah, D., Balesdent, M.-H., Buée, M., and Rouxel, T. (1995). Genetic characterization of AvrLm1, the first avirulence gene of Leptosphaeria maculans. Phytopathology 85, 1525-1529. doi: 10.1094/Phyto-85-1525

Ansan-Melayah, D., Balesdent, M.-H., Delourme, R., Pilet, M. L., Tanguy, X., Renard, M., et al. (1998). Genes for race-specific resistance against blackleg disease in Brassica napus L. Plant Breed. 117, 373-378. doi: 10.1111/j.1439-0523.1998.tb01956.x

Australian Bureau of Statistics (2016). 7503.0 - Value of Principal Agricultural Commodities Produced, Australia, Preliminary, 2014-15 [Online]. Canberra, ACT. Available online at: http://www.abs.gov.au/ausstats/abs@.nsf/mf/7503.0 (Accessed May 1, 2017).

Australian Oilseeds Federation (2016). AOF Crop Report: Sep 2016 [Online]. Australian Oilseeds Federation. Available online at: http://www. australianoilseeds.com/_data/assets/pdf_file/0014/10832/AOF_Crop_ Report_September_2016.pdf (AccessedMay 4, 2017).

Badawy, H. M. A., Hoppe, H. H., and Koch, E. (1991). Differential reactions between the genus Brassica and aggressive single spore isolates of Leptosphaeria maculans. Phytopathology 131, 109-119. doi: 10.1111/j.1439-0434.1991.tb04737.x

Badawy, H. M. A., Kakau, J., and Hoppe, H. H. (1992). Temperature and ageing of host tissue affect the interactions between different oilseed rape cultivars and pathotype groups of Leptosphaeria maculans. J. Phytopathol. 134, 255-263. doi: 10.1111/j.1439-0434.1992.tb01234.x

Balesdent, M.-H., Attard, A., Ansan-Melayah, D., Delourme, R., Renard, M., and Rouxel, T. (2001). Genetic control and host range of avirulence toward Brassica napus cultivars Quinta and Jet Neuf in Leptosphaeria maculans. Phytopathology 91, 70-76. doi: 10.1094/PHYTO.2001.91.1.70

Balesdent, M.-H., Attard, A., Kuhn, M. L., and Rouxel, T. (2002). New avirulence genes in the phytopathogenic fungus Leptosphaeria maculans. Phytopathology 92, 1122-1133. doi: 10.1094/PHYTO.2002.92.10.1122

Balesdent, M.-H., Barbetti, M. J., Li, H., Sivasithamparam, K., Gout, L., and Rouxel, T. (2005). Analysis of Leptosphaeria maculans race structure in a worldwide collection of isolates. Phytopathology 95, 1061-1071. doi: 10.1094/PHYTO-95-1061

Balesdent, M.-H., Fudal, I., Ollivier, B., Bally, P., Grandaubert, J., Eber, F., et al. (2013). The dispensable chromosome of Leptosphaeria maculans shelters an effector gene conferring avirulence towards Brassica rapa. New Phytol. 198, 887-898. doi: 10.1111/nph.12178

Balesdent, M.-H., Louvard, K., Pinochet, X., and Rouxel, T. (2006). "A large-scale survey of races of Leptosphaeria maculans occurring on oilseed rape in France," and more durable disease resistances that secure the future of B. napus as a major food crop worldwide.

\section{AUTHOR CONTRIBUTIONS}

TN conceptualized and drafted the manuscript, with additions and edits from JB and MB. The figures and tables were prepared by TN. All authors read and approved the final manuscript.

\section{FUNDING}

The authors acknowledge funding support from Australian Research Council Projects FT130100604, DP1601004497, LP140100537, LP160100030.

in Sustainable Strategies for Managing Brassica napus (oilseed rape) Resistance to Leptosphaeria maculans (phoma stem canker): Under the Aegis of a EuropeanAustralian Workshop held at INRA, Versailles, France, in Association with the EU SECURE project (QLK5-CT-2002-01813), eds B. D. L. Fitt, N. Evans, B. J. Howlett, and B. M. Cooke. (Dordrecht: Springer), 53-65.

Balint-Kurti, P. J., and Holland, J. B. (2015). New insight into a complex plantfungal pathogen interaction. Nat. Genet. 47, 101-103. doi: 10.1038/ng.3203

Barbetti, M. J., Banga, S. K., Fu, T. D., Li, Y. C., Singh, D., Liu, S. Y., et al. (2014). Comparative genotype reactions to Sclerotinia sclerotiorum within breeding populations of Brassica napus and B. juncea from India and China. Euphytica 197, 47-59. doi: 10.1007/s10681-013-1049-1

Barbetti, M. J., Banga, S. S., and Salisbury, P. A. (2012). Challenges for crop production and management from pathogen biodiversity and diseases under current and future climate scenarios - Case study with oilseed Brassicas. Field Crops Res. 127, 225-240. doi: 10.1016/j.fcr.2011.11.021

Barbetti, M. J., Li, C. X., Banga, S. S., Banga, S. K., Singh, D., Sandhu, P. S., et al. (2015). New host resistances in Brassica napus and Brassica juncea from Australia, China and India: key to managing Sclerotinia stem rot (Sclerotinia sclerotiorum) without fungicides. Crop Prot. 78, 127-130. doi: 10.1016/j.cropro.2015.09.004

Barnes, A. P., Wreford, A., Butterworth, M. H., Semenov, M. A., Moran, D., Evans, N., et al. (2010). Adaptation to increasing severity of phoma stem canker on winter oilseed rape in the UK under climate change. J. Agric. Sci. 148, 683-694. doi: 10.1017/S002185961000064X

Batley, J., Dolatabadian, A., Yang, H., Severn-Ellis, A., Alamery, S., Tollenaere, R., et al. (2016). "The more the merrier? Investigating copy number variation in Brassica disease resistance," in Plant and Animal Genome Conference (PAG) Asia (Singapore).

Bayer, P. E., Hurgobin, B., Golicz, A. A., Chan, C.-K. K., Yuan, Y., Lee, H., et al. (2017). Assembly and comparison of two closely related Brassica napus genomes. Plant Biotechnol. J. doi: 10.1111/pbi.12742. [Epub ahead of print].

Bayer, P. E., Ruperao, P., Mason, A. S., Stiller, J., Chan, C. K. K., Hayashi, S., et al. (2015). High-resolution skim genotyping by sequencing reveals the distribution of crossovers and gene conversions in Cicer arietinum and Brassica napus. Theor. Appl. Genet. 128, 1039-1047. doi: 10.1007/s00122-0152488-y

Becker, H. C., Engqvist, G. M., and Karlsson, B. (1995). Comparison of rapeseed cultivars and resynthesized lines based on allozyme and RFLP markers. Theor. Appl. Genet. 91, 62-67. doi: 10.1007/BF00220859

Bent, A. (2016). Resistance from relatives. Nat. Biotech. 34, 620-621. doi: 10.1038/nbt.3591

Bent, A. F., and Mackey, D. (2007). Elicitors, effectors, and R genes: the new paradigm and a lifetime supply of questions. Annu. Rev. Phytopathol. 45, 399-436. doi: 10.1146/annurev.phyto.45.062806.094427

Bevan, M. W., Uauy, C., Wulff, B. B. H., Zhou, J., Krasileva, K., and Clark, M. D. (2017). Genomic innovation for crop improvement. Nature 543, 346-354. doi: 10.1038/nature22011

Bittner-Eddy, P. D., Crute, I. R., Holub, E. B., and Beynon, J. L. (2000). RPP13 is a simple locus in Arabidopsis thaliana for alleles that specify downy mildew 
resistance to different avirulence determinants in Peronospora parasitica. Plant J. 21, 177-188. doi: 10.1046/j.1365-313x.2000.00664.x

Blondeau, K., Blaise, F., Graille, M., Kale, S. D., Linglin, J., Ollivier, B., et al. (2015). Crystal structure of the effector AvrLm4-7 of Leptosphaeria maculans reveals insights into its translocation into plant cells and recognition by resistance proteins. Plant J. 83, 610-624. doi: 10.1111/tpj.12913

Botella, M. A., Parker, J. E., Frost, L. N., Bittner-Eddy, P. D., Beynon, J. L., Daniels, M. J., et al. (1998). Three genes of the Arabidopsis RPP1 complex resistance locus recognize distinct Peronospora parasitica avirulence determinants. Plant Cell 10, 1847-1860. doi: 10.1105/tpc.10.11.1847

Brun, H., Chèvre, A.-M., Fitt, B. D. L., Powers, S., Besnard, A.-L., Ermel, M., et al. (2010). Quantitative resistance increases the durability of qualitative resistance to Leptosphaeria maculans in Brassica napus. New Phytol. 185, 285-299. doi: 10.1111/j.1469-8137.2009.03049.x

Brun, H., Levivier, S., Somda, I., Ruer, D., Renard, M., and Chevre, A. M. (2000). A field method for evaluating the potential durability of new resistance sources: application to the Leptosphaeria maculans-Brassica napus pathosystem. Phytopathology 90, 961-966. doi: 10.1094/PHYTO.2000.90.9.961

Buczacki, S. T., Toxopeus, H., Mattusch, P., Johnston, T. D., Dixon, G. R., and Hobolth, L. A. (1975). Study of physiologic specialization in Plasmodiophora brassicae: proposals for attempted rationalization through an international approach. Trans. Br. Mycol. Soc. 65, 295-303. doi: 10.1016/S0007-1536(75)80013-1

Burdon, J. J., Barrett, L. G., Rebetzke, G., and Thrall, P. H. (2014). Guiding deployment of resistance in cereals using evolutionary principles. Evol. Appl. 7, 609-624. doi: 10.1111/eva.12175

Burdon, J. J., and Thrall, P. H. (2009). Co-evolution of plants and their pathogens in natural habitats. Science 324, 755-756. doi: 10.1126/science.1171663

Bus, A., Hecht, J., Huettel, B., Reinhardt, R., and Stich, B. (2012). Highthroughput polymorphism detection and genotyping in Brassica napus using next-generation RAD sequencing. BMC Genomics 13:281. doi: 10.1186/1471-2164-13-281

Cai, C., Wang, X., Liu, B., Wu, J., Liang, J., Cui, Y., et al. (2017). Brassica rapa genome 2.0: a reference upgrade through sequence re-assembly and gene re-annotation. Mol. Plant 10, 649-651. doi: 10.1016/j.molp.2016.11.008

Cai, X., Huang, Y., Jiang, D., Fitt, B. D. L., Li, G., and Yang, L. (2017). Evaluation of oilseed rape seed yield losses caused by Leptosphaeria biglobosa in central China. Eur. J. Plant Pathol. doi: 10.1007/s10658-017-1266-x. [Epub ahead of print].

Carlier, J. D., Alabaça, C. A., Coelho, P. S., Monteiro, A. A., and Leitão, J. M. (2012). The downy mildew resistance locus Pp523 is located on chromosome C8 of Brassica oleracea L. Plant Breed. 131, 170-175. doi: 10.1111/j.1439-0523.2011.01904.x

Carlier, J. D., Alabaça, C. S., Sousa, N. H., Coelho, P. S., Monteiro, A. A., Paterson, A. H., et al. (2011). Physical mapping in a triplicated genome: mapping the downy mildew resistance locus Pp523 in Brassica oleracea L. G3 (Bethesda) 1, 593-601. doi: 10.1534/g3.111.001099

Carlsson, M., Bothmer, R. V., and Merker, A. (2004). Screening and evaluation of resistance to downy mildew (Peronospora parasitica) and clubroot (Plasmodiophora brassicae) in genetic resources of Brassica oleracea. Hereditas 141, 293-300. doi: 10.1111/j.1601-5223.2004.01818.x

Chai, A. L., Xie, X. W., Shi, Y. X., and Li, B. J. (2014). Research status of clubroot (Plasmodiophora brassicae) on cruciferous crops in China. Can. J. Plant Pathol. 36, 142-153. doi: 10.1080/07060661.2013.868829

Chalhoub, B., Denoeud, F., Liu, S., Parkin, I., A., Tang, H., Wang, X., et al. (2014). Early allopolyploid evolution in the post-neolithic Brassica napus oilseed genome. Science 345, 950-953. doi: 10.1126/science.1253435

Chatterjee, D., Banga, S., Gupta, M., Bharti, S., Salisbury, P. A., and Banga, S. S. (2016). Resynthesis of Brassica napus through hybridization between B. juncea and B. carinata. Theor. Appl. Genet. 129, 977-990. doi: 10.1007/s00122-016-2677-3

Chattopadhyay, C., and Séguin-Swartz, G. (2005). Breeding for disease resistance in oilseed crops in India. Annu. Rev. Plant Pathol. 3, 101-142.

Chen, J., Jing, J., Zhan, Z., Zhang, T., Zhang, C., and Piao, Z. (2013). Identification of novel QTLs for isolate-specific partial resistance to Plasmodiophora brassicae in Brassica rapa. PLoS ONE 8:e85307. doi: 10.1371/journal.pone.0085307

Chen, L., Zhang, X., Xu, H., Song, B., and Fan, X. (2016). Introgression of clubroot resistance into an elite pak choi inbred line through marker-assisted introgression breeding. Plant Breed. 135, 471-475. doi: 10.1111/pbr. 12379

Chen, S., Zou, J., Cowling, W. A., and Meng, J. (2010). Allelic diversity in a novel gene pool of canola-quality Brassica napus enriched with alleles from B. rapa and B. carinata. Crop Pasture Sci. 61, 483-492. doi: 10.1071/CP09327

Chen, Z. J. (2007). Genetic and epigenetic mechanisms for gene expression and phenotypic variation in plant polyploids. Ann. Rev. Plant Biol. 58, 377-406. doi: 10.1146/annurev.arplant.58.032806.103835

Cheng, F., Wu, J., Cai, C., Fu, L., Liang, J., Borm, T., et al. (2016). Genome resequencing and comparative variome analysis in a Brassica rapa and Brassica oleracea collection. Sci. Data 3:160119. doi: 10.1038/sdata.2016.119

Cheng, F., Wu, J., Fang, L., Sun, S., Liu, B., Lin, K., et al. (2012). Biased gene fractionation and dominant gene expression among the subgenomes of Brassica rapa. PLoS ONE 7:e36442. doi: 10.1371/journal.pone.0036442

Cheng, Z., Li, J. F., Niu, Y., Zhang, X. C., Woody, O. Z., Xiong, Y., et al. (2015). Pathogen-secreted proteases activate a novel plant immune pathway. Nature 521, 213-216. doi: 10.1038/nature14243

Cheung, F., Trick, M., Drou, N., Lim, Y. P., Park, J. Y., Kwon, S. J., et al. (2009). Comparative analysis between homoeologous genome segments of Brassica napus and its progenitor species reveals extensive sequence-level divergence. Plant Cell 21, 1912-1928. doi: 10.1105/tpc. 108.060376

Chevre, A. M., Eber, F., This, P., Barret, P., Tanguy, X., Brun, H., et al. (1996). Characterization of Brassica nigra chromosomes and of blackleg resistance in B. napus-B. nigra addition lines. Plant Breed. 115, 113-118. doi: 10.1111/j.1439-0523.1996.tb00884.x

Chiang, B. Y., Chiang, M. S., Grant, W. F., and Crete, R. (1980). Transfer of resistance to race 2 of Plasmodiophora brassicae from Brassica napus to cabbage (B. oleracea spp. capitata). IV. A resistant 18-chromosome B1 plant and its B2 progenies. Euphytica 29, 47-55. doi: 10.1007/BF00037248

Chisholm, S. T., Coaker, G., Day, B., and Staskawicz, B. J. (2006). Host-microbe interactions: shaping the evolution of the plant immune response. Cell 124, 803-814. doi: 10.1016/j.cell.2006.02.008

Choi, Y. J., Hong, S. B., and Shin, H. D. (2003). Diversity of the Hyaloperonospora parasitica complex from core brassicaceous hosts based on ITS rDNA sequences. Mycol. Res. 107, 1314-1322. doi: 10.1017/S0953756203008578

Christianson, J. A., Rimmer, S. R., Good, A. G., and Lydiate, D. J. (2006). Mapping genes for resistance to Leptosphaeria maculans in Brassica juncea. Genome 49, 30-41. doi: 10.1139/g05-085

Chu, M., Song, T., Falk, K. C., Zhang, X., Liu, X., Chang, A., et al. (2014). Fine mapping of Rcrl and analyses of its effect on transcriptome patterns during infection by Plasmodiophora brassicae. BMC Genomics 15:1166. doi: 10.1186/1471-2164-15-1166

Chu, M., Yu, F., Falk, K. C., Liu, X., Zhang, X., Chang, A., et al. (2013). Identification of the clubroot resistance gene Rpb1 and introgression of the resistance gene into canola breeding lines using a marker-assisted selection approach. Acta Hortic. 1005, 599-605. doi: 10.17660/ActaHortic.2013.1005.74

Clarke, W. E., Higgins, E. E., Plieske, J., Wieseke, R., Sidebottom, C., Khedikar, Y., et al. (2016). A high-density SNP genotyping array for Brassica napus and its ancestral diploid species based on optimised selection of single-locus markers in the allotetraploid genome. Theor. Appl. Genet. 129, 1887-1899. doi: 10.1007/s00122-016-2746-7

Clarkson, J. P., Warmington, R. J., Walley, P. G., Denton-Giles, M., Barbetti, M. J., Brodal, G., et al. (2017). Population structure of Sclerotinia subarctica and Sclerotinia sclerotiorum in England, Scotland and Norway. Front. Microbiol. 8:490. doi: $10.3389 /$ fmicb.2017.00490

Coelho, P., Bahcevandziev, K., Valério, L., Monteiro, A., Leckie, D., Astley, D., et al. (1998). The relationship between cotyledon and adult plant resistance to downy mildew (Peronospora parasitica) in Brassica oleracea. Acta Hortic. 459, 335-342. doi: 10.17660/ActaHortic.1998.459.39

Coelho, P. S., Vicente, J. G., Monteiro, A. A., and Holub, E. B. (2012). Pathotypic diversity of Hyaloperonospora brassicae collected from Brassica oleracea. Eur. J. Plant Pathol. 134, 763-771. doi: 10.1007/s10658-012-0052-z

Comai, L. (2005). The advantages and disadvantages of being polyploid. Nat. Rev. Genet. 6, 836-846. doi: 10.1038/nrg1711

Cooper, A. J., Latunde-Dada, A. O., Woods-Tor, A., Lynn, J., Lucas, J. A., Crute, I. R., et al. (2008). Basic compatibility of Albugo candida in Arabidopsis thaliana and Brassica juncea causes broad-spectrum suppression of innate immunity. Mol. Plant Microbe Interact. 21, 745-756. doi: 10.1094/MPMI-21-6-0745 
Dafwa (2015). 2015 WA Agribusiness Crop Updates: Research Delivers Opportunities to Cut Canola Production Costs. Western Australia: Department of Agriculture and Food Western Australia.

Dangl, J. L., Ritter, C., Gibbon, M. J., Mur, L. A., Wood, J. R., Goss, S., et al. (1992). Functional homologs of the Arabidopsis RPM1 disease resistance gene in bean and pea. Plant Cell 4, 1359-1369. doi: 10.1105/tpc.4.11.1359

Daverdin, G., Rouxel, T., Gout, L., Aubertot, J. N., Fudal, I., Meyer, M., et al. (2012). Genome structure and reproductive behaviour influence the evolutionary potential of a fungal phytopathogen. PLoS Pathog. 8:e1003020. doi: 10.1371/journal.ppat.1003020

Delmas, C. E. L., Fabre, F., Jolivet, J., Mazet, I. D., Richart Cervera, S., Delière, L., et al. (2016). Adaptation of a plant pathogen to partial host resistance: selection for greater aggressiveness in grapevine downy mildew. Evol. Appl. 9, 709-725. doi: 10.1111/eva.12368

Delourme, R., Barbetti, M., Snowdon, R., Zhao, J., and Manzanares-Dauleux, J. M. (2012). "Genetics and genomics of disease resistance," in Genetics, Genomics and Breeding of Oilseed Brassicas, eds D. Edwards, J. Batley, I. A. Parkin, and C. Kole (New York, NY: CRC Press), 301-343.

Delourme, R., Bousset, L., Ermel, M., Duffe, P., Besnard, A. L., Marquer, B., et al. (2014). Quantitative resistance affects the speed of frequency increase but not the diversity of the virulence alleles overcoming a major resistance gene to Leptosphaeria maculans in oilseed rape. Infect. Genet. Evol. 27, 490-499. doi: 10.1016/j.meegid.2013.12.019

Delourme, R., Chèvre, A.-M., Brun, H., Rouxel, T., Balesdent, M. H., Dias, J. S., et al. (2006). Major gene and polygenic resistance to Leptosphaeria maculans in oilseed rape (Brassica napus). Eur. J. Plant Pathol. 114, 41-52. doi: 10.1007/s10658-005-2108-9

Delourme, R., Pilet-Nayel, M. L., Archipiano, M., Horvais, R., Tanguy, X., Rouxel, T., et al. (2004). A cluster of major specific resistance genes to Leptosphaeria maculans in Brassica napus. Phytopathology 94, 578-583. doi: 10.1094/PHYTO.2004.94.6.578

Dickinson, C. H., and Greenhalgh, J. R. (1977). Host range and taxonomy of Peronospora on crucifers. Trans. Br. Mycol. Soc. 69, 111-116. doi: 10.1016/S0007-1536(77)80121-6

Dickson, M. H., and Petzoldt, R. (1993). Plant age and isolate source affect expression of downy mildew resistance in broccoli. HortScience 28, 730-731.

Diederichsen, E., Beckmann, J., Schondelmeier, J., and Dreyer, F. (2006). Genetics of clubroot resistance in Brassica napus 'Mendel'. Acta Hortic. 706, 307-312. doi: 10.17660/ActaHortic.2006.706.35

Diederichsen, E., Frauen, M., Linders, E. G., Hatakeyama, K., and Hirai, M. (2009). Status and perspectives of clubroot resistance breeding in crucifer crops. J. Plant Growth Regul. 28, 265-281. doi: 10.1007/s00344-009-9100-0

Diederichsen, E., Frauen, M., and Ludwig-Müller, J. (2014). Clubroot disease management challenges from a German perspective. Can. J. Plant Pathol. 36, 85-98. doi: 10.1080/07060661.2013.861871

Diederichsen, E., and Sacristan, M.D. (1996). Disease response of resynthesized Brassica napus L. lines carrying different combinations of resistance to Plasmodiophora brassicae Wor. Plant Breed. 115, 5-10. doi: 10.1111/j.1439-0523.1996.tb00862.x

Diederichsen, E., Wagenblatt, B., and Schallehn, V. (2016). Production of pure genotype isolates of Plasmodiophora brassicae Wor. - comparison of inoculations with root hairs containing single sporangiosori or with single resting spores. Eur. J. Plant Pathol. 145, 621-627. doi: 10.1007/s10658-016-0876-Z

Diers, B. W., and Osborn, T. C. (1994). Genetic diversity of oilseed Brassica napus germplasm based on restriction fragment length polymorphisms. Theor. Appl. Genet. 88, 662-668. doi: 10.1007/BF01253968

Dilmaghani, A., Balesdent, M. H., Didier, J. P., Wu, C., Davey, J., Barbetti, M. J., et al. (2009). The Leptosphaeria maculans - Leptosphaeria biglobosa species complex in the American continent. Plant Pathol. 58, 1044-1058. doi: 10.1111/j.1365-3059.2009.02149.x

Dion, Y., Gugel, R. K., Rakow, G. F., Seguin-Swartz, G., and Landry, B. S. (1995). RFLP mapping of resistance to the blackleg disease [causal agent, Leptosphaeria maculans (Desm.) Ces. et de Not.] in canola (Brassica napus L.). Theor. Appl. Genet. 91, 1190-1194. doi: 10.1007/BF00220928

Disi, J. O., Mei, J., Wei, D., Ding, Y., and Qian, W. (2014). Inheritance of leaf and stem resistance to Sclerotinia sclerotiorum in a cross between Brassica incana and Brassica oleracea var. alboglabra. J. Agric. Sci. 152, 146-152. doi: $10.1017 /$ S0021859613000087

Dixon, G. R. (2014). Clubroot (Plasmodiophora brassicae Woronin) - an agricultural and biological challenge worldwide. Can. J. Plant Pathol. 36, 5-18. doi: 10.1080/07060661.2013.875487

Dodds, P. N., and Rathjen, J. P. (2010). Plant immunity: towards an integrated view of plant-pathogen interactions. Nat. Rev. Genet. 11, 539-548. doi: $10.1038 / \mathrm{nrg} 2812$

Donald, E. C., Cross, S. J., Lawrence, J. M., and Porter, I. J. (2006). Pathotypes of Plasmodiophora brassicae, the cause of clubroot, in Australia. Ann. Appl. Biol. 148, 239-244. doi: 10.1111/j.1744-7348.2006.00062.x

Donald, E. C., Jaudzems, G., and Porter, I. J. (2008). Pathology of cortical invasion by Plasmodiophora brassicae in clubroot resistant and susceptible Brassica oleracea hosts. Plant Pathol. 57, 201-209. doi: 10.1111/j.1365-3059.2007.01765.x

Donald, E. C., and Porter, I. J. (2014). Clubroot in Australia: the history and impact of Plasmodiophora brassicae in Brassica crops and research efforts directed towards its control. Can. J. Plant Pathol. 36, 66-84. doi: 10.1080/07060661.2013.873482

Durrant, W. E., and Dong, X. (2004). Systemic acquired resistance. Annu. Rev. Phytopathol. 42, 185-209. doi: 10.1146/annurev.phyto.42.040803.140421

Editorial (2015). Growing access to phenotype data. Nat. Genet. 47:99. doi: $10.1038 /$ ng.3213

Edwards, D., Batley, J., and Snowdon, R. J. (2013). Accessing complex crop genomes with next-generation sequencing. Theor. Appl. Genet. 126, 1-11. doi: 10.1007/s00122-012-1964-x

Elliott, V. L., Marcroft, S. J., Howlett, B. J., and Van De Wouw, A. P. (2016). Genefor-gene resistance is expressed in cotyledons, leaves and pods, but not during late stages of stem colonization in the Leptosphaeria maculans-Brassica napus pathosystem. Plant Breed. 135, 200-207. doi: 10.1111/pbr.12343

Essenberg, M., Bayles, M. B., Pierce, M. L., and Verhalen, L. M. (2014). Pyramiding $B$ genes in cotton achieves broader but not always higher resistance to bacterial blight. Phytopathology 104, 1088-1097. doi: 10.1094/PHYTO-06-13-0167-R

Eurostat (2016). Crop statistics (from 2000 onwards) [Online]. Luxembourg: The Statistical Office of the European Union. Available online at: http:// appsso.eurostat.ec.europa.eu/nui/submitViewTableAction.do (Accessed May 10, 2017).

Farinhó, M., Coelho, P., Carlier, J., Svetleva, D., Monteiro, A., and Leitão, J. (2004). Mapping of a locus for adult plant resistance to downy mildew in broccoli (Brassica oleracea convar. italica). Theor. Appl. Genet. 109, 1392-1398. doi: 10.1007/s00122-004-1747-0

Farinhó, M., Coelho, P., Monteiro, A., and Leitão, J. (2007). SCAR and CAPS markers flanking the Brassica oleracea L. Pp523 downy mildew resistance locus demarcate a genomic region syntenic to the top arm end of Arabidopsis thaliana L. chromosome 1. Euphytica 157, 215-221. doi: 10.1007/s10681-007-9414-6

Farnham, M., Wang, M., and Thomas, C. (2002). A single dominant gene for downy mildew resistance in broccoli. Euphytica 128, 405-407. doi: 10.1023/A:1021279426050

Feng, J., Jiang, J., Feindel, D., Strelkov, S. E., and Hwang, S.-F. (2016). The gene Cr811 is present exclusively in pathotype 5 and new emerged pathotypes of the clubroot pathogen Plasmodiophora brassicae. Eur. J. Plant Pathol. 145, 615-620. doi: 10.1007/s10658-016-0903-0

Ferreira, M. E., Rimmer, S. R., Williams, P. H., and Osborn, T. C. (1995). Mapping loci controlling Brassica napus resistance to Leptosphaeria maculans under different screening conditions. Phytopathology 85, 213-217. doi: 10.1094/Phyto-85-213

Figdore, S. S., Ferreira, M. E., Slocum, M. K., and Williams, P. H. (1993). Association of RFLP markers with trait loci affecting clubroot resistance and morphological characters in Brassica oleracea L. Euphytica 69, 33-44. doi: $10.1007 /$ BF00021723

Fizgerald, T. (2016). "The impact of climate change on agricultural crops," in Plant Genomics and Climate Change, eds D. Edwards and J. Batley (New York, NY: Springer), 1-13.

Fomeju, B. F., Falentin, C., Lassalle, G., Manzanares-Dauleux, M. J., and Delourme, R. (2014). Homoeologous duplicated regions are involved in quantitative resistance of Brassica napus to stem canker. BMC Genomics 15:498. doi: 10.1186/1471-2164-15-498 
Fomeju, B. F., Falentin, C., Lassalle, G., Manzanares-Dauleux, M. J., and Delourme, R. (2015). Comparative genomic analysis of duplicated homoeologous regions involved in the resistance of Brassica napus to stem canker. Front. Plant Sci. 6:772. doi: 10.3389/fpls.2015.00772

Fredua-Agyeman, R., Coriton, O., Huteau, V., Parkin, I. A., Chèvre, A.-M., and Rahman, H. (2014). Molecular cytogenetic identification of B genome chromosomes linked to blackleg disease resistance in Brassica napus $\times$ B. carinata interspecific hybrids. Theor. Appl. Genet. 127, 1305-1318. doi: 10.1007/s00122-014-2298-7

Fredua-Agyeman, R., and Rahman, H. (2016). Mapping of the clubroot disease resistance in spring Brassica napus canola introgressed from European winter canola cv. 'Mendel'. Euphytica 211, 201-213. doi: 10.1007/s10681-016-1730-2

Fudal, I., Ross, S., Gout, L., Blaise, F., Kuhn, M. L., Eckert, M. R., et al. (2007). Heterochromatin-like regions as ecological niches for avirulence genes in the Leptosphaeria maculans genome: map-based coning of AvrLm6. Mol. Plant Microbe Interact. 20, 459-470. doi: 10.1094/MPMI-20-4-0459

Gaeta, R. T., and Pires, J. C. (2010). Homoeologous recombination in allopolyploids: the polyploid ratchet. New Phytol. 186, 18-28. doi: 10.1111/j.1469-8137.2009.03089.x

Gao, F., Hirani, A. H., Liu, J., Liu, Z., Fu, G., Wu, C., et al. (2014). Fine mapping a clubroot resistance locus in Chinese cabbage. J. Am. Soc. Hortic. Sci. 139, 247-252.

Garg, H., Atri, C., Sandhu, P. S., Kaur, B., Renton, M., Banga, S.K., et al. (2010a). High level of resistance to Sclerotinia sclerotiorum in introgression lines derived from hybridization between wild crucifers and the crop Brassica species $B$. napus and B. juncea. Field Crops Res. 117, 51-58. doi: 10.1016/j.fcr.2010. 01.013

Garg, H., Kohn, L. M., Andrew, M., Li, H., Sivasithamparam, K., and Barbetti, M. J. (2010b). Pathogenicity of morphologically different isolates of Sclerotinia sclerotiorum with Brassica napus and B. juncea genotypes. Eur. J. Plant Pathol. 126, 305-315. doi: 10.1007/s10658-009-9547-7

Garg, H., Li, H., Sivasithamparam, K., Kuo, J., and Barbetti, M. J. (2010c). The infection processes of Sclerotinia sclerotiorum in cotyledon tissue of a resistant and a susceptible genotype of Brassica napus. Ann. Bot. 106, 897-908. doi: $10.1093 / \mathrm{aob} / \mathrm{mcq} 196$

Garg, H., Sivasithamparam, K., Banga, S. S., and Barbetti, M. J. (2008). Cotyledon assay as a rapid and reliable method of screening for resistance against Sclerotinia sclerotiorum in Brassica napus genotypes. Australas. Plant Pathol. 37, 106-111. doi: 10.1071/AP08002

Ge, X., Li, Y. P., Wan, Z. J., You, M. P., Finnegan, P. M., Banga, S. S., et al. (2012). Delineation of Sclerotinia sclerotiorum pathotypes using differential resistance responses on Brassica napus and B. juncea genotypes enables identification of resistance to prevailing pathotypes. Field Crops Res. 127, 248-258. doi: 10.1016/j.fcr.2011.11.022

Ge, X. T., Li, H., Han, S., Sivasithamparam, K., and Barbetti, M. J. (2008). Evaluation of Australian Brassica napus genotypes for resistance to the downy mildew pathogen, Hyaloperonospora parasitica. Aust. J. Agric. Res. 59, 1030-1034. doi: 10.1071/AR08032

Ge, X. T., You, M. P., and Barbetti, M. J. (2015). Virulence differences among Sclerotinia sclerotiorum isolates determines host cotyledon resistance responses in Brassicaceae genotypes. Eur. J. Plant Pathol. 143, 527-541. doi: 10.1007/s10658-015-0696-6

Ghanbarnia, K., Fudal, I., Larkan, N. J., Links, M. G., Balesdent, M. H., Profotova, B., et al. (2015). Rapid identification of the Leptosphaeria maculans avirulence gene AvrLm2 using an intraspecific comparative genomics approach. Mol. Plant Pathol. 16, 699-709. doi: 10.1111/mpp.12228

Gibriel, H. A., Thomma, B. P., and Seidl, M. F. (2016). The age of effectors: genome-based discovery and applications. Phytopathology 106, 1206-1212. doi: 10.1094/PHYTO-02-16-0110-FI

Gil-Humanes, J., and Voytas, D. F. (2014). Wheat rescued from fungal disease. Nat. Biotech. 32, 886-887. doi: 10.1038/nbt.3013

Golicz, A. A., Bayer, P. E., Barker, G. C., Edger, P. P., Kim, H., Martinez, P. A., et al. (2016). The pangenome of an agronomically important crop plant Brassica oleracea. Nat. Commun. 7:13390. doi: 10.1038/ncomms13390

Golicz, A. A., Martinez, P. A., Zander, M., Patel, D. A., Van De Wouw, A. P., Visendi, P., et al. (2015). Gene loss in the fungal canola pathogen Leptosphaeria maculans. Funct. Integr. Genomics 15, 189-196. doi: 10.1007/s10142-014-0412-1
Goodwin, S. B., Allard, R. W., and Webster, R. K. (1990). A nomenclature for Rhynchosporium secalis pathotypes. Phytopathology 80, 1330-1336. doi: 10.1094/Phyto-80-1330

Gossen, B. D., Deora, A., Peng, G., Hwang, S. F., and Mcdonald, M. R. (2014). Effect of environmental parameters on clubroot development and the risk of pathogen spread. Can. J. Plant Pathol. 36, 37-48. doi: 10.1080/07060661.2013.859635

Gout, L., Fudal, I., Kuhn, M.-L., Blaise, F., Eckert, M., Cattolico, L., et al. (2006). Lost in the middle of nowhere: the AvrLm1 avirulence gene of the Dothideomycete Leptosphaeria maculans. Mol. Microbiol. 60, 67-80. doi: 10.1111/j.1365-2958.2006.05076.x

Grandclément, C., and Thomas, G. (1996). Detection and analysis of QTLs based on RAPD markers for polygenic resistance to Plasmodiophora brassicae Woron in Brassica oleracea L. Theor. Appl. Genet. 93, 86-90. doi: 10.1007/BF00 225731

Gunasinghe, N., You, M. P., Banga, S. S., and Barbetti, M. J. (2014). High level resistance to Pseudocercosporella capsellae offers new opportunities to deploy host resistance to effectively manage white leaf spot disease across major cruciferous crops. Eur. J. Plant Pathol. 138, 873-890. doi: 10.1007/s10658-013-0360-y

Gunasinghe, N., You, M. P., Li, X. X., Banga, S. S., Banga, S. K., and Barbetti, M. J. (2016). New host resistances to Pseudocercosporella capsellae and implications for white leaf spot management in Brassicaceae crops. Crop Prot. 86, 69-76. doi: 10.1016/j.cropro.2016.04.014

Guyon, K., Balagué, C., Roby, D., and Raffaele, S. (2014). Secretome analysis reveals effector candidates associated with broad host range necrotrophy in the fungal plant pathogen Sclerotinia sclerotiorum. BMC Genomics 15:336. doi: 10.1186/1471-2164-15-336

Gyawali, S., Harrington, M., Durkin, J., Horner, K., Parkin, I. A. P., Hegedus D. D., et al. (2016). Microsatellite markers used for genome-wide association mapping of partial resistance to Sclerotinia sclerotiorum in a world collection of Brassica napus. Mol. Breed. 36:72. doi: 10.1007/s11032-016-0496-5

Hasan, M., Seyis, F., Badani, A. G., Pons-Kühnemann, J., Friedt, W., Lühs, W., et al. (2006). Analysis of genetic diversity in the Brassica napus L. gene pool using SSR markers. Genet. Resour. Crop Evol. 53, 793-802. doi: 10.1007/s10722-004-5541-2

Hatakayema, K., Fujimura, M., Ishida, M., Suzuki, T., and Sato, T. (2006). Classification of pathogenicity of Plasmodiophora brassicae field isolates in Japan based on resistance of F1 cultivars of Chinese cabbage (Brassica rapa L.) to clubroot. Acta Hortic. 706, 323-328. doi: 10.17660/ActaHortic.2006.706.38

Hatakeyama, K., Fujimura, M., Ishida, M., and Suzuki, T. (2004). New classification method for Plasmodiophora brassicae field isolates in Japan based on resistance of F1 cultivars of Chinese cabbage (Brassica rapa L.) to cubroot. Breed. Sci. 54, 197-201. doi: 10.1270/jsbbs.54.197

Hatakeyama, K., Niwa, T., Kato, T., Ohara, T., Kakizaki, T., and Matsumoto, S. (2017). The tandem repeated organization of NB-LRR genes in the clubrootresistant CRb locus in Brassica rapa L. Mol. Genet. Genomics 292, 397-405. doi: 10.1007/s00438-016-1281-1

Hatakeyama, K., Suwabe, K., Tomita, R. N., Kato, T., Nunome, T., Fukuoka, H., et al. (2013). Identification and characterization of Crrla, a gene for resistance to clubroot disease (Plasmodiophora brassicae Woronin) in Brassica rapa L. PLoS ONE 8:e54745. doi: 10.1371/journal.pone.0054745

Hayashida, N., Takabatake, Y., Nakazawa, N., Aruga, D., Nakanishi, H., Taguchi, G., et al. (2008). Construction of a practical SCAR marker linked to clubroot resistance in Chinese cabbage, with intensive analysis of HC352b genes. Engei Gakkai Zasshi 77, 150-154. doi: 10.2503/jjshs1.77.150

Hayden, H. L., Cozijnsen, A. J., and Howlett, B. J. (2007). Microsatellite and minisatellite analysis of Leptosphaeria maculans in Australia reveals regional genetic differentiation. Phytopathology 97, 879-887. doi: 10.1094/PHYTO-97-7-0879

He, Z., Cheng, F., Li, Y., Wang, X., Parkin, I. A., Chalhoub, B., et al. (2015). Construction of Brassica A and C genome-based ordered pantranscriptomes for use in rapeseed genomic research. Data Brief 4, 357-362. doi: 10.1016/j.dib.2015.06.016

Hirai, M., Harada, T., Kubo, N., Tsukada, M., Suwabe, K., and Matsumoto, S. (2004). A novel locus for clubroot resistance in Brassica rapa and its linkage markers. Theor. Appl. Genet. 108, 639-643. doi: 10.1007/s00122-003-1475-x

Hirani, A. H., Gao, F., Liu, J., Fu, G., Wu, C., Yuan, Y., et al. (2016). Transferring clubroot resistance from Chinese cabbage (Brassica rapa) to 
canola (B. napus). Can. J. Plant Pathol. 38, 82-90. doi: 10.1080/07060661.2016. 1141799

Howlett, B. J., Lowe, R. G. T., Marcroft, S. J., and Van De Wouw, A. P. (2015). Evolution of virulence in fungal plant pathogens: exploiting fungal genomics to control plant disease. Mycologia 107, 441-451. doi: 10.3852/14-317

Huang, S., Deng, L., Guan, M., Li, J., Lu, K., Wang, H., et al. (2013). Identification of genome-wide single nucleotide polymorphisms in allopolyploid crop Brassica napus. BMC Genomics 14:717. doi: 10.1186/1471-2164-14-717

Huang, Y. J., Evans, N., Li, Z. Q., Eckert, M., Chèvre, A.-M., Renard, M., et al. (2006). Temperature and leaf wetness duration affect phenotypic expression of Rlm6-mediated resistance to Leptosphaeria maculans in Brassica napus. New Phytol. 170, 129-141. doi: 10.1111/j.1469-8137.2006.01651.x

Huang, Y. J., Jestin, C., Welham, S. J., King, G. J., Manzanares-Dauleux, M. J., Fitt, B. D. L., et al. (2016). Identification of environmentally stable QTL for resistance against Leptosphaeria maculans in oilseed rape (Brassica napus). Theor. Appl. Genet. 129, 169-180. doi: 10.1007/s00122-015-2620-z

Huang, Y. J., Pirie, E. J., Evans, N., Delourme, R., King, G. J., and Fitt, B. D. L. (2009). Quantitative resistance to symptomless growth of Leptosphaeria maculans (phoma stem canker) in Brassica napus (oilseed rape). Plant Pathol. 58, 314-323. doi: 10.1111/j.1365-3059.2008.01957.x

Huang, Y. J., Qi, A., King, G. J., and Fitt, B. D. L. (2014). Assessing quantitative resistance against Leptosphaeria maculans (phoma stem canker) in Brassica napus (oilseed rape) in young plants. PLoS ONE 9:e84924. doi: 10.1371/journal.pone.0084924

Huang, Z., Peng, G., Liu, X., Deora, A., Falk, K. C., Gossen, B. D., et al. (2017). Fine mapping of a clubroot resistance gene in Chinese cabbage using SNP markers identified from bulked segregant RNA sequencing. Front. Plant Sci. 8:1448. doi: 10.3389/fpls.2017.01448

Hulbert, S. H., Webb, C. A., Smith, S. M., and Sun, Q. (2001). Resistance gene complexes: evolution and utilization. Annu. Rev. Phytopathol. 39, 285-312. doi: 10.1146/annurev.phyto.39.1.285

Hwang, S.-F., Strelkov, S. E., Peng, G., Ahmed, H., Zhou, Q., and Turnbull, G. (2016). Blackleg (Leptosphaeria maculans) severity and yield loss in canola in Alberta, Canada. Plants 5:31. doi: 10.3390/plants5030031

Hwang, S. F., Strelkov, S. E., Feng, J., Gossen, B. D., and Howard, R. J. (2012). Plasmodiophora brassicae: a review of an emerging pathogen of the Canadian canola (Brassica napus) crop. Mol. Plant Pathol. 13, 105-113. doi: 10.1111/j.1364-3703.2011.00729.x

Jakir Hasan, M., Strelkov, S. E., Howard, R. J., and Rahman, H. (2012). Screening of Brassica germplasm for resistance to Plasmodiophora brassicae pathotypes prevalent in Canada for broadening diversity in clubroot resistance. Can. J. Plant Sci. 92, 501-515. doi: 10.4141/cjps2010-006

Jensen, B. D., Hockenhull, J., and Munk, L. (1999a). Seedling and adult plant resistance to downy mildew (Peronospora parasitica) in cauliflower (Brassica oleracea convar. botrytis var. botrytis). Plant Pathol. 48, 604-612. doi: 10.1046/j.1365-3059.1999.00388.x

Jensen, B. D., Værbak, S., Munk, L., and Andersen, S. B. (1999b). Characterization and inheritance of partial resistance to downy mildew, Peronospora parasitica, in breeding material of broccoli, Brassica oleracea convar. botrytis var. italica. Plant Breed. 118, 549-554. doi: 10.1046/j.1439-0523.1999.00409.x

Jestin, C., Lodé, M., Vallée, P., Domin, C., Falentin, C., Horvais, R., et al. (2011). Association mapping of quantitative resistance for Leptosphaeria maculans in oilseed rape (Brassica napus L.). Mol. Breed.. 27, 271-287. doi: 10.1007/s11032-010-9429-x

Jiang, M., He, C. M., Miao, L. X., and Zhang, Y. C. (2012). Overexpression of a broccoli defensin gene BoDFN enhances downy mildew resistance. J. Integr. Agric. 11, 1137-1144. doi: 10.1016/S2095-3119(12)60107-5

Jiang, M., Liu, Q.-E., Liu, Z.-N., Li, J.-Z., and He, C.-M. (2016). Over-expression of a WRKY transcription factor gene BoWRKY6 enhances resistance to downy mildew in transgenic broccoli plants. Aus. Plant Pathol. 45, 327-334. doi: 10.1007/s13313-016-0416-5

Jones, D. A., Thomas, C. M., Hammond-Kosack, K. E., Balint-Kurti, P. J., and Jones, J. D. (1994). Isolation of the tomato Cf-9 gene for resistance to Cladosporium fulvum by transposon tagging. Science 266, 789-793. doi: $10.1126 /$ science.7973631

Jones, D. R., Ingram, D. S., and Dixon, G. R. (1982). Factors affecting tests for differential pathogenicity in populations of Plasmodiophora brassicae. Plant Pathol. 31, 229-238. doi: 10.1111/j.1365-3059.1982.tb01273.x
Jones, J. D.G., and Dangl, J. L. (2006). The plant immune system. Nature 444, 323-329. doi: $10.1038 /$ nature 05286

Jorgensen, T. H. (2012). The effect of environmental heterogeneity on RPW8mediated resistance to powdery mildews in Arabidopsis thaliana. Ann. Bot. 109, 833-842. doi: $10.1093 / \mathrm{aob} / \mathrm{mcr} 320$

Kato, T., Hatakayema, K., Fukino, N., and Matsumoto, S. (2012). Identificaton of a clubroot resistance locus conferring resistance to a Plasmodiophora brassicae classified into pathotype group 3 in Chinese cabbage (Brassica rapa L.). Breed. Sci. 62, 282-287. doi: 10.1270/jsbbs.62.282

Kato, T., Hatakayema, K., Fukino, N., and Matsumoto, S. (2013). Fine mapping of the clubroot resistance gene $\mathrm{CRb}$ and development of a useful selectable marker in Brassica rapa. Breed. Sci. 63, 116-124. doi: 10.1270/jsbbs.63.116

Kaur, P., Sivasithamparam, K., Li, H., and Barbetti, M. J. (2011). Preinoculation with Hyaloperonospora parasitica reduces incubation period and increases severity of disease caused by Albugo candida in a Brassica juncea variety resistant to downy mildew. J. Gen. Plant Pathol. 77, 101-106. doi: 10.1007/s10327-011-0293-2

Kazan, K., and Lyons, R. (2014). Intervention of phytohormone pathways by pathogen effectors. Plant Cell 26, 2285-2309. doi: 10.1105/tpc.114.125419

Kearney, B., and Staskawicz, B. J. (1990). Widespread distribution and fitness contribution of Xanthomonas campestris avirulence gene avrBs2. Nature 346, 385-386. doi: 10.1038/346385a 0

Kim, S., Song, Y. H., Lee, J.-Y., Choi, S. R., Dhandapani, V., Jang, C. S., et al. (2011). Identification of the BrRHP1 locus that confers resistance to downy mildew in Chinese cabbage (Brassica rapa ssp. pekinensis) and development of linked molecular markers. Theor. Appl. Genet. 123, 1183-1192. doi: 10.1007/s00122-011-1658-9

Koch, E., Song, K., Osborn, T. C., and Williams, P. H. (1991). Relationship between pathogenicity and phylogeny based on restriction fragment length polymorphism in Leptosphaeria maculans. Mol. Plant Microbe Interact. 4, 341-349. doi: 10.1094/MPMI-4-341

Kohn, L. M., Stasovski, E., Carbone, I., Royer, J., and Anderson, J. B. (1991). Mycelial incompatibility and molecular markers identify genetic variability in field populations of Sclerotinia sclerotiorum. Phytopathology 81, 480-485. doi: 10.1094/Phyto-81-480

Kuginuki, Y., Ajisaka, H., Yui, M., Yoshikawa, H., Hida, K.-I., and Hirai, M. (1997). RAPD markers linked to a clubroot-resistance locus in Brassica rapa L. Euphytica 98, 149-154. doi: 10.1023/A:1003147815692

Kuginuki, Y., Yoshikawa, H., and Hirai, M. (1999). Variation in virulence of Plasmodiophora brassicae in Japan tested with clubroot-resistant cultivars of Chinese cabbage (Brassica rapa L. ssp. pekinensis). Eur. J. Plant Pathol. 105, 327-332. doi: 10.1023/A:1008705413127

Kushalappa, A. C., Yogendra, K. N., and Karre, S. (2016). Plant innate immune response: qualitative and quantitative resistance. CRC. Crit. Rev. Plant Sci. 35, 38-55. doi: 10.1080/07352689.2016.1148980

Kutcher, H. R., Balesdent, M. H., Rimmer, S. R., Rouxel, T., Chèvre, A.-M., Delourme, R., et al. (2010). Frequency of avirulence genes in Leptosphaeria maculans in western Canada. Can. J. Plant Pathol. 32, 77-85. doi: 10.1080/07060661003594109

Kutcher, H. R., Van Den Berg, C. G. J., and Rimmer, S. R. (1993). Variation in pathogenicity of Leptosphaeria maculans on Brassica spp. based on cotyledon and stem reactions. Can. J. Plant Pathol. 15, 253-258. doi: $10.1080 / 07060669309501920$

Landry, B. S., Hubert, N., Crete, R., Chang, M. S., Lincoln, S. E., and Etoh, T. (1992). A genetic map for Brassica oleracea based on RFLP markers detected with expressed DNA sequences and mapping of resistance genes to race 2 of Plasmodiophora brassicae (Woronin). Genome 35, 409-420. doi: 10.1139/g92-061

Larkan, N. J., Lydiate, D. J., Parkin, I. A. P., Nelson, M. N., Epp, D. J., Cowling, W. A., et al. (2013). The Brassica napus blackleg resistance gene LepR3 encodes a receptor-like protein triggered by the Leptosphaeria maculans effector AVRLM1. New Phytol. 197, 595-605. doi: 10.1111/nph.12043

Larkan, N. J., Ma, L., and Borhan, M. H. (2015). The Brassica napus receptorlike protein RLM2 is encoded by a second allele of the LepR3/Rlm2 blackleg resistance locus. Plant Biotechnol. J. 13, 983-992. doi: 10.1111/pbi. 12341

Larkan, N. J., Raman, H., Lydiate, D. J., Robinson, S. J., Yu, F., Barbulescu, D. M., et al. (2016a). Multi-environment QTL studies suggest a role for cysteine-rich 
protein kinase genes in quantitative resistance to blackleg disease in Brassica napus. BMC Plant Biol. 16:183. doi: 10.1186/s12870-016-0877-2

Larkan, N. J., Yu, F., Lydiate, D. J., Rimmer, S. R., and Borhan, M. H. (2016b). Single R gene introgression lines for accurate dissection of the Brassica - Leptosphaeria pathosystem. Front. Plant Sci. 7:1771. doi: 10.3389/fpls.2016.01771

Laurens, F., and Thomas, G. (1993). Inheritance of resistance to clubroot (Plasmodiophora brassicae Wor.) in kale (Brassica oleracea ssp. acephala). Hereditas 119, 253-262. doi: 10.1111/j.1601-5223.1993.00253.x

Lee, J., Izzah, N. K., Choi, B.-S., Joh, H. J., Lee, S.-C., Perumal, S., et al. (2016). Genotyping-by-sequencing map permits identification of clubroot resistance QTLs and revision of the reference genome assembly in cabbage (Brassica oleracea L.). DNA Res. 23, 29-41. doi: 10.1093/dnares/dsv034

Li, C. X., and Cowling, W. A. (2003). Identification of a single dominant allele for resistance to blackleg in Brassica napus 'Surpass 400'. Plant Breed. 122, 485-488. doi: 10.1111/j.1439-0523.2003.00863.x

Li, C. X., Li, H., Siddique, A. B., Sivasithamparam, K., Salisbury, P., Banga, S. S., et al. (2007). The importance of the type and time of inoculation and assessment in the determination of resistance in Brassica napus and B. juncea to Sclerotinia sclerotiorum. Aust. J. Agric. Res. 58, 1198-1203. doi: 10.1071/AR07094

Li, C. X., Liu, S. Y., Sivasithamparam, K., and Barbetti, M. J. (2009). New sources of resistance to Sclerotinia stem rot caused by Sclerotinia sclerotiorum in Chinese and Australian Brassica napus and B. juncea germplasm screened under Western Australian conditions. Aus. Plant Pathol. 38, 149-152. doi: 10.1071/AP08087

Li, H., Barbetti, M. J., and Sivasithamparam, K. (2006a). Concomitant inoculation of an avirulent strain of Leptosphaeria maculans prevents break-down of a single dominant gene-based resistance in Brassica napus cv. Surpass 400 by a virulent strain. Field Crops Res. 95, 206-211. doi: 10.1016/j.fcr.2005.02.010

Li, H., Ge, X., Han, S., Sivasithamparam, K., and Barbetti, M. J. (2011). Histological responses of host and non-host plants to Hyaloperonospora parasitica. Eur. J. Plant Pathol. 129, 221-232. doi: 10.1007/s10658-010-9664-3

Li, H., Sivasithamparam, K., and Barbetti, M. J. (2003). Breakdown of a Brassica rapa subsp. sylvestris single dominant blackleg resistance gene in B. napus rapeseed by Leptosphaeria maculans field isolates in Australia. Plant Dis. 87, 752-752. doi: 10.1094/PDIS.2003.87.6.752A

Li, H., Smyth, F., Barbetti, M. J., and Sivasithamparam, K. (2006b). Relationship between Brassica napus seedling and adult plant responses to Leptosphaeria maculans is determined by plant growth stage at inoculation and temperature regime. Field Crops Res. 96, 428-437. doi: 10.1016/j.fcr.2005.08.006

Li, J., Zhao, Z., Hayward, A., Cheng, H., and Fu, D. (2015). Integration analysis of quantitative trait loci for resistance to Sclerotinia sclerotiorum in Brassica napus. Euphytica 205, 483-489. doi: 10.1007/s10681-015-1417-0

Li, L., Luo, Y., Chen, B., Xu, K., Zhang, F., Li, H., et al. (2016). A genome-wide association study reveals new loci for resistance to clubroot disease in Brassica napus. Front. Plant Sci. 7:1483. doi: 10.3389/fpls.2016.01483

Li, P., Quan, X., Jia, G., Xiao, J., Cloutier, S., and You, F. M. (2016). RGAugury: a pipeline for genome-wide prediction of resistance gene analogs (RGAs) in plants. BMC Genomics 17:852. doi: 10.1186/s12864-016-3197-X

Liang, Z., Chen, K., Li, T., Zhang, Y., Wang, Y., Zhao, Q., et al. (2017). Efficient DNA-free genome editing of bread wheat using CRISPR/Cas9 ribonucleoprotein complexes. Nat. Commun. 8:14261. doi: $10.1038 /$ ncomms 14261

Liban, S. H., Cross, D. J., Kutcher, H. R., Peng, G., and Fernando, W. G. D. (2016). Race structure and frequency of avirulence genes in the western Canadian Leptosphaeria maculans pathogen population, the causal agent of blackleg in brassica species. Plant Pathol. 65, 1161-1169. doi: 10.1111/ppa.12489

Light, K. A., Gororo, N. N., and Salisbury, P. A. (2011). Usefulness of winter canola (Brassica napus) race-specific resistance genes against blackleg (causal agent Leptosphaeria maculans) in southern Australian growing conditions. Crop Pasture Sci 62, 162-168. doi: 10.1071/CP10187

Liu, S., Liu, Y., Yang, X., Tong, C., Edwards, D., Parkin, I., Parkin, I. A. P. et al. (2014). The Brassica oleracea genome reveals the asymmetrical evolution of polyploid genomes. Nat. Commun. 5:3930. doi: 10.1038/ncomms4930

Liu, S. L., and Adams, K. L. (2010). Dramatic change in function and expression pattern of a gene duplicated by polyploidy created a paternal effect gene in the Brassicaceae. Genome Biol. Evol. 27, 2817-2828. doi: 10.1093/molbev/msq169

Liu, Z., Latunde-Dada, A. O., Hall, A. M., and Fitt, B. D. L. (2014). Phoma stem canker disease on oilseed rape (Brassica napus) in China is caused by Leptosphaeria biglobosa 'brassicae.' Eur. J. Plant Pathol. 140, 841-857. doi: 10.1007/s10658-014-0513-7

Lob, S., Jaspers, M. V., Ridgway, H. J., and Jones, E. E. (2013). First Report of Leptosphaeria biglobosa as a stem canker pathogen of Brassicas in New Zealand. Plant Dis. 97, 1113-1113. doi: 10.1094/PDIS-12-12-1122-PDN

Long, Y., Wang, Z., Sun, Z., Fernando, D. W., Mcvetty, P. B., and Li, G. (2011). Identification of two blackleg resistance genes and fine mapping of one of these two genes in a Brassica napus canola cultivar 'Surpass 400.' Theor. Appl. Genet. 122, 1223-1231. doi: 10.1007/s00122-010-1526-z

Lucas, J. A., Crute, I. R., Sherriff, C., and Gordon, P. L. (1988). The identification of a gene for race-specific resistance to Peronospora parasitica (downy mildew) in Brassica napus var. oleifera (oilseed rape). Plant Pathol. 37, 538-545. doi: 10.1111/j.1365-3059.1988.tb02112.x

Ma, L., and Borhan, M. H. (2015). The receptor-like kinase SOBIR1 interacts with Brassica napus LepR3 and is required for Leptosphaeria maculans AvrLm1triggered immunity. Front. Plant Sci. 6:933. doi: 10.3389/fpls.2015.00933

Mahajan, V., Gill, H. S., and More, T. A. (1995). Inheritance of downy mildew resistance in Indian cauliflower (group III). Euphytica 86, 1-3. doi: $10.1007 / \mathrm{BF} 00035932$

Manzanares-Dauleux, M. J., Delourme, R., Baron, F., and Thomas, G. (2000). Mapping of one major gene and of QTLs involved in resistance to clubroot in Brassica napus. Theor. Appl. Genet. 101, 885-891. doi: 10.1007/s001220 051557

Marcroft, S. J., Elliott, V. L., Cozijnsen, A. J., Salisbury, P. A., Howlett, B. J., and Van De Wouw, A. P. (2012a). Identifying resistance genes to Leptosphaeria maculans in Australian Brassica napus cultivars based on reactions to isolates with known avirulence genotypes. Crop Pasture Sci. 63, 338-350. doi: 10.1071/CP11341

Marcroft, S. J., Van De Wouw, A. P., Salisbury, P. A., Potter, T. D., and Howlett, B. J. (2012b). Effect of rotation of canola (Brassica napus) cultivars with different complements of blackleg resistance genes on disease severity. Plant Pathol. 61, 934-944. doi: 10.1111/j.1365-3059.2011.02580.x

Mason, A. S., and Snowdon, R. J. (2016). Oilseed rape: learning about ancient and recent polyploid evolution from a recent crop species. Plant Biol. 18, 883-892. doi: $10.1111 / \mathrm{plb} .12462$

Matsumoto, E., Ueno, H., Aruga, D., Sakamoto, K., and Hayashida, N. (2012). Accumulation of three clubroot resistance genes through narker-assisted selection in Chinese cabbage (Brassica rapa ssp. pekinensis). J. Jpn. Soc. Hort. Sci. 81, 184-190. doi: 10.2503/jjshs1.81.184

Matsumoto, E., Yasui, C., Ohi, M., and Tsukada, M. (1998). Linkage analysis of RFLP markers for clubroot resistance and pigmentation in Chinese cabbage (Brassica rapa ssp. pekinensis). Euphytica 104, 79-86. doi: 10.1023/A:1018370418201

Mayerhofer, R., Good, A. G., Bansal, V. K., Thiagarajah, M. R., and Stringam, G. R. (1997). Molecular mapping of resistance to Leptosphaeria maculans in Australian cultivars of Brassica napus. Genome 40, 294-301. doi: 10.1139/g97-041

Mayerhofer, R., Wilde, K., Mayerhofer, M., Lydiate, D., Bansal, V. K., Good, A. G., et al. (2005). Complexities of chromosome landing in a highly duplicated genome: toward map-based cloning of a gene controlling blackleg resistance in Brassica napus. Genetics 171, 1977-1988. doi: 10.1534/genetics.105.049098

McDonald, B. A., and Linde, C. (2002). Pathogen population genetics, evolutionary potential and durable resistance. Annu. Rev. Phytopathol. 40, 349-379. doi: 10.1146/annurev.phyto.40.120501.101443

McDowell, J. M., Dhandaydham, M., Long, T. A., Aarts, M. G., Goff, S., Holub, E. B., et al. (1998). Intragenic recombination and diversifying selection contribute to the evolution of downy mildew resistance at the RPP8 locus of Arabidopsis. Plant Cell 10, 1861-1874. doi: 10.1105/tpc.10.11.1861

McDowell, J. M., Williams, S. G., Funderburg, N. T., Eulgem, T., and Dangl, J. L. (2005). Genetic analysis of developmentally regulated resistance to downy mildew (Hyaloperonospora parasitica) in Arabidopsis thaliana. Mol. Plant Microbe Interact.. 18, 1226-1234. doi: 10.1094/MPMI-18-1226

McHale, L. K., Haun, W. J., Xu, W. W., Bhaskar, P. B., Anderson, J. E., Hyten, D. L., et al. (2012). Structural variants in the soybean genome localize to clusters of biotic stress response genes. Plant Physiol. 159, 1295-1308. doi: $10.1104 / p p .112 .194605$

Mei, J., Ding, Y., Lu, K., Wei, D., Liu, Y., Disi, J. O., et al. (2013). Identification of genomic regions involved in resistance against Sclerotinia 
sclerotiorum from wild Brassica oleracea. Theor. Appl. Genet. 126, 549-556. doi: 10.1007/s00122-012-2000-x

Mei, J., Qian, L., Disi, J. O., Yang, X., Li, Q., Li, J., et al. (2011). Identification of resistant sources against Sclerotinia sclerotiorum in Brassica species with emphasis on B. oleracea. Euphytica 177, 393-399. doi: 10.1007/s10681-010-0274-0

Mendes-Pereira, E., Balesdent, M. H., Brun, H., and Rouxel, T. (2003). Molecular phylogeny of the Leptosphaeria maculans-L. biglobosa species complex. Mycol. Res. 107, 1287-1304. doi: 10.1017/S0953756203008554

Mengistu, A., Rimmer, S. R., Koch, E., and Williams, P. H. (1991). Pathogenicity grouping of isolates of Leptosphaeria maculans on Brassica napus cultivars and their disease reaction profiles on rapid-cycling brassicas. Plant Dis. 75, 1279-1282. doi: 10.1094/PD-75-1279

Meyers, B. C., Kozik, A., Griego, A., Kuang, H., and Michelmore, R. W. (2003). Genome-wide analysis of NBS-LRR-encoding genes in Arabidopsis. Plant Cell 15, 809 - 834. doi: 10.1105/tpc.009308

Mohammed, A. E., You, M. P., and Barbetti, M. (2017). New resistances offer opportunity for effective management of the downy mildew (Hyaloperonospora parasitica) threat to canola. Crop Pasture Sci 68, 234-242. doi: 10.1071/CP16363

Mollier, P. (2015). One Avirulence Precludes Another (Rapeseed). INRA News Portal.

Monteiro, A. A., Coelho, P. S., Bahcevandziev, K., and Valério, L. (2005). Inheritance of downy mildew resistance at cotyledon and adult-plant stages in 'Couve Algarvia' (Brassica oleracea var. tronchuda). Euphytica 141, 85-92. doi: 10.1007/s10681-005-5696-8

Moriguchi, K., Kimizuka-Takagi, C., Ishii, K., and Nomura, K. (1999). A genetic map based on RAPD, RFLP, isozyme, morphological markers and QTL analysis for clubroot resistance in Brassica oleracea. Breed. Sci. 49, 257-265. doi: $10.1270 /$ jsbbs. 49.257

Nagaoka, T., Doullah, M. A. U., Matsumoto, S., Kawasaki, S., Ishikawa, T., Okazaki, K. et al. (2010). Identification of QTLs that control clubroot resistance in Brassica oleracea and comparative analysis of clubroot resistance genes between B. rapa and B. oleracea. Theor. Appl. Genet. 120, 1335-1346. doi: $10.1007 / \mathrm{s} 00122-010-1259-\mathrm{z}$

Nashaat, N. I., and Awasthi, R. P. (1995). Evidence for differential resistance to Peronospora parasitica (downy mildew) in accessions of Brassica juncea (mustard) at the cotyledon stage. J. Phytopathol. 143, 157-159. doi: 10.1111/j.1439-0434.1995.tb00250.x

Nashaat, N. I., Heran, A., Awasthi, R. P., and Kolte, S. J. (2004). Differential response and genes for resistance to Peronospora parasitica (downy mildew) in Brassica juncea (mustard). Plant Breed. 123, 512-515. doi: 10.1111/j.1439-0523.2004.01037.x

Nashaat, N. I., Heran, A., Mitchell, S. E., and Awasthi, R. P. (1997). New genes for resistance to downy mildew (Peronospora parasitica) in oilseed rape (Brassica napus ssp. oleifera). Plant Pathol. 46, 964-968. doi: 10.1046/j.1365-3059.1997.d01-76.x

National Bureau of Statistics of China (2015). 12-11 Output of Major Farm Products Per Hectare [Online]. Available online at: http://www.stats.gov.cn/tjsj/ndsj/ 2015/indexeh.htm (Accessed May 8, 2017).

Natti, J. J. (1958). Resistance of broccoli and other crucifers to downy mildew. Plant Dis. Rptr. 42, 656-662.

Natti, J. J., Dickson, M. H., and Aktin, J. D. (1967). Resistance of Brasssica oleracea cultivars to downy mildew. Phytopathology 57, 144-147.

Navabi, Z. K., Strelkov, S. E., Good, A. G., Thiagarajah, M. R., and Rahman, M. H. (2010). Brassica B-genome resistance to stem rot (Sclerotinia sclerotiorum) in a doubled haploid population of Brassica napus $\times$ Brassica carinata. Can. J. Plant Pathol. 32, 237-246. doi: 10.1080/07060661.2010.484229

Netea, M. G., Quintin, J., and Van der meer, J. W. M. (2011). Trained immunity: a memory for innate host defense. Cell Host Microbe 9, 355-361. doi: 10.1016/j.chom.2011.04.006

Niks, R. E., and Marcel, T. C. (2009). Nonhost and basal resistance: how to explain specificity? New Phytol. 182, 817-828. doi: 10.1111/j.1469-8137.2009.02849.x

Nomura, K., Minegishi, Y., Kimizuka-Takagi, C., Fujioka, T., Moriguchi, K., Shishido, R., et al. (2005). Evaluation of F2 and F3 plants introgressed with QTLs for clubroot resistance in cabbage developed by using SCAR markers. Plant Breed. 124, 371-375. doi: 10.1111/j.1439-0523.2005.01105.x

Nováková, M., Kim, P. D., Šašek, V., Burketová, L., Jindrichová, B., Šantruček, J., et al. (2016a). Separation and identification of candidate protein elicitors from the cultivation medium of Leptosphaeria maculans inducing resistance in Brassica napus. Biotechnol. Prog. 32, 918-928. doi: 10.1002/btpr.2266

Nováková, M., Šašek, V., Trdá, L., Krutinová, H., Mongin, T., Valentová, O., et al. (2016b). Leptosphaeria maculans effector AvrLm4-7 affects salicylic acid (SA) and ethylene (ET) signalling and hydrogen peroxide $\left(\mathrm{H}_{2} \mathrm{O}_{2}\right)$ accumulation in Brassica napus. Mol. Plant Pathol. 17, 818-831. doi: 10.1111/mpp.12332

Osborn, T. C., Butrulle, D. V., Sharpe, A. G., Pickering, K. J., Parkin, I. A. P., Parker, J. S. (2003). Detection and effects of a homeologous reciprocal transposition in Brassica napus. Genetics 165, 1569-1577.

Pang, W., Liang, S., Li, X., Li, P., Yu, S., Lim, Y. P., et al. (2014). Genetic detection of clubroot resistance loci in a new population of Brassica rapa. Hortic. Environ. Biotechnol. 55, 540-547. doi: 10.1007/s13580-014-0079-5

Parker, J. E., Coleman, M. J., Szabò, V., Frost, L. N., Schmidt, R., Van Der Biezen, E. A., et al. (1997). The Arabidopsis downy mildew resistance gene RPP5 shares similarity to the toll and interleukin-1 receptors with $\mathrm{N}$ and L6. Plant Cell 9, 879-894. doi: 10.1105/tpc.9.6.879

Parkin, I. A. P., Gulden, S. M., Sharpe, A. G., Lukens, L., Trick, M., and Osborn, T. C. (2005). Segmental structure of the Brassica napus genome based on comparative analysis with Arabidopsis thaliana. Genetics 171, 765-781. doi: 10.1534 /genetics. 105.042093

Parkin, I. A. P., Koh, C., Tang, H., Robinson, S. J., Kagale, S., Clarke, W. E., et al., (2014). Transcriptome and methylome profiling reveals relics of genome dominance in the mesopolyploid Brassica oleracea. Genome Biol. 15, R77-R77. doi: 10.1186/gb-2014-15-6-r77

Parlange, F., Daverdin, G., Fudal, I., Kuhn, M. L., Balesdent, M. H., Blaise, F., et al. (2009). Leptosphaeria maculans avirulence gene AvrLm4-7 confers a dual recognition specificity by the $\mathrm{R} \operatorname{lm} 4$ and $\mathrm{Rlm} 7$ resistance genes of oilseed rape, and circumvents $\mathrm{Rlm} 4$-mediated recognition through a single amino acid change. Mol. Microbiol. 71, 851-863. doi: 10.1111/j.1365-2958.2008.06547.x

Patel, D., Zander, M., Van De Wouw, A., Mason, A., Edwards, D., and Batley, J. (2015). Population diversity of Leptosphaeria maculans in Australia. Int. J. Biol. 7, 18-36. doi: 10.5539/ijb.v7n3p18

Peng, G., Falk, K. C., Gugel, R. K., Franke, C., Yu, F., James, B., et al. (2014). Sources of resistance to Plasmodiophora brassicae (clubroot) pathotypes virulent on canola. Can. J. Plant Pathol. 36, 89-99. doi: 10.1080/07060661.2013.863805

Petit, Y., Degrave, A., Meyer, M., Blaise, F., Ollivier, B., Rouxel, T., et al. (2016). "A two genes-for-one gene interaction between Leptosphaeria maculans and Brassica napus," in 11th Meeting of Phytopatics-Mycology (Aussois).

Piao, Z. Y., Deng, Y. Q., Choi, S. R., Park, Y. J., and Lim, Y. P. (2004). SCAR and CAPS mapping of CRb, a gene conferring resistance to Plasmodiophora brassicae in Chinese cabbage (Brassica rapa ssp. pekinensis). Theor. Appl. Genet. 108, 1458-1465. doi: 10.1007/s00122-003-1577-5

Pilet, M. L., Delourme, R., Foisset, N., and Renard, M. (1998). Identification of loci contributing to quantitative field resistance to blackleg disease, causal agent Leptosphaeria maculans (Desm.) Ces. et de Not., in winter rapeseed (Brassica napus L.). Theor. Appl. Genet. 96, 23-30. doi: 10.1007/s001220050704

Pilet, M. L., Duplan, G., Archipiano, M., Barret, P., Baron, C., Horvais, R., et al. (2001). Stability of QTL for field resistance to blackleg across two genetic backgrounds in oilseed rape. Crop Sci. 41, 197-205. doi: $10.2135 /$ cropsci2001.411197x

Pires, J. C., and Gaeta, R. T. (2011). "Structural and functional evolution of resynthesized polyploids," in Genetics and Genomics of the Brassicaceae, eds R. Schmidt and I. Bancroft (New York, NY: Springer), 195-214.

Plieske, J., and Struss, D. (2001). Microsatellite markers for genome analysis in Brassica. I. development in Brassica napus and abundance in Brassicaceae species. Theor. Appl. Genet. 102, 689-694. doi: 10.1007/s001220051698

Plieske, J., Struss, D., and Röbbelen, G. (1998). Inheritance of resistance derived from the B-genome of Brassica against phoma lingam in rapeseed and the development of molecular markers. Theor. Appl. Genet. 97, 929-936. doi: $10.1007 / \mathrm{s} 001220050973$

Plissonneau, C., Blaise, F., Ollivier, B., Leflon, M., Carpezat, J., Rouxel, T., et al. (2017a). Unusual evolutionary mechanisms to escape effector-triggered immunity in the fungal phytopathogen Leptosphaeria maculans. Mol. Ecol. 26, 2183-2198. doi: 10.1111/mec.14046

Plissonneau, C., Daverdin, G., Ollivier, B., Blaise, F., Degrave, A., Fudal, I., et al. (2016). A game of hide and seek between avirulence genes AvrLm47 and AvrLm3 in Leptosphaeria maculans. New Phytol. 209, 1613-1624. doi: $10.1111 / \mathrm{nph} .13736$ 
Plissonneau, C., Rouxel, T., Chèvre, A. M., Van De Wouw, A. P., and Balesdent, M. H. (2017b). One gene-one name: the AvrLmJ1 avirulence gene of Leptosphaeria maculans is AvrLm5. Mol. Plant Pathol. doi: 10.1111/mpp.12574. [Epub ahead of print].

Prakash, S., Wu, X. M., and Bhat, S. R. (2011). "History, evolution, and domestication of Brassica crops," in Plant Breeding Reviews, ed J. Janick. (Hoboken, NJ: John Wiley \& Sons, Inc.), 19-84.

Purwantara, A., Barrins, J. M., Cozijnsen, A. J., Ades, P. K., and Howle, B. J. (2000). Genetic diversity of isolates of the Leptosphaeria maculans species complex from Australia, Europe and North America using amplified fragment length polymorphism analysis. Mycol. Res. 104, 772-781. doi: $10.1017 /$ S095375629900235X

Qian, L., Qian, W., and Snowdon, R. J. (2014). Sub-genomic selection patterns as a signature of breeding in the allopolyploid Brassica napus genome. $B M C$ Genomics 15:1170. doi: 10.1186/1471-2164-15-1170

Rahman, H., Peng, G., Yu, F., Falk, K. C., Kulkarni, M., and Selvaraj, G. (2014). Genetics and breeding for clubroot resistance in Canadian spring canola (Brassica napus L.). Can. J. Plant Pathol. 36, 122-134. doi: 10.1080/07060661.2013.862571

Rahman, H., Shakir, A., and Jakir Hasan, M. (2011). Breeding for clubroot resistant spring canola (Brassica napus L.) for the Canadian prairies: can the European winter canola cv. Mendel be used as a source of resistance? Can. J. Plant Sci. 91, 447-458. doi: 10.4141/cjps10073

Rahman, H., Xu, Y. P., Zhang, X. R., and Cai, X. Z. (2016). Brassica napus genome possesses extraordinary high number of CAMTA Genes and CAMTA3 contributes to PAMP triggered immunity and resistance to Sclerotinia sclerotiorum. Front. Plant Sci. 7:581. doi: 10.3389/fpls.2016.00581

Rahman, M., Mamidi, S., Del Rio, L., Ross, A., Kadir, M. M., Rahaman, M. M., et al. (2016). Association mapping in Brassica napus (L.) accessions identifies a major QTL for blackleg disease resistance on chromosome A01. Mol. Breed. 36:90. doi: 10.1007/s11032-016-0513-8

Raman, H., Raman, R., Coombes, N., Song, J., Diffey, S., Kilian, A., et al. (2016). Genome-wide association study identifies new loci for resistance to Leptosphaeria maculans in canola. Front. Plant Sci. 7:1513. doi: $10.3389 /$ fpls.2016.01513

Raman, R., Diffey, S., Carling, J., Cowley, R. B., Kilian, A., Luckett, D. J., et al. (2016). Quantitative genetic analysis of grain yield in an Australian Brassica napus doubled-haploid population. Crop Pasture Sci. 67, 298-307. doi: $10.1071 / \mathrm{CP} 15283$

Raman, R., Taylor, B., Lindbeck, K., Coombes, N., Barbulescu, D., Salisbury, P., et al. (2012a). Molecular mapping and validation of Rlm1 gene for resistance to Leptosphaeria maculans in canola (Brassica napus L.). Crop Pasture Sci. 63, 1007-1017. doi: 10.1071/CP12255

Raman, R., Taylor, B., Marcroft, S., Stiller, J., Eckermann, P., Coombes, N., et al. (2012b). Molecular mapping of qualitative and quantitative loci for resistance to Leptosphaeria maculans causing blackleg disease in canola (Brassica napus L.). Theor. Appl. Genet. 125, 405-418. doi: 10.1007/s00122-012-1842-6

Rameneni, J. J., Lee, Y., Dhandapani, V., Yu, X., Choi, S. R., Oh, M.-H., et al. (2015). Genomic and post-translational modification analysis of leucinerich-repeat receptor-like kinases in Brassica rapa. PLoS ONE 10:e0142255. doi: 10.1371/journal.pone. 0142255

Rana, K., Atri, C., Gupta, M., Akhatar, J., Sandhu, P. S., Kumar, N., et al. (2017). Mapping resistance responses to Sclerotinia infestation in introgression lines of Brassica juncea carrying genomic segments from wild Brassicaceae $B$. fruticulosa. Sci. Rep. 7:5904. doi: 10.1038/s41598-017-05992-9

Remington, D. L., and Purugganan, M. D. (2003). Candidate genes, quantitative trait loci, and functional trait evolution in plants. Int. J. Plant Sci.. 164, S7-S20. doi: $10.1086 / 367812$

Rempel, C. B., Hutton, S. N., and Jurke, C. J. (2014). Clubroot and the importance of canola in Canada. Can. J. Plant Pathol. 36, 19-26. doi: 10.1080/07060661.2013.864336

Ren, L., Xu, L., Liu, F., Chen, K., Sun, C., Li, J., et al. (2016). Host range of Plasmodiophora brassicae on cruciferous crops and weeds in China. Plant Dis. 100, 933-939. doi: 10.1094/PDIS-09-15-1082-RE

Ríčarová, V., Kazda, J., Singh, K., and Ryšánek, P. (2016). Clubroot caused by Plasmodiophora brassicae Wor.: a review of emerging serious disease of oilseed rape in the Czech Republic. Plant Protect. Sci. 52, 71-86. doi: $10.17221 / 87 / 2015$-PPS
Rimmer, S. R. (2006). Resistance genes to Leptosphaeria maculans in Brassica napus. Can. J. Plant Pathol. 28, S288-S297. doi: 10.1080/07060660609507386

Rimmer, S. R., Borhan, M. H., Zhu, B., and Somers, D. (1999). "Mapping resistance genes in Brassica napus to Leptophaeria maculans," in 10th International Rapeseed Congress (Canberra, ACT: The Regional Institute).

Rimmer, S. R., and van den Berg, C. G.J. (1992). Resistance of oilseed Brassica spp. to blackleg caused by Leptosphaeria maculans. Can. J. Plant Pathol. 14, 56-66. doi: 10.1080/07060669209500906

Rocherieux, J., Glory, P., Giboulot, A., Boury, S., Barbeyron, G., Thomas, G., et al. (2004). Isolate-specific and broad-spectrum QTLs are involved in the control of clubroot in Brassica oleracea. Theor. Appl. Genet. 108, 1555-1563. doi: 10.1007/s00122-003-1580-x

Rouxel, T., and Balesdent, M. H. (2013). From model to crop plant-pathogen interactions: cloning of the first resistance gene to Leptosphaeria maculans in Brassica napus. New Phytol. 197, 356-358. doi: 10.1111/nph.12099

Rouxel, T., Grandaubert, J., Hane, J. K., Hoede, C., Van De Wouw, A. P., Couloux, A., et al. (2011). Effector diversification within compartments of the Leptosphaeria maculans genome affected by Repeat-Induced Point mutations. Nat. Commun. 2:202. doi: 10.1038/ncomms1189

Rouxel, T., Penaud, A., Pinochet, X., Brun, H., Gout, L., Delourme, R., et al. (2003a). A 10-year survey of populations of Leptosphaeria maculans in France indicates a rapid adaptation towards the Rlm1 resistance gene of oilseed rape. Eur. J. Plant Pathol. 109, 871-881. doi: 10.1023/A:1026189225466

Rouxel, T., Willner, E., Coudard, L., and Balesdent, M. H. (2003b). Screening and identification of resistance to Leptosphaeria maculans (stem canker) in Brassica napus accessions. Euphytica 133, 219-231. doi: 10.1023/A:1025597622490

Sacristan, M. D., and Gerdemann, M. (1986). Different behavior of Brassica juncea and $B$. carinata as sources of Phoma lingam resistance in experiments of interspecific transfer to B. napus. Plant Breed. 97, 304-314. doi: 10.1111/j.1439-0523.1986.tb01071.x

Saito, M., Kubo, N., Matsumoto, S., Suwabe, K., Tsukada, M., and Hirai, M. (2006). Fine mapping of the clubroot resistance gene, Crr3, in Brassica rapa. Theor Appl. Genet. 114, 81-91. doi: 10.1007/s00122-006-0412-1

Sakamoto, K., Saito, A., Hayashida, N., Taguchi, G., and Matsumoto, E. (2008). Mapping of isolate-specific QTLs for clubroot resistance in Chinese cabbage (Brassica rapa L. ssp. pekinensis). Theor. Appl. Genet. 117, 759-767. doi: 10.1007/s00122-008-0817-0

Sanogo, S., Lujan, P. A., and Baucom, D. (2015). First report of Sclerotinia sclerotiorum on cabbage in New Mexico. Plant Dis. 99:891. doi: 10.1094/PDIS-12-14-1328-PDN

Saxena, R. K., Edwards, D., and Varshney, R. K. (2014). Structural variations in plant genomes. Brief. Funct. Genomics 13, 296-307. doi: 10.1093/bfgp/elu016

Scheben, A., Batley, J., and Edwards, D. (2017a). Genotyping-by-sequencing approaches to characterize crop genomes: choosing the right tool for the right application. Plant Biotechnol. J. 15, 149-161. doi: 10.1111/pbi.12645

Scheben, A., Wolter, F., Batley, J., Puchta, H., and Edwards, D. C. (2017b). Towards CRISPR/Cas crops - bringing together genomics and genome editing. New Phytol. 216, 682-698. doi: 10.1111/nph.14702

Schmutzer, T., Samans, B., Dyrszka, E., Ulpinnis, C., Weise, S., Stengel, D., et al. (2015). Species-wide genome sequence and nucleotide polymorphisms from the model allopolyploid plant Brassica napus. Sci Data 2:150072. doi: 10.1038 /sdata.2015.72

Schranz, M. E., Lysak, M. A., and Mitchell-Olds, T. (2006). The ABC's of comparative genomics in the Brassicaceae: building blocks of crucifer genomes. Trends Plant Sci. 11, 535-542. doi: 10.1016/j.tplants.2006.09.002

Schwartz, H. F., Otto, K., Terán, H., Lema, M., and Singh, S. P. (2006). Inheritance of white mold resistance in Phaseolus vulgaris $\times$ P. coccineus crosses. Plant Dis. 90, 1167-1170. doi: 10.1094/PD-90-1167

Schwelm, A., Fogelqvist, J., Knaust, A., Jülke, S., Lilja, T., Bonilla-Rosso, G., et al. (2015). The Plasmodiophora brassicae genome reveals insights in its life cycle and ancestry of chitin synthases. Sci. Rep. 5:11153. doi: 10.1038/srep11153

Sekhwal, M. K., Li, P., Lam, I., Wang, X., Cloutier, S., and You, F. M. (2015). Disease resistance gene analogs (RGAs) in plants. Int. J. Mol. Sci. 16, 19248-19290. doi: $10.3390 /$ ijms 160819248

Sexton, A. C., Whitten, A. R., and Howlett, B. J. (2006). Population structure of Sclerotinia sclerotiorum in an Australian canola field at flowering and stem-infection stages of the disease cycle. Genome 49, 1408-1415. doi: $10.1139 / \mathrm{g} 06-101$ 
Sharma, K., Gossen, B. D., Greenshields, D., Selvaraj, G., Strelkov, S. E., and Mcdonald, M. R. (2012). Reaction of lines of the rapid cycling Brassica collection and Arabidopsis thaliana to four pathotypes of Plasmodiophora brassicae. Plant Dis. 97, 720-727. doi: 10.1094/PDIS-08-12-0752-RE

Sherriff, C., and Lucas, J. A. (1990). The host range of isolates of downy mildew, Peronospora parasitica, from Brassica crop species. Plant Pathol. 39, 77-91. doi: 10.1111/j.1365-3059.1990.tb02478.x

Sinapidou, E., Williams, K., Nott, L., Bahkt, S., Tör, M., Crute, I., et al. (2004). Two TIR:NB:LRR genes are required to specify resistance to Peronospora parasitica isolate Cala2 in Arabidopsis. Plant J. 38, 898-909. doi: 10.1111/j.1365-313X.2004.02099.x

Singh, S., Sharma, S. R., Kalia, P., Deshmukh, R., Kumar, V., Sharma, P., et al. (2012). Molecular mapping of the downy mildew resistance gene Ppa3 in cauliflower (Brassica oleracea var. botrytis L.). J. Hortic. Sci. Biotechnol. 87, 137-143. doi: 10.1080/14620316.2012.11512844

Singh, U. S., Nashaat, N. I., Doughty, K. J., and Awasthi, R. P. (2002). Altered phenotypic response to Peronospora parasitica in Brassica juncea seedlings following prior inoculation with an avirulent or virulent isolate of Albugo candida. Eur. J. Plant Pathol. 108, 555-564. doi: 10.1023/A:1019937115378

Sivasithamparam, K., Barbetti, M. J., and Li, H. U. A. (2005). Recurring challenges from a necrotrophic fungal plant pathogen: a case study with Leptosphaeria maculans (causal agent of Blackleg disease in Brassicas) in Western Australia. Ann. Bot. 96, 363-377. doi: 10.1093/aob/mci194

Snowdon, R., LüHs, W., and Friedt, W. (2007). “Oilseed rape," in Genome Mapping and Molecular Breeding in Plants Vol 2: Oilseeds, ed C. Kole (Berlin, Heidelberg; New York, NY: Springer), 55-114.

Snowdon, R. J., Winter, H., Diestel, A., and Sacristán, M. D. (2000). Development and characterisation of Brassica napus-Sinapis arvensis addition lines exhibiting resistance to Leptosphaeria maculans. Theor. Appl. Genet. 101, 1008-1014. doi: 10.1007/s001220051574

Somé, A., Manzanares, M. J., Laurens, F., Baron, F., Thomas, G., and Rouxel, F. (1996). Variation for virulence on Brassica napus L. amongst Plasmodiophora brassicae collections from France and derived single-spore isolates. Plant Pathol. 45, 432-439. doi: 10.1046/j.1365-3059.1996.d01-155.x

Soyer, J. L., Hamiot, A., Ollivier, B., Balesdent, M. H., Rouxel, T., and Fudal, I. (2015). The APSES transcription factor LmStuA is required for sporulation, pathogenic development and effector gene expression in Leptosphaeria maculans. Mol. Plant Pathol. 16, 1000-1005. doi: 10.1111/mpp.12249

Sprague, S. J., Marcroft, S. J., Hayden, H. L., and Howlett, B. J. (2006). Major gene resistance to blackleg in Brassica napus overcome within three years of commercial production in Southeastern Australia. Plant Dis. 90, 190-198. doi: 10.1094/PD-90-0190

Springer, N. M., Ying, K., Fu, Y., Ji, T., Yeh, C. T., Jia, Y., et al. (2009). Maize inbreds exhibit high levels of copy number variation (CNV) and presence/absence variation (PAV) in genome content. PLoS Genet. 5:e1000734. doi: 10.1371/journal.pgen.1000734

Stachowiak, A., Olechnowicz, J., Jedryczka, M., Rouxel, T., Balesdent, M.-H., Happstadius, I., et al. (2006). Frequency of avirulence alleles in field populations of Leptosphaeria maculans in Europe. Eur. J. Plant Pathol. 114, 67-75. doi: $10.1007 /$ s10658-005-2931-z

Statistics Canada (2017). Table 001-0010 - Estimated Areas, Yield, Production and Average Farm Price of Principal Field Crops, in Metric Units (Year-to-date (averages)), annual, CANSIM (database). [Online]. Available online at: http:// www5.statcan.gc.ca/cansim/a26?lang=eng\&id=10010 (Accessed May 10, 2017).

Steuernagel, B., Periyannan, S. K., Hernandez-Pinzon, I., Witek, K., Rouse, M. N., Yu, G., et al. (2016). Rapid cloning of disease-resistance genes in plants using mutagenesis and sequence capture. Nat. Biotechnol. 34, 652-655. doi: $10.1038 /$ nbt. 3543

Stotz, H. U., Mitrousia, G. K., De Wit, P. J.G. M., and Fitt, B. D.L. (2014). Effectortriggered defence against apoplastic fungal pathogens. Trends Plant Sci. 19, 491-500. doi: 10.1016/j.tplants.2014.04.009

Strelkov, S. E., and Hwang, S.-F. (2014). Clubroot in the Canadian canola crop: 10 years into the outbreak. Can. J. Plant Pathol. 36, 27-36. doi: 10.1080/07060661.2013.863807

Strelkov, S. E., Hwang, S.-F., Manolii, V. P., Cao, T., and Feindel, D. (2016). Emergence of new virulence phenotypes of Plasmodiophora brassicae on canola (Brassica napus) in Alberta, Canada. Eur. J. Plant Pathol. 145, 517-529. doi: $10.1007 /$ s10658-016-0888-8
Strelkov, S. E., Manolii, V. P., Cao, T., Xue, S., and Hwang, S. F. (2007). Pathotype classification of Plasmodiophora brassicae and its occurence in Brassica napus in Alberta, Canada. J. Phytopathol. 155, 706-712. doi: 10.1111/j.1439-0434.2007.01303.x

Strelkov, S. E., and Tewari, J. P. (2005). Clubroot on canola in Alberta in 2003 and 2004. Can. Plant Dis. Surv. 85, 72-73.

Strelkov, S. E., Tewari, J. P., and Smith-Degenhardt, E. (2006). Characterization of Plasmodiophora brassicae populations from Alberta, Canada. Can. J. Plant Pathol. 28, 467-474. doi: 10.1080/07060660609507321

Subramaniam, S., Wang, X., Freeling, M., and Pires, J. C. (2013). The fate of Arabidopsis thaliana homeologous CNSs and their motifs in the paleohexaploid Brassica rapa. Genome Biol. Evol. 5, 646-660. doi: 10.1093/gbe/evt035

Suwabe, K., Suzuki, G., Nunome, T., Hatakeyama, K., Mukai, Y., Fukuoka, H., et al. (2012). Microstructure of a Brassica rapa genome segment homoeologous to the resistance gene cluster on Arabidopsis chromosome 4. Breed. Sci. 62, 170-177. doi: 10.1270/jsbbs.62.170

Suwabe, K., Tsukazaki, H., Iketani, H., Hatakeyama, K., Fujimura, M., Nunome, T., et al. (2003). Identification of two loci for resistance to clubroot (Plasmodiophora brassicae Woronin) in Brassica rapa L. Theor. Appl. Genet. 107, 997-1002. doi: 10.1007/s00122-003-1309-x

Suwabe, K., Tsukazaki, H., Iketani, H., Hatakeyama, K., Kondo, M., Fujimura, M., et al. (2006). Simple sequence repeat-based comparative genomics between Brassica rapa and Arabidopsis thaliana: the genetic origin of clubroot resistance. Genetics 173, 309-319. doi: 10.1534/genetics.104.038968

Svitashev, S., Schwartz, C., Lenderts, B., Young, J. K., and Mark Cigan, A. (2016). Genome editing in maize directed by CRISPR-Cas9 ribonucleoprotein complexes. Nat. Commun. 7:13274. doi: 10.1038/ncomms 13274

Swiderski, M. R., and Innes, R. W. (2001). The Arabidopsis PBS1 resistance gene encodes a member of a novel protein kinase subfamily. Plant J. 26, 101-112. doi: 10.1046/j.1365-313x.2001.01014.x

Tai, T. H., Dahlbeck, D., Clark, E. T., Gajiwala, P., Pasion, R., Whalen, M. C., et al. (1999). Expression of the Bs2 pepper gene confers resistance to bacterial spot disease in tomato. Proc. Natl. Acad. Sci. U.S.A. 96, 14153-14158. doi: $10.1073 /$ pnas. 96.24 .14153

Tanaka, S., and Ito, S. I. (2013). Pathogenic and genetic diversity in Plasmodiophora brassicae (clubroot) from Japan. J. Gen. Plant Pathol. 79, 297-306. doi: 10.1007/s10327-013-0456-4

Tanaka, S., Mido, H., and Ito, S.-I. (2006). Colonization by two isolates of Plasmodiophora brassicae with differing pathogenicity on a clubroot-resistant cultivar of Chinese cabbage (Brassica rapa L. subsp. pekinensis). J. Gen. Plant Pathol. 72, 205-209. doi: 10.1007/s10327-006-0276-x

Thomas, C. E., and Jourdain, E. L. (1990). Evaluation of broccoli and cauliflower germplasm for resistance to Race 2 of Peronospora parasitica. HortScience 25, 1429-1431.

Thomma, B. P. H. J., Nürnberger, T., and Joosten, M. H. A. J. (2011). Of PAMPs and effectors: the blurred PTI-ETI dichotomy. Plant Cell 23, 4-15. doi: $10.1105 /$ tpc. 110.082602

Tollenaere, R., Hayward, A., Dalton-Morgan, J., Campbell, E., Lee, J. R. M. Lorenc, M. T., et al. (2012). Identification and characterization of candidate Rlm4 blackleg resistance genes in Brassica napus using next-generation sequencing. Plant Biotechnol. J. 10, 709-715. doi: 10.1111/j.1467-7652.2012. 00716.x

Town, C. D., Cheung, F., Maiti, R., Crabtree, J., Haas, B. J., Wortman, J. R., et al. (2006). Comparative genomics of Brassica oleracea and Arabidopsis thaliana reveal gene loss, fragmentation, and dispersal after polyploidy. Plant Cell 18, 1348-1359. doi: 10.1105/tpc.106.041665

Travadon, R., Sache, I., Dutech, C., Stachowiak, A., Marquer, B., and Bousset, L. (2011). Absence of isolation by distance patterns at the regional scale in the fungal plant pathogen Leptosphaeria maculans. Fungal Biol. 115, 649-659. doi: 10.1016/j.funbio.2011.03.009

Truco, M. J., Hu, J., Sadowski, J., and Quiros, C. F. (1996). Inter- and intra-genomic homology of the Brassica genomes: implications for their origin and evolution. Theor. Appl. Genet. 93, 1225-1233. doi: 10.1007/BF00223454

Ueno, H., Matsumoto, E., Aruga, D., Kitagawa, S., Matsumura, H., and Hayashida, N. (2012). Molecular characterization of the CRa gene conferring clubroot resistance in Brassica rapa. Plant Mol. Biol. 80, 621-629. doi: 10.1007/s11103-012-9971-5 
Uloth, M., You, M. P., Finnegan, P. M., Banga, S. S., Yi, H., and Barbetti, M. J. (2014). Seedling resistance to Sclerotinia sclerotiorum as expressed across diverse cruciferous species. Plant Dis. 98, 184-190. doi: 10.1094/PDIS-06-13-0612-RE

Uloth, M. B., Clode, P. L., You, M. P., and Barbetti, M. J. (2016). Attack modes and defence reactions in pathosystems involving Sclerotinia sclerotiorum, Brassica carinata, B. juncea and B. napus. Ann. Bot. 117, 79-95. doi: $10.1093 / \mathrm{aob} / \mathrm{mcv} 150$

Uloth, M. B., You, M. P., and Barbetti, M. J. (2015a). Host resistance to Sclerotinia stem rot in historic and current Brassica napus and B. juncea varieties: critical management implications. Crop Pasture Sci. 66, 841-848. doi: 10.1071/CP15064

Uloth, M. B., You, M. P., Cawthray, G., and Barbetti, M. J. (2015b). Temperature adaptation in isolates of Sclerotinia sclerotiorum affects their ability to infect Brassica carinata. Plant Pathol. 64, 1140-1148. doi: 10.1111/ppa.12338

Uloth, M. B., You, M. P., Finnegan, P. M., Banga, S. S., Banga, S. K., Sandhu, P. S., et al. (2013). New sources of resistance to Sclerotinia sclerotiorum for crucifer crops. Field Crops Res. 154, 40-52. doi: 10.1016/j.fcr.2013.07.013

Van De Wouw, A. P., Cozijnsen, A. J., Hane, J. K., Brunner, P. C., Mcdonald, B. A., Oliver, R. P., et al. (2010). Evolution of linked avirulence effectors in Leptosphaeria maculans is affected by genomic environment and exposure to resistance genes in host plants. PLoS Pathog. 6:e1001180. doi: 10.1371/journal.ppat.1001180

Van de Wouw, A. P., Howlett, B. J., and Idnurm, A. (2017). Changes in allele frequencies of avirulence genes in the blackleg fungus, Leptosphaeria maculans, over two decades in Australia. Crop Pasture Sci. CP16411. doi: 10.1071/CP16411

Van de Wouw, A. P., Idnurm, A., Davidson, J. A., Sprague, S. J., Khangura, R. K., Ware, A. H., et al. (2016a). Fungal diseases of canola in Australia: identification of trends, threats and potential therapies. Australas. Plant Pathol. 45, 415-423. doi: 10.1007/s13313-016-0428-1

Van de Wouw, A. P., Lowe, R. G. T., Elliott, C. E., Dubois, D. J., and Howlett, B. J. (2014). An avirulence gene, AvrLmJ1, from the blackleg fungus, Leptosphaeria maculans, confers avirulence to Brassica juncea cultivars. Mol. Plant Pathol. 15, 523-530. doi: 10.1111/mpp.12105

Van de Wouw, A. P., Marcroft, S. J., Barbetti, M. J., Hua, L., Salisbury, P. A., Gout, L., et al. (2009). Dual control of avirulence in Leptosphaeria maculans towards a Brassica napus cultivar with 'sylvestris-derived' resistance suggests involvement of two resistance genes. Plant Pathol. 58, 305-313. doi: 10.1111/j.1365-3059.2008.01982.x

Van De Wouw, A. P., Marcroft, S. J., and Howlett, B. J. (2016b). Blackleg disease of canola in Australia. Crop Pasture Sci. 67, 273-283. doi: 10.1071/CP15221

Vera Cruz, C. M., Bai, J., Oña, I., Leung, H., Nelson, R. J., Mew, T. W., et al. (2000). Predicting durability of a disease resistance gene based on an assessment of the fitness loss and epidemiological consequences of avirulence gene mutation. Proc. Natl. Acad. Sci. U.S.A. 97, 13500-13505. doi: 10.1073/pnas.250271997

Voigt, K., Cozijnsen, A. J., Kroymann, J., Pöggeler, S., and Howlett, B. J. (2005). Phylogenetic relationships between members of the crucifer pathogenic Leptosphaeria maculans species complex as shown by mating type (MAT12), actin, and $\beta$-tubulin sequences. Mol. Phylogenet. Evol. 37, 541-557. doi: 10.1016/j.ympev.2005.07.006

Voorrips, R. E. (1995). Plasmodiophora brassicae: aspects of pathogenesis and resistance in Brassica oleracea. Euphytica 83, 139-146. doi: $10.1007 / \mathrm{BF} 01678041$

Voorrips, R. E., Jongerius, M. C., and Kanne, H. J. (1997). Mapping of two genes for resistance to clubroot (Plasmodiophora brassicae) in a population of doubled haploid lines of Brassica oleracea by means of RFLP and AFLP markers. Theor. Appl. Genet. 94, 75-82. doi: 10.1007/s001220050384

Voorrips, R. E., and Visser, D. L. (1993). Examination of resistance to clubroot in accessions of Brassica oleracea using a glasshouse seedling test. Nether. J. Plant Pathol. 99, 269-276. doi: 10.1007/BF01974308

Wang, M., Farnham, M. W., and Thomas, C. E. (2000). Phenotypic variation for downy mildew resistance among inbred broccoli. HortScience 35, 925-929.

Wang, M., Farnham, M. W., and Thomas, C. E. (2001). Inheritance of true leaf stage downy mildew resistance in broccoli. J. Am. Soc. Hortic. Sci. 126, 727-729.

Wang, X., Wang, H., Wang, J., Sun, R., Wu, J., Liu, S., et al. (2011). Brassica rapa genome sequencing project consortium. The genome of the mesopolyploid crop species Brassica rapa. Nat. Genet. 43, 1035-1039. doi: 10.1038/ng.919
Wang, Y., Cheng, X., Shan, Q., Zhang, Y., Liu, J., Gao, C., et al. (2014). Simultaneous editing of three homoeoalleles in hexaploid bread wheat confers heritable resistance to powdery mildew. Nat. Biotechnol. 32, 947-951. doi: $10.1038 /$ nbt.2969

Ward, E. W. B. (1983). Effects of mixed or consecutive inoculations on the interaction of soybeans with races of Phytophthora megasperma f.sp. glycinea. Physiol. Plant Pathol. 23, 281-294. doi: 10.1016/0048-4059(83) 90011-5

Wei, C., Chen, J., and Kuang, H. (2016). Dramatic number variation of R genes in Solanaceae species accounted for by a few R gene subfamilies. PLoS ONE 11:e0148708. doi: 10.1371/journal.pone.0148708

Wei, D., Mei, J., Fu, Y., Disi, J. O., Li, J., and Qian, W. (2014). Quantitative trait loci analyses for resistance to Sclerotinia sclerotiorum and flowering time in Brassica napus. Mol. Breed. 34, 1797-1804. doi: 10.1007/s11032-014-0139-7

Wei, L., Jian, H., Lu, K., Filardo, F., Yin, N., Liu, L., et al. (2016). Genomewide association analysis and differential expression analysis of resistance to Sclerotinia stem rot in Brassica napus. Plant Biotechnol. J. 14, 1368-1380. doi: $10.1111 /$ pbi. 12501

Werner, S., Diederichsen, E., Frauen, M., Schondelmaier, J., and Jung, C. (2007). Genetic mapping of clubroot resistance genes in oilseed rape. Theor. Appl. Genet.. 116, 363-372. doi: 10.1007/s00122-007-0674-2

Westman, A. L., Kresovich, S., and Dickson, M. H. (1999). Regional variation in Brassica nigra and other weedy crucifers for disease reaction to Alternaria brassicicola and Xanthomonas campestris pv. campestris. Euphytica 106, 253-259. doi: 10.1023/A:1003544025146

Williams, P. H. (1966). A system for the determination of races of Plasmodiophora brassicae that infect cabbage and rutabaga. Phytopathology 56, 624-626.

Wilson, L. M., and Howlett, B. J. (2005). Leptosphaeria maculans, a fungal pathogen of Brassica napus, secretes a subtilisin-like serine protease. Eur. J. Plant Pathol. 112, 23-29. doi: 10.1007/s10658-004-7088-7

Winter, H., Snowdon, R. J., Diestel, A., Gartig, S., and Sacristan, M. D. (2003). "Transfer of new blackleg resistances into oilseed rape," in 11th Int Rapeseed Congress (Copenhagen), 19-21.

Winter, M., and Koopmann, B. (2016). Race spectra of Leptosphaeria maculans, the causal agent of blackleg disease of oilseed rape, in different geographic regions in northern Germany. Eur. J. Plant Pathol. 145, 629-641. doi: 10.1007/s10658-016-0932-8

Witek, K., Jupe, F., Witek, A. I., Baker, D., Clark, M. D., and Jones, J. D.G. (2016). Accelerated cloning of a potato late blight-resistance gene using RenSeq and SMRT sequencing. Nat. Biotechnol. 34, 656-660. doi: 10.1038/nbt.3540

Wu, J., Cai, G., Tu, J., Li, L., Liu, S., Luo, X., et al. (2013). Identification of QTLs for resistance to Sclerotinia Stem Rot and BnaC.IGMT5.a as a candidate gene of the major resistant QTL SRC6 in Brassica napus. PLoS ONE 8:e67740. doi: 10.1371/journal.pone.0067740

Wu, J., Li, F., Xu, K., Gao, G., Chen, B., Yan, G., et al. (2014). Assessing and broadening genetic diversity of a rapeseed germplasm collection. Breed. Sci. 64, 321-330. doi: 10.1270/jsbbs.64.321

Wu, J., Zhao, Q., Liu, S., Shahid, M., Lan, L., Cai, G., et al. (2016a). Genome-wide association study identifies new loci for resistance to Sclerotinia Stem Rot in Brassica napus. Front. Plant Sci. 7:1418. doi: 10.3389/fpls.2016.01418

Wu, J., Zhao, Q., Yang, Q., Liu, H., Li, Q., Yi, X., et al. (2016b). Comparative transcriptomic analysis uncovers the complex genetic network for resistance to Sclerotinia sclerotiorum in Brassica napus. Sci. Rep. 6:19007. doi: 10.1038/srep19007

Xu, X., Liu, X., Ge, S., Jensen, J. D., Hu, F., Li, X., et al. (2012). Resequencing 50 accessions of cultivated and wild rice yields markers for identifying agronomically important genes. Nat. Biotechnol. 30, 105-111. doi: $10.1038 /$ nbt.2050

Yang, B., Jiang, Y., Rahman, M. H., Deyholos, M. K., and Kav, N. N.V. (2009). Identification and expression analysis of WRKY transcription factor genes in canola (Brassica napus L.) in response to fungal pathogens and hormone treatments. BMC Plant Biol. 9:68. doi: 10.1186/1471-2229-9-68

Yang, J., Liu, D., Wang, X., Ji, C., Cheng, F., Liu, B., et al. (2016). The genome sequence of allopolyploid Brassica juncea and analysis of differential homoeolog gene expression influencing selection. Nat. Genet. 48, 1225-1232. doi: 10.1038/ng.3657

Yin, X., Yi, B., Chen, W., Zhang, W., Tu, J., Fernando, W. G. D., et al. (2010). Mapping of QTLs detected in a Brassica napus DH population for resistance 
to Sclerotinia sclerotiorum in multiple environments. Euphytica 173, 25-35. doi: 10.1007/s10681-009-0095-1

Yoshikawa, H. (1980). "Breeding for clubroot resistance in Chinese cabbage," in First International Symposium on Chinese Cabbage, Tsukuba Science City, Japan, eds N. S. Talekar and G. W. Selleck (Tainan: Hong Wen Printing Works).

You, M. P., Uloth, M. B., Li, X. X., Banga, S. S., Banga, S. K., and Barbetti, M. J. (2016). Valuable new resistances ensure improved management of Sclerotinia Stem Rot (Sclerotinia sclerotiorum) in horticultural and oilseed Brassica species. J. Phytopathol. 164, 291-299. doi: 10.1111/jph.12456

Yu, F., Gugel, R. K., Kutcher, H. R., Peng, G., and Rimmer, S. R. (2013). Identification and mapping of a novel blackleg resistance locus LepR4 in the progenies from Brassica napus $\times$ B. rapa subsp. sylvestris. Theor. Appl. Genet. 126, 307-315. doi: 10.1007/s00122-012-1919-2

Yu, F., Lydiate, D. J., and Rimmer, S. R. (2005). Identification of two novel genes for blackleg resistance in Brassica napus. Theor. Appl. Genet. 110, 969-979. doi: 10.1007/s00122-004-1919-y

Yu, F., Lydiate, D. J., and Rimmer, S. R. (2008). Identification and mapping of a third blackleg resistance locus in Brassica napus derived from B. rapa subsp. sylvestris. Genome 51, 64-72. doi: 10.1139/G07-103

Yu, F., Zhang, X., Huang, Z., Chu, M., Song, T., Falk, K. C., et al. (2016). Identification of genome-wide variants and discovery of variants associated with Brassica rapa clubroot resistance gene Rcrl through bulked segregant RNA sequencing. PLoS ONE 11:e0153218. doi: 10.1371/journal.pone. 0153218

Yu, F., Zhang, X., Peng, G., Falk, K. C., Strelkov, S. E., and Gossen, B. D. (2017). Genotyping-by-sequencing reveals three QTL for clubroot resistance to six pathotypes of Plasmodiophora brassicae in Brassica rapa. Sci. Rep. 7:4516. doi: 10.1038/s41598-017-04903-2

Yu, J., Tehrim, S., Zhang, F., Tong, C., Huang, J., Cheng, X., et al. (2014). Genomewide comparative analysis of NBS-encoding genes between Brassica species and Arabidopsis thaliana. BMC Genomics 15:3. doi: 10.1186/1471-2164-15-3

Yu, S., Su, T., Zhi, S., Zhang, F., Wang, W., Zhang, D., et al. (2016). Construction of a sequence-based bin map and mapping of QTLs for downy mildew resistance at four developmental stages in Chinese cabbage (Brassica rapa L. ssp. pekinensis). Mol. Breed. 36, 1-12. doi: 10.1007/s11032-0160467-x

Yu, S., Zhang, F., Yu, R., Zou, Y., Qi, J., Zhao, X., et al. (2009). Genetic mapping and localization of a major QTL for seedling resistance to downy mildew in Chinese cabbage (Brassica rapa ssp. pekinensis). Mol. Breed. 23, 573-590. doi: 10.1007/s11032-009-9257-Z

Yu, S., Zhang, F., Zhao, X., Yu, Y., and Zhang, D. (2011). Sequence-characterized amplified region and simple sequence repeat markers for identifying the major quantitative trait locus responsible for seedling resistance to downy mildew in Chinese cabbage (Brassica rapa ssp. pekinensis). Plant Breed. 130, 580-583. doi: 10.1111/j.1439-0523.2011.01874.x

Zander, M., Patel, D. A., Van De Wouw, A., Lai, K., Lorenc, M. T., Campbell, E., et al. (2013). Identifying genetic diversity of avirulence genes in Leptosphaeria maculans using whole genome sequencing. Funct. Integr. Genomics 13, 295-308. doi: 10.1007/s10142-013-0324-5

Zarinpanjeh, N., Motallebi, M., Zamani, M. R., and Ziaei, M. (2016). Enhanced resistance to Sclerotinia sclerotiorum in Brassica napus by co-expression of defensin and chimeric chitinase genes. J. Appl. Genet. 57, 417-425. doi: 10.1007/s13353-016-0340-y

Zhang, H., Feng, J., Hwang, S. F., Strelkov, S. E., Falak, I., Huang, X., et al. (2016). Mapping of clubroot (Plasmodiophora brassicae) resistance in canola (Brassica napus). Plant Pathol. 65, 435-440. doi: 10.1111/ppa.12422
Zhang, H., Feng, J., Zhang, S., Zhang, S., Li, F., Strelkov, S. E., et al. (2015). Resistance to Plasmodiophora brassicae in Brassica rapa and Brassica juncea genotypes from China. Plant Dis. 99, 776-779. doi: 10.1094/PDIS-08-14-0863-RE

Zhang, T., Zhao, Z., Zhang, C., Pang, W., Choi, S. R., Lim, Y. P., et al. (2014). Fine genetic and physical mapping of the CRb gene conferring resistance to clubroot disease in Brassica rapa. Mol. Breed. 34, 1173-1183. doi: 10.1007/s11032-014-0108-1

Zhang, X., Peng, G., Kutcher, H. R., Balesdent, M. H., Delourme, R., and Fernando, W. G. D. (2016a). Breakdown of Rlm3 resistance in the Brassica napusLeptosphaeria maculans pathosystem in western Canada. Eur. J. Plant Pathol. 145, 659-674. doi: 10.1007/s10658-015-0819-0

Zhang, X., Peng, G., Parks, P., Hu, B., Li, Q., Jiang, L., et al. (2016b). Identifying seedling and adult plant resistance of Chinese Brassica napus germplasm to Leptosphaeria maculans. Plant Pathol. 66, 752-762. doi: 10.1111/ppa.12626

Zhang, X., White, R. P., Demir, E., Jedryczka, M., Lange, R. M., Islam, M., et al. (2014). Leptosphaeria spp., phoma stem canker and potential spread of L. maculans on oilseed rape crops in China. Plant Pathol. 63, 598-612. doi: $10.1111 /$ ppa. 12146

Zhang, Y.-M., Shao, Z.-Q., Wang, Q., Hang, Y.-Y., Xue, J.-Y., Wang, B., et al. (2016). Uncovering the dynamic evolution of nucleotide-binding site-leucinerich repeat (NBS-LRR) genes in Brassicaceae. J. Integr. Plant Biol. 58, 165-177. doi: $10.1111 /$ jipb. 12365

Zhao, J., Buchwaldt, L., Rimmer, S. R., Sharpe, A., Mcgregor, L., Bekkaoui, D., et al. (2009). Patterns of differential gene expression in Brassica napus cultivars infected with Sclerotinia sclerotiorum. Mol. Plant Pathol. 10, 635-649. doi: 10.1111/j.1364-3703.2009.00558.x

Zhao, J., and Meng, J. (2003). Genetic analysis of loci associated with partial resistance to Sclerotinia sclerotiorum in rapeseed (Brassica napus L.). Theor. Appl. Genet. 106, 759-764. doi: 10.1007/s00122-002-1171-2

Zhao, J., Peltier, A. J., Meng, J., Osborn, T. C., and Grau, C. R. (2004). Evaluation of Sclerotinia Stem Rot resistance in oilseed Brassica napus using a petiole inoculation technique under greenhouse conditions. Plant Dis. 88, 1033-1039. doi: 10.1094/PDIS.2004.88.9.1033

Zhao, J., Udall, J. A., Quijada, P. A., Grau, C. R., Meng, J., and Osborn, T. C. (2006). Quantitative trait loci for resistance to Sclerotinia sclerotiorum and its association with a homeologous non-reciprocal transposition in Brassica napus L. Theor. Appl. Genet. 112, 509-516. doi: 10.1007/s00122-005-0154-5

Zhou, J. M., Tang, X. Y., and Martin, G. B. (1997). The Pto kinase conferring resistance to tomato bacterial speck disease interacts with proteins that bind a cis-element of pathogenesis-related genes. EMBO J. 16, 3207-3218. doi: 10.1093/emboj/16.11.3207

Zuo, W., Chao, Q., Zhang, N., Ye, J., Tan, G., Li, B., et al. (2015). A maize wallassociated kinase confers quantitative resistance to head smut. Nat. Genet. 47, 151-157. doi: 10.1038/ng.3170

Conflict of Interest Statement: The authors declare that the research was conducted in the absence of any commercial or financial relationships that could be construed as a potential conflict of interest.

Copyright (C) 2017 Neik, Barbetti and Batley. This is an open-access article distributed under the terms of the Creative Commons Attribution License (CC BY). The use, distribution or reproduction in other forums is permitted, provided the original author(s) or licensor are credited and that the original publication in this journal is cited, in accordance with accepted academic practice. No use, distribution or reproduction is permitted which does not comply with these terms. 